This item was submitted to Loughborough's Institutional Repository (https://dspace.lboro.ac.uk/) by the author and is made available under the following Creative Commons Licence conditions.

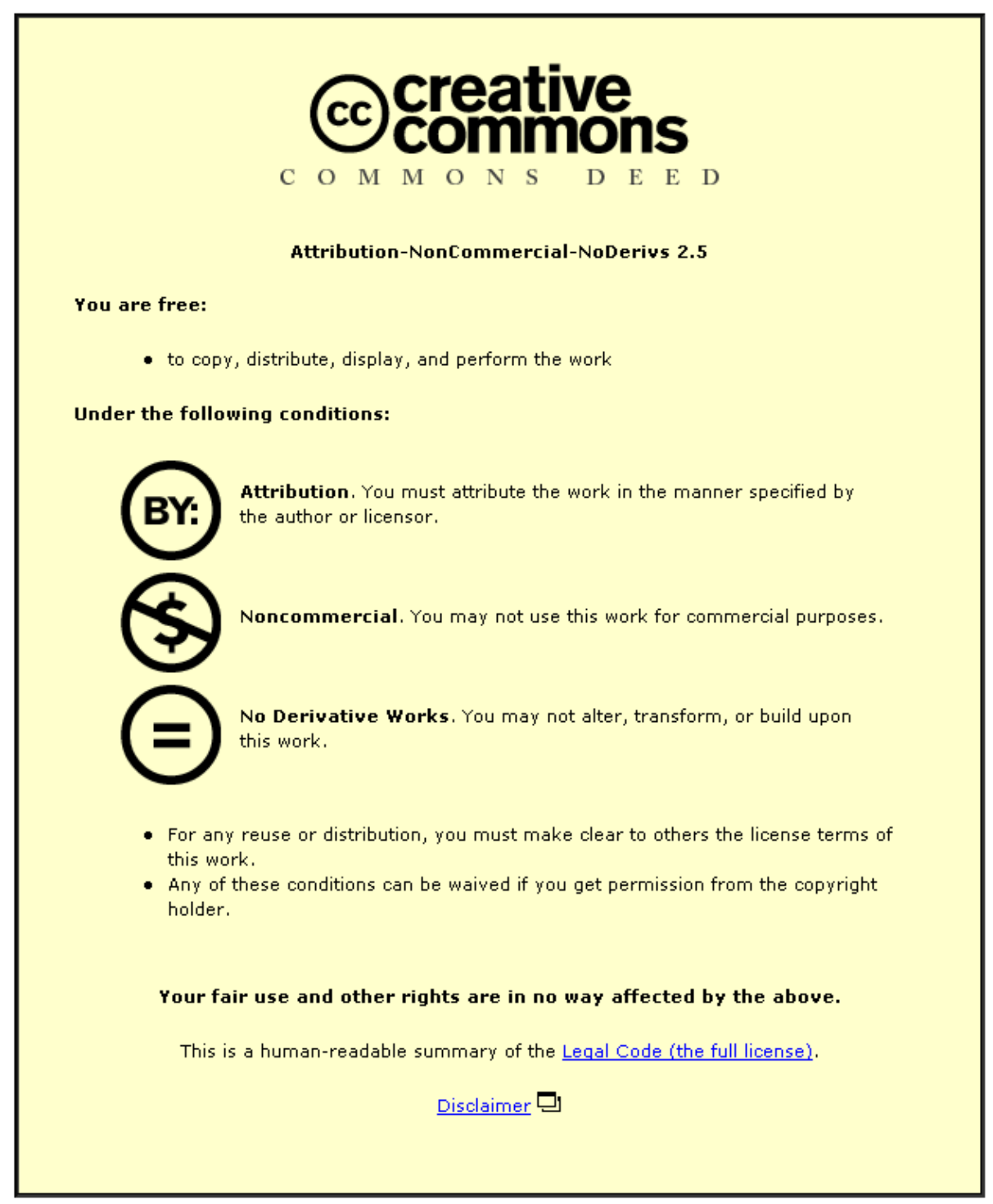

For the full text of this licence, please go to: http://creativecommons.org/licenses/by-nc-nd/2.5/ 


\title{
Resilience of naturally ventilated buildings to climate change: advanced natural ventilation and hospital wards
}

\author{
Kevin John Lomas ${ }^{\mathrm{a}}$, Yingchun $\mathrm{Ji}^{\mathrm{b}}$ \\ ${ }^{a}$ Department of Civil and Building Engineering, Loughborough University, Ashby Road, \\ Loughborough, Leicester, United Kingdom \\ ${ }^{\mathrm{b}}$ Institute of Energy and Sustainable Development, De Montfort University, Leicester, United \\ Kingdom
}

\begin{abstract}
Naturally ventilated buildings have a key role to play mitigating climate change. The predicted indoor temperatures in spaces with simple single-sided natural ventilation (SNV) are compared with those in spaces conditioned using a form of edge in, edge out advanced natural ventilation (ANV) for various UK locations. A criterion, for use in conjunction with the BSEN15251 adaptive thermal comfort method, is proposed for determining when the risk of overheating, both now and in the future, might be deemed unacceptable. The work is presented in the context building new, and refurbishing existing, healthcare buildings and in particular hospital wards. The spaces conditioned using the ANV strategy were much more resilient to increases in both internal heat gains and climatic warming than spaces with SNV. The ANV strategy used less energy, and emitted less $\mathrm{CO}_{2}$ than conventional, mechanically ventilated (MV) alternatives. In a warming world, the 'life-expectancy' of passively cooled buildings can be substantially influenced by the internal heat gains. Therefore, resilience to climate change, susceptibility to internal heat gains and the impact of future heat waves should be an integral part of any new building or building refurbishment design process.
\end{abstract}

\section{Background}

\subsection{Mitigating climate change}

It is now recognised that climate change, caused by carbon $\left(\mathrm{CO}_{2}\right)$ emissions that result from the burning of fossil fuels, poses the single greatest threat to humanity in the $21 \mathrm{st}$ century. The UK, in keeping with other developed countries has set ambitious $\mathrm{CO}_{2}$ reduction targets. The 2003 energy white paper [1] set a long term target of a $60 \%$ carbon emission reduction by 2050 and more recently, the Secretary of State for Energy and Climate Change, announced that the target would be increased to $80 \%$ in the forthcoming Climate Change Bill [2]. This bill will establish 'a long term legally binding framework to tackle the dangers of climate change'. However, whilst the UK looks set to meet its Kyoto target of cutting greenhouse gas emissions to $12.5 \%$ below the 1990 level by 2008-2012, the self-imposed target of cutting $\mathrm{CO}_{2}$ levels to $20 \%$ of the 1990 level by 2010 (see e.g. [3]) is unlikely to be achieved [4]. Notwithstanding, the government endorses the EU target of cutting carbon dioxide emissions by $20 \%$ from 1990 levels by the year 2020 [5].

In the UK, in 2001, buildings and the activities in them were responsible for around $50 \%$ of the nation's $\mathrm{CO}_{2}$ emissions; they account for a similar proportion of national emissions in other developed countries. Buildings are therefore the focus of numerous initiatives aimed at reducing their $\mathrm{CO}_{2}$ emissions. In the $\mathrm{UK}$ all new homes are to be zerocarbon by 2016 [6] and a report from the UK Green Building Council [7] proposes that all new non- domestic buildings should be zero-carbon before 2020. Policies to achieve such 
ambitions are gradually being put in place, for example, statutory instruments such as the building regulations [8], and the energy labelling of buildings, and planning guidance, such as the Planning Policy Statement: Planning and Climate Change [9], that requires all local authorities to adopt a Merton rule whereby a proportion of the energy use in new and refurbished buildings must be met by renewable sources. Making deep cuts in the $\mathrm{CO}_{2}$ emissions of existing buildings are however even more challenging. Although it is plausible to imagine achieving emission cuts of $40 \%$ or so in UK's 24 million or so houses through efficiency measures [10,11], making similar reductions from the $1.7 \mathrm{~m}$ or so non-domestic premises seems very onerous; and cuts in emissions form the entire building stock of the order of $80 \%$ are very unlikely to materialise without massive improvements in energy efficiency and the decarbonisation of the electricity supply $[12,13]$.

The NHS currently occupies and manages around 14,040 premises (about 1\% of UK's non-domestic premises) it is “... Europe's largest employer with 1.3 million people; 5 per cent of the United Kingdom workforce and is often the largest single employer in each of the regions of England. Given its size, the NHS in England is responsible for nearly 3 per cent of UK carbon dioxide emissions and 30 per cent of public sector emissions" [9]. In response to the 2000 Climate Change Programme [14], the NHS has, since 2001, worked to stringent energy use reduction targets. These require energy efficiency savings of $15 \%$ or $0.15 \mathrm{MtC}$ (million tonnes carbon) from March 2000 to March 2010 [15]. Around 44\% of the energy used in a typical UK hospital is for air and space heating [15] so superficial considerations would suggests that climatic warming may lead to reduced consumption through reduced winter heating requirements. However, statistics on NHS energy performance in England between 1999 and 2005 [16] indicate that whilst energy is being used more efficiently within the NHS over this period, consumption has increased by $7 \%$ to 44.8 million GJ: total carbon and $\mathrm{CO}_{2}$ emissions attributed to NHS Trusts in England increased by $11 \%$. This recent evidence suggests that NHS organisations in "both England and Wales are struggling to meet their energy-reduction targets and the 15 per cent emissions-reduction target is unlikely to be met" [17].

On top of the energy efficiency savings, NHS Trusts are expected to achieve targets of 35-55 GJ/100 m3 for new build and 55-65 GJ/100 m3 for the refurbishment of existing facilities [18]. However, the NHS Retained Estate data [19] shows that energy use of the majority of NHS Trusts in England was in the range of 44.8-98.0GJ/100m3 for 2004/2005 peaking at $125 \mathrm{GJ} / 100 \mathrm{~m} 3$; well above the target for refurbishments. Against this background it is proposed that, by 2009, all NHS organisations should have a board-approved carbon management strategy [18]. The ambitious carbon reduction challenge set by this proposed strategy would require "all our new buildings to be low carbon by 2015 and meet our ambition of zero-carbon by 2018 ” [20].

\subsection{Adaptation to climate change}

Whilst mitigation of climate change drives many national and NHS initiatives, some climate change up to 2040 is inevitable and beyond this the predicted temperature rise depends on the form that future global social and economic development takes, the use that is made of low-carbon sources of energy, etc. Assuming that economic development and population growth continues on broadly the same path as a present, which corresponds to the IPCC-SRES A2 story line and the UKCIP02 medium-high emissions scenario, called National Enterprise, then the daily average temperature rise in the London region will be about $4.8 \mathrm{~K}$ and in the region of $4 \mathrm{~K}$ in Manchester and 3.4 $\mathrm{K}$ in Edinburgh [21]. Associated with the generally elevated temperatures will be more frequent and more intense heat waves, 
particularly in England and Wales. Based on UKCIPO2 predictions [22] 'extremely warm' (90th percentile) days are expected to be between $4 \mathrm{~K}$ and $7 \mathrm{~K}$ warmer in the south-west of England by the 2080s and such conditions can have serious consequences for comfort and health. For example Hajat et al. [23] found an increase in deaths in London for average daily temperatures above $19^{\circ} \mathrm{C}$, and Johnson et al. [24], who studied the link between the 2003 heat wave and hospital admissions and mortality in England, found a 17\% increase in mortality rates in England and a 42\% increase in London. The effects are greatest in vulnerable groups, including the very young but particularly the elderly, who are physiologically less able to regulate their body temperatures and/or able to take adaptive action. However, all are affected by high night-time temperatures that can reduce the quality of sleep. As people live longer, and ambient temperatures rise, the numbers at risk will also increase.

Adapting to climate change in the UK could easily exacerbate, rather than mitigate, its causes. Whereas in the vast bulk of the country most public buildings can be kept comfortable using natural ventilation, in the London area, and more widely as climate change advances, simple natural ventilation will not provide acceptable internal conditions [21]. The consequence could so easily be the much wider uptake of air-conditioning or mechanical ventilation; and buildings with these systems invariably consume more energy than those with natural ventilation [25].

\subsection{Hospital wards}

Hospitals must be particularly resilient to climate change: firstly, because they must provide a safe and comfortable working environment for staff, whose performance can have life or death consequences for patients; secondly because they must support patients who may be particularly sensitive to high temperatures: those with weak or impaired thermoregulatory systems (older people; those on multiple medications; on psychiatric medication affecting thermoregulation and sweating; with chronic or severe illness) and those who are unable to take logical adaptive action to ameliorate the effect of high temperatures (the very young, the bed-bound, patients with mental illness); and thirdly because they are at the centre of the National strategy to protect citizens in the event of a heat wave: by providing warnings, advice and, crucially, a 'safe haven' [26]. The potential inability of new hospitals even in today's climate to fulfil this triple role was illustrated by the overheating of wards in the newly built Evalina Children's Hospital in Lambeth, London [27]: external temperatures regularly reached $32^{\circ} \mathrm{C}$ through a series of days in July 2006, the warmest external UK temperatures on record, threatening the welfare of vulnerable children. The Evalina is, in part, mechanically ventilated and cooled, but much of the NHS Retained Estate is not airconditioned and climate mitigation considerations would suggest that wide-scale installation of air-conditioning should be avoided.

The NHS Heatwave Plan for England implicitly recognises that not all care spaces in existing hospitals are resilient to elevated temperatures and so recommends establishing cool rooms to which vulnerable individuals can be moved. However, such a strategy problematically intertwines care programmes, disrupts the proper functioning of the hospital, presents infection control problems, and places onerous requirements on cool room design. Further, in a hospital context, other factors associated with elevated temperatures might need to be considered, such as the effects on pathogen species and their virulence. It is proposed that the forthcoming Climate Change Bill [2] will require the NHS, like other public authorities, to assess and address their particular needs for adaptation to climate change. 
Wards are particularly worthy of study because they occupy a substantial fraction of the floor area of hospitals and thus there is great potential for replication of a low-energy and resilient design solution. Ward spaces are intensively used in UK hospitals (empty beds are specifically avoided), they must protect patients from hospital acquired infections (either airborne of through contact) and the quality of the internal environment might perhaps have an impact on the comfort, recovery and well-being of patients [28]. Nursing staff will spend much of their working life in wards and they are areas visited by the public (friends and relatives of patients). The problem of controlling temperatures in wards may be exacerbated by the increasing use of electrical equipment that adds to the heat gains in spaces; and in this context, the increasing use of such equipment as a key component of patient care programmes is particularly relevant.

Wards are a particular topic of current interest because there is a move away from open wards towards single bed spaces. This offers the prospect of improved privacy, reduced ambient noise and better cross-infection control. Cellular spaces may also enable patients to exercise personal control over lighting and ventilation. Wards thus represent a significant design challenge.

Wards are specifically identified as spaces that may be naturally ventilated in HTM0301 [29] which is concerned with 'specialist ventilation for healthcare premises'. This memorandum states that 'natural ventilation is always the preferred solution for a space, provided that the quantity and quality of air required, and the consistency of control to suit the requirements of the space, are achievable'. The challenge for health care building design professionals is to provide this preferred natural ventilation solution in new hospital buildings and to retain natural ventilation, which is used to ventilate the majority of existing wards, when hospitals are refurbished. Retention of natural ventilation will contribute to the nation's, and the NHS's, drive to mitigate climate change; but the precise natural ventilation design strategy adopted must ensure that new buildings are resilient to the anticipated changes in climate and that the resilience of existing buildings to climate change is improved.

The research reported here addresses this challenge through a modelling study that evaluates the likely current and future day and night-time temperatures in hospital wards in different parts of the country. Alternative ventilation strategies, passive temperature control techniques, and internal heat gain scenarios are considered. The likely adaptation of individuals to future temperatures is accounted for and an overheating risk criterion compatible with adaptive thermal comfort assessment is proposed. The current and future energy demands and $\mathrm{CO}_{2}$ emissions of various passive and active environmental control strategies are also studied. The results and conclusions have implications beyond the confines of this particular, health care oriented, study and these are discussed.

Particular consideration is given to advanced natural ventilation (ANV) which has been shown by both field monitoring [30,31] and modelling studies [21] to offer greater resilience to climate change than simple natural ventilation; at least for some types of non-domestic building. The work thus contributes to our better understanding of ANV buildings, particularly as a refurbishment strategy.

\section{Advanced natural ventilation and refurbishing hospital wards}

Simple natural ventilation involves opening windows or other apertures between a space and the outdoors and many buildings, including hospital wards, are ventilated in this way. The strategy use apertures on one side of a space, single-sided natural ventilation (SNV), or on two (or more), usually opposing, sides of a space, cross- flow ventilation (Table 
1). These strategies are well understood by building occupants, they are low cost, and many types of window with different opening formats are available. Although SNV is only effective up to a depth of about 2.5 times ceiling height [32], this can be sufficient for single bed hospital wards. The strategy does however, have some practical limitations: the potential ingress of noise and pollution, which can preclude SNV on urban sites, and, in a hospital context, the restriction of ventilation rates because the size of window openings must be limited for safety reasons [29]. Further, whilst SNV enables occupant control, which is, quite rightly, portrayed as a benefit in most circumstances, such control is not so much enabled as demanded: and in the context of hospital wards, where occupants and nurses cannot, for a many reasons, be relied on to logically operate windows, this is an important distinction. This requirement means that SNV strategies cannot capitalise reliably and optimally on the passive cooling potential of exposed internal thermal mass and night ventilation. From a designers ${ }^{1}$ perspective, therefore, it is difficult to predict the likely performance of SNV designs and this undermines confidence in decisions about whether or not such buildings are likely to overheat or, stated more specifically, whether a summertime overheating risk criterion will, or will not, be met. This uncertainty is exacerbated when performance under future climatic regimes is being assessed because ventilation rates depend on local wind speed and direction and these are poorly predicted by climate modelling software. Whilst considering the future, we may also note that SNV provide no obvious 'up-grade path' by which fan assisted ventilation or ventilation pre-cooling can be incorporated, either to combat the known, near term, increases in ambient temperatures, or future, greater but less well defined, increases in temperature and heat- wave intensity.

Advanced natural ventilation strategies, of which four broad types have been identified ([33] and Fig. 1), have the capability to overcome some of these limitations (Table 1). Such strategies combine careful fabric design to reduce undesirable heat loss and summertime solar gain, and controlled day and night-time ventilation in combination with exposed internal thermal mass, to provide comfortable interiors. They utilise stacks to exhaust air from the building and so the ventilation rates are dependent almost entirely on natural buoyancy forces generated by the inside-to-outside air temperature differences. ${ }^{2}$ This makes the flow rates more reliable and controllable and the impact of interior air temperatures easier to predict.

The air-flow control is provided by a building management system (BMS) linked to louvers located at air inlets and outlets linked and to temperature and air quality (usually $\mathrm{CO}_{2}$ sensors) in the spaces. Because the air-flow can be carefully controlled at all times, the benefits of passive cooling can be more effectively harnessed. The reliability of the strategy can be further improved by including an intermittently operating fan in exhaust stacks. Thus, minimum air- flow rates can be assured and reverse flow, which could occur when the internal temperatures are below those outside the buildings, can be prevented. As mechanical systems, with their associated fans pumps and dampers, etc., are not necessary to distribute the air, energy consumption is generally lower than in similar mechanically conditioned spaces (e.g. [31]), maintenance costs could be lower, and resilience to equipment failures could be enhanced.

Post-occupancy monitoring of a deep-plan building that uses a combination of the C-C and $\mathrm{C}$-E strategy has shown that ANV is capable of producing comfortable internal temperatures below $26.5^{\circ} \mathrm{C}$ even when external temperatures exceed $35^{\circ} \mathrm{C}$ [31] and therefore that the building would be very likely to remain thermally comfortable in summer, in most of

\footnotetext{
${ }^{1}$ This should also be a concern of clients, but sadly most are much less concerned about energy and environmental performance in use than restrictive budgets and construction timescales

${ }^{2}$ Wind driven flows are often deliberately stifled to prevent reverse flows, drafts and difficult-to-control flow regimes.
} 
the UK, well into the 21 st century [30]. There is however uncertainty about future temperatures, the temperature elevations that do, and will, occur in city centre locations, and the future uses to which buildings will be put — and thus the internal heat gains. But one of the big advantages of ANV strategies is that they enable the integration of either passive or active cooling systems. The School of Slavonic and East European Studies (SSEES) in central London (C-E) uses passive downdraught cooling to temper supply air in summer [34], the Braunstone health and social care centre in Leicester utilises an under floor earth-contact labyrinth to pre-cool ventilation air [35], and the Judson building, near Chicago in the USA (C-E and E-E) [36,37] and the Science and Technology Museum in Hangzhou, China (E-C) [38] integrate full mechanical cooling. In principle, the large, accessible, and clearly defined air-flow paths make the integration of such cooling systems, as a future retrofit measure, relatively straight forward.

The centre-in strategies (C-E, C-C) use a central lightwell (or similar 'object') fed by a plenum (or from above) to get air into the middle of a building. They enable the facade of the building to be completely sealed so concerns about security and the ingress of urban noise and pollution can be overcome. In fact, the facade must be sealed if the desired air-flow regimes are to be set up and in the context of hospital wards this may be a concern - operable windows do provide useful line of defence against occasional and unanticipated events (spillage of toxic or noxious substances, small fires, etc.). For refurbishment application, the centre-in strategies are reliant on their already being a central air-supply object, or it being relatively easy to create one, and on having an unbroken and contained ${ }^{3}$ air-flow path linking the central supply to the perimeter (C-E) or central (C-C) exhaust. This may be achievable in non-clinical areas, in outpatient areas, and in areas with relatively open floor plans, such as multi-bed wards. However, hospitals tend to be composed of numerous cellular spaces that are arranged to produce the adjacencies required for each care 'process' and the trend is away from open wards and towards single bed wards; a refurbishment strategy that works against this structure is unlikely to find favour. Thus opportunities for centre-in strategies in hospitals are likely to be limited.

The edge-in strategies (E-E, E-C) avoid the need to have large air-supply objects penetrating the floor plates by delivering air directly to perimeter spaces where hospital wards are invariably located. The strategy thus enjoys the advantages of SNV and the air-flows are more predictable and controllable, but some disadvantages remain: urban noise and pollution ingress, the need for occupant control of windows, possible drafts, and no prospect of precooling supply air. The centre-out approach (E-C), where a stack is located at the in board side of each perimeter room, requires the stacks to penetrate through the floor plates. Whilst, compared to central air-supply objects, the stacks are relatively small in cross-sectional area, they are rather numerous and they may be impractical, expensive and disruptive to introduce in a refurbishment context.

The edge-out approach (E-E) overcomes these problems but still suffers the disadvantages of SNV and in the standard design (as shown in Fig. 1) flow across the building is required. All these disadvantages can be overcome, however, by providing vertical shafts on the edge of the building through which the fresh air is supplied to BMS-controlled air inlets and by locating the exhaust stack on the same perimeter as the supply shaft. This rather elegant solution can be effected without invading a building's floor plate purely by applying a new external facade. This evolved solution (Table 1), which was first used for perimeter offices in the new- build Judson building [36,37], enables the windows, that lie

\footnotetext{
${ }^{3}$ Of course, flow of air from a central space through another space to either a perimeter (edge-out) or central (centre-out) stack is probably unacceptable in clinical areas on infection control grounds.
} 
between the shafts and stacks, to be opened without disrupting the ventilation strategy but it does not require that they are operated. In a hospital context the possibility of either enabling window operation or of sealing windows, in response to the current patient's needs, could be very useful. The shafts and stacks add insulation to the facade, support shading devices (that can be tailored to protect windows with different orientations), provide pathways for routing new electrical (and other) services and can improve the external appearance of the building. In a new-build context, the shafts could supply air that has been tempered, either actively or passively, for example via a labyrinth. Up-grades, to combat future climatic conditions or changes of space use, such as mechanically cooling the supply air, can be introduced relatively easily without disrupting the operation of the parent building.

This evolved edge-in, edge-out strategy was the focus of attention in this research. It was explored both as a refurbishment measure and for use in new buildings. The specific arrangement investigated here was proposed by architects Short and Associates as a way of ventilating a new three storey hospital with perimeter ward rooms that were $7.2 \mathrm{~m}$ deep, 3.6 $\mathrm{m}$ wide and $3.6 \mathrm{~m}$ high (Fig. 2$)^{4}$. It can be seen that the external shafts and stacks occupy a large percentage of the building's facade, a percentage which increases with the building's height, the depth of perimeter rooms and the required size (free area) of the ventilation components. These geometrical relationships are explored more fully in Appendix A, which shows that for rooms that are twice as deep as they are wide (like those explored here), the strategy might not be possible for buildings that exceed 3 or 4 stories. The stacks, as shown in Fig. 2, are internally partitioned to reduce the risk of air flowing from one room to another, but they coalesce in a single wind-protected outlet, which can contain a fan if necessary. A shaded recess is created around the $1.4 \mathrm{~m}$ wide by $1.6 \mathrm{~m}$ high windows so introducing a horizontal shading device, for example over the south-facing windows, is relatively straight forward.

The analysis in this paper focuses on a south-facing third floor room, as it is likely to be the most difficult to keep cool with natural ventilation alone: it has probably the highest solar gains, the shortest exhaust stack and the longest supply shaft. For comparison purposes, the internal temperatures, and in particular the risk of overheating, is compared with the corresponding characteristics of 'conventional' rooms ventilated by operable windows (SNV). The energy use of the ANV design is compared with that of 'conventional' spaces which are mechanically ventilated. Firstly, however, it was necessary to determine which of the available guidelines, standards and criteria related to ventilation and overheating risk are most appropriate for hospital wards and to studying the affects of climate change.

\section{Thermal comfort and ventilation guidelines and criteria}

Determining the criteria to be used for quantifying the risk of day and night-time overheating in new or refurbished hospital wards proved more complicated than expected. It is useful therefore to spend a little time on the topic so that others might benefit from the study.

In the UK, guidelines are provided in the DoH's own documents, and in particular HTM03-01 [29], in the recommendations contained in the CIBSE design guides, in particular CIBSE Guide A [39], and, most importantly in British Standards, which increasingly defer to the relevant European Standard/Norm, and here BSEN15251 [40] is most relevant.

\footnotetext{
${ }^{4}$ The option of introducing air into the shafts from a basement tunnel below the building in order to pre-cool the air was studied, but this work is not reported in this paper.
} 
Memorandum HTM03-01, 2007, which is concerned with 'specialist ventilation for healthcare premises', offers some data by which to determining whether the internal temperatures and ventilation rates are acceptable or not. For general wards, the range of internal temperature 'over which the temperature may float' is quoted as $18^{\circ} \mathrm{C}$, which is rather cool, for sedentary persons even for those wearing a full office suit, to $28^{\circ} \mathrm{C}$ in Appendix 2 of (HTMO3-01): the relevant temperature being (HTM03-01, par 3.5) dryresultant. The standard suggests minimum fresh air ventilation rates of $10 \mathrm{l} / \mathrm{s}$ per person but Appendix 2 in HTM03-01 gives desired air change rates and here a value of $6 \mathrm{ach}^{-1}$ is given: for a typically sized ward room this exceeds the minimum fresh air rate by a factor of about 10 . When and why this ventilation rate should be achieved, and the basis for the precise choice of $6 \mathrm{ach}^{-1}$ is not given, however, one might presume that it is intended for use when wards are mechanically ventilated.

Regarding summertime temperatures, HTM03-01 states that 'Calculations and thermal modelling should be undertaken to see whether, during the summertime, internal temperatures in patient areas will exceed $28^{\circ} \mathrm{C}$ dry bulb temperature for more than 50 hours per year'. Three points are worth making. Firstly, the criterion relates to all hours during the (undefined) summertime, although there is evidence that at night-time temperatures lower than $28^{\circ} \mathrm{C}$ will still cause discomfort: HTM03-01 is silent on the matter of night-time temperatures. Secondly, the weather data to be associated with the modelling is not specified, the memorandum merely states that 'the most accurate data available for the summer and winter conditions at the site should be used'! And thirdly, the criterion uses dry bulb temperature, rather than operative (or dry- resultant) temperature, which more closely approximates the perception of comfort: the reason for this is not explained, and the choice seems odd, especially as elsewhere HTM03-01 quotes dry-resultant temperatures. Since, in thermally heavy weight night-ventilated buildings, operative (or dry-resultant) temperature is often below dry bulb temperature, the criterion is more stringent than it initially appears. ${ }^{5}$ The memorandum, does hint at more sophisticated approaches to determining acceptable temperatures noting that 'the relationship between preferred indoor temperatures and mean outside temperature is discussed in CIBSE Guide A'. This presumably refers to the adaptive approach to thermal comfort. The memorandum does not explain how and when designers should/could make use of this information: but it does open up the possibility of considering the adaptive approach to assessing naturally ventilated hospital spaces.

Overall then, the HTM03-01 is rather unconvincing and incomplete in its discussion and recommendations with regard to the internal conditions to be achieved in naturally ventilated health care spaces, so it is necessary to look to other guides and standards, most obviously the 'industry standard' the CIBSE Guide A [39], and the new British Standard BSEN15251 [40], which provides a more sophisticated method for identifying the risk of overheating in summer that is based on adaptive comfort consideration.

The CIBSE Guide A 'is the premier reference source for designers of low-energy sustainable buildings'. It recommends an air-supply rate of $10 \mathrm{l} / \mathrm{s}$ per persons, which is in line with the HTM03-01 recommended minimum and this is also the minimum rate required by

\footnotetext{
${ }^{5}$ HTM03-01 includes the following two sentences related to this matter: 'It can be generally assumed that for a naturally ventilated building, the internal temperature [type undefined] will be approximately $3 \mathrm{~K}$ above the external shade temperature. For a building with simple mechanical ventilation, the internal temperature [again of undefined type] can never be less than the external shade temperature and will inevitably be higher'. The first sentence is debatable especially if the internal temperature is dry-resultant or operative, it is certainly not true for a well-designed thermally heavy weight building. The second sentence is simply untrue. The combined effect of such statements is to push designers of healthcare facilities away from natural ventilation and towards potentially more energy intensive mechanical solutions, which is unfortunate. The provenance of neither of the sentences is given.
} 
the 2006 UK Building Regulations [8]. This rate corresponds to an indoor air quality classification between medium and moderate, using the BS EN 13779 [41] classification [42]. In spaces occupied by sedentary individuals, such as patients in wards, a supply of $10 \mathrm{l} / \mathrm{s}$ per person will result in a steady state elevation of $\mathrm{CO}_{2}$ levels above ambient of about $600 \mathrm{ppm}$, which equates to a value of about $1000 \mathrm{ppm}$. In ANV buildings the $\mathrm{CO}_{2}$ level can therefore be used to provide the feedback to a BMS to control the opening and closing of air inlet and outlet louvers, etc.

Turning to space temperatures, for air-conditioned wards the CIBSE Guide A (in its Table 1.5) gives target operative temperatures of $22-24^{\circ} \mathrm{C}$ in winter (note that the lower end is much higher than the HTM03-01 value of $18^{\circ} \mathrm{C}$ ) and $23-25^{\circ} \mathrm{C}$ in summer. For free-running, i.e. NV buildings, the Guide notes that "during warm summer weather $25^{\circ} \mathrm{C}$ is an acceptable indoor temperature", this accords with the temperature at which $90 \%$ of healthy sedentary adults wearing office clothing (e.g. shirt and tie but no jacket) will be comfortable according to the standard Fanger model of thermal comfort (see e.g. CIBSE Guide A). The Guide goes on to note that "the peak temperature during the day should not be more than $3 \mathrm{~K}$ above the design temperature, giving a benchmark maximum of $28^{\circ} \mathrm{C}$ ". Using a Fanger model this is the upper limit of temperature at which $90 \%$ of healthy adults will still be comfortable wearing light summer dress (i.e. light shirt and trousers and no tie).

Based on these observations the Guide then provides a method of assessing overheating risk. For offices, schools and living areas in dwellings the overheating criterion is " $1 \%$ annual occupied hours over operative temperature of $28^{\circ} \mathrm{C}$ ”. The HTM03-01 criterion (see above) is framed in a rather similar way to this CIBSE criterion but the limit of $50 \mathrm{~h}$ dry-bulb is more conservative, and for designers more restrictive, than the CIBSE criterion of $88 \mathrm{~h}$ (wards may be permanently occupied $8760 \mathrm{~h} /$ year) above $28^{\circ} \mathrm{C}$ dry-resultant (see comment above).

The CIBSE Guide A is the only one of those studied that defines the weather data to be used when testing spaces against the overheating criterion, and this is the Design Summer Year (DSY) for the location of the building, i.e. the third hottest year in a recent successive string of 20 years. ${ }^{6}$ In 2005 the CIBSE first distributed its current hourly data sets for use in simulation modelling [43] ${ }^{7}$; these supersede the 2002 data sets [44] and covered 14 UK sites from Edinburgh and Glasgow (Scotland) and Belfast (Ireland) in the North to Southampton and Plymouth (England) in the South. For each site, in addition to the DSY05, data representing an average year, i.e. a Test Reference Year (TRY05), ${ }^{8}$ was also distributed. A list of sites and the number of hours for which various ambient temperatures were exceeded in the DSY05 and the TRY05 are given in Figs. 3 and 4 respectively. ${ }^{9}$ It is worth noting that in London, the hottest place, there are $63 \mathrm{~h}$ in the DSY05 with an ambient temperature over $28^{\circ} \mathrm{C}$ so unless the air temperature in a ward is kept below ambient, the space cannot satisfy the HTM03-01 temperature criterion (maximum $50 \mathrm{~h}$ ).

\footnotetext{
${ }^{6}$ The DSY for any site is determined by arranging a string of 20 successive years of hourly weather data in order of the average daily mean ambient dry bulb temperature recorded during the period from April to September and then choosing the third hottest year.

${ }^{7}$ The CIBSE now also distribute future weather data, but this was not available at the time the work presented here was published.

${ }^{8}$ A TRY is a year constructed by selecting the January that most closely typifies the average of all 20 Januarys, chaining that the most typical February, etc., and then smoothing the joins between months.

${ }^{9}$ It can be seen that for Manchester, Newcastle, Norwich, Nottingham, and Southampton the number of hours over $25^{\circ} \mathrm{C}$ is greater in the TRY than in the DSY. This is because DSYs are selected using the average temperature recorded from April to September and not the number of hours over a specified temperature (such as $28^{\circ} \mathrm{C}$ ).
} 
Interestingly, the CIBSE Guide A also comments that acceptable nighttime temperatures may be lower than the daytime temperatures; noting that "thermal comfort and quality of sleep begins to decrease if bedroom temperatures rise much above $2{ }^{\circ} C$ " and stating that "bedroom temperatures at night should not exceed $26^{\circ} \mathrm{C}$ unless ceiling fans are available" (Guide A section 1.6.4.3). The data available to the CIBSE refer to houses and not to health care facilities, but the NHS Heatwave Plan adopts a similar temperature, advising Trust Managers to ensure that "rooms are consistently below $26^{\circ} \mathrm{C}$ as this is the temperature at which vulnerable patients find it difficult to cool themselves naturally if sweating is impaired". Research work on domestic air-conditioning has shown that, if given free choice, householders will set the night-time temperature in bedrooms at $20^{\circ} \mathrm{C}$ [45]. The CIBSE Guide provides a domestic bedroom over heating criterion - no more than "1\% of occupied hours over an operative temperature of $26^{\circ} C$ ", which is to be applied in conjunction with the relevant DSY: the applicability of this criterion to patients in hospital wards is unknown. There are also some questions about if, and how, it should be used in the context of hospital wards where the 'bedroom' is occupied all day: are there 24 occupied hours or are just the night-time hours of sleep to be considered? And if all $24 \mathrm{~h}$ are to be considered as occupied, how does the criterion work alongside the CIBSE $28^{\circ} \mathrm{C} / 1 \%$ criterion or the $28^{\circ} \mathrm{C} / 50 \mathrm{~h}$ HTM03-01 criterion - do night-time hours over $28^{\circ} \mathrm{C}$ 'count' against both the day and night criteria? More trenchantly, is the criterion relevant at all to hospital patients that may have impaired thermoregulatory function and be particularly in need of rest as an aid to recovery. And more generally, even for health individuals, one might imagine that if sleep is affected on successive nights it will be more detrimental to general well-being than occasional separated nights or hours of lost sleep, so the juxtaposition of warm night-time hours could be important (and more important perhaps than the juxtaposition of warm daytime hours); and this brings into question the basis on which the design (DSY) weather data is selected. Notwithstanding these questions, it would seem prudent when assessing ward temperatures to consider the occurrence of elevated night-time temperatures using $26^{\circ} \mathrm{C}$ as a benchmark figure, and this is done in the research reported here.

The thermal comfort criteria described above are intended for assessing buildings under the present climatic conditions. When considering comfort in the future climate, it is important to account for the likely acclimatisation of individuals as they become 'accustomed' to a warmer climate. Extensive work beginning in the 1970s in the UK [46] and elsewhere has clearly demonstrates that individuals' prior thermal experiences have a marked impact on their perception of subsequent conditions. Standards based on the adaptive theory, for use in assessing whether spaces are comfortable or not are in place in the UK [39] and the USA [47] but these are probably not directly applicable to the occupants of health care buildings. Assuming that the populace of the UK will display the same sensitivity to elevated internal temperatures in the future as they do today is incorrect.

The new Standard BSEN15251 [40] provides a method for identifying the risk of overheating in summer in naturally ventilated buildings which is based on adaptive comfort principles and until better criteria for overheating have been developed [48] the Standard's approach is likely to be adopted in the UK by the CIBSE for assessing overheating. ${ }^{10}$ The key to the standard is the establishment of limits for the operative temperature in existing and planned buildings, which depend on the running mean of the outdoor temperature. (The method of calculating the running mean temperature, and the relationship of the maximum and minimum operative temperature limits to it, is explained in Appendix B.) Clearly, as ambient temperatures increase the running mean temperature will do so, and thus the

\footnotetext{
${ }^{10}$ In fact, the CIBSE Guide A already includes an adaptive method for overheating assessment similar to that described in BSEN15251.
} 
Standard seems appropriate for studying the impact of future climates on the thermal comfort of building occupants.

Further, the Standard proposes that the maximum limit temperature at which individuals can be comfortable depends on the extent to which they able to adapt their environment and how well-functioning their thermoregulatory system is. Thus spaces are divided into four categories, where Category I is 'High level of expectation and is recommended for spaces occupied by very sensitive and fragile persons with special requirements like, handicapped, sick, very young children and elderly persons', this Category would seem to be applicable to ward spaces, and Category II is 'normal level of expectation and should be used for new buildings and renovations', in health care buildings this might be appropriate to staff rest areas public areas, administrative offices, etc. (Category III is 'acceptable, moderate level of expectation and should be used for existing buildings'.) The upper temperature limit is lowest, and the range of allowable temperatures narrowest, for Category I spaces and both the upper limit and allowable range increase with category number (Fig. 5). Thus, the method is responsive to the characteristics of a space's occupants - unlike the CIBSE and HTM03-01 criteria noted above, which use a fixed threshold temperature.

Because the temperature limits change with ambient temperature it is more difficult at an early design stage to judge whether NV is likely to be a successful strategy or not. However, for any given locality (and hourly weather data file) the hourly temperature limits only have to be calculated once and can then be applied in all subsequent projects in that locality (i.e. using that weather data). Interestingly, for the London DSY05 data, the Standard produces a peak limit on the operative temperature of $28.1{ }^{\circ} \mathrm{C}$, which is rather similar to the CIBSE and HTM03-01 values of $28^{\circ} \mathrm{C}$ dry-resultant and $28^{\circ} \mathrm{C}$ dry-bulb respectively (see Appendix B).

The Standard [40] does however include some caveats: (1) that the temperature limits 'are valid for office buildings and other buildings of similar type .. with mainly sedentary activities ... .. where there is easy access to operable windows and occupants may freely adapt $^{11}$ their clothing to the indoor and/or outdoor thermal conditions"; (2) that "the spaces at hand are regulated primarily by the occupants through opening and closing windows '; and (3) that these windows 'open to outdoors and [which] can be readily opened and adjusted by the occupants of the spaces. There shall be no mechanical cooling in operation in the space'. Taking each of these in turn: whilst some patients in wards will be unable to freely adapt clothing, there is the strongest implication (Category I) that the method is applicable to health care spaces; the proposed ANV design does give occupants access to operable windows by which temperatures can be, rather than are, regulated ${ }^{12}$ in operation; and the intention of this work is, of course to avoid mechanical cooling, and where it is essential, some other temperature criterion can be used.

Before the BSEN15251 standard can be used for studying the thermal comfort affects of future climate, there are three problems to overcome: firstly the preferred method of quantifying the frequency of occurrence of temperatures outside the limits needs to be resolved (the Standard suggest that either the total number of hours; the percentage of time; or the number of degree- hours outside the limits is counted); secondly, a criterion for judging if the values so calculated represent an acceptable overheating risk or not, is not provided,

\footnotetext{
${ }^{11}$ Bold font by current authors.

${ }^{12}$ It is not clear why the provision of fresh air through controlled inlets should preclude the use of the Standard, the restriction is probably precautionary given the lack of experience of such spaces. In any case, in the ANV designs proposed here operable windows supplement the controlled inlets.
} 
and so this must be created; and thirdly, the weather data to be used in conjunction with the adaptive method is not stated - but since the temperature limits change with the ambient temperature the choice of weather data might be less critical than when fixed criteria (e.g. CIBSE and HTM03-01) are used. These matters are the subject of this paper.

Finally, it is worth noting that the Standard cannot be used for assessing night-time thermal comfort - the Standard was based primarily on studies of NV offices, adaptive opportunity is much restricted at night, and the operation of windows disrupts sleep. A way of assessing night-time thermal comfort in future climates needs to be produced if heatwave planning in the UK is to be put on a sure footing.

\section{Modelling the ward rooms}

Thermal simulations were undertaken using the IES simulation system, virtual environment version 5.8 [49] in five phases: firstly, using the current London DSY, studies were conducted to refine the control of the heating and ventilation systems in the ward with ANV (Fig. 2) and to understand the hour-by-hour internal conditions (internal temperatures, $\mathrm{CO}_{2}$ levels, ventilation rates, heating energy demands; and relative humidity ${ }^{13}$ ); secondly, the frequency of occurrence of elevated temperatures was compare the performance of thirdly, the sensitivity of the internal summertime temperatures to the internal gains and geographical location was explored; fourthly, a criterion for assessing future comfort levels was developed and the resilience of the wards to future weather conditions assessed; and finally, the current and future energy and $\mathrm{CO}_{2}$ implications of alternative designs were the considered.

The basic design consisted of a single space (Fig. 6) that was $7.2 \mathrm{~m}$ deep, $3.6 \mathrm{~m}$ wide and $3.6 \mathrm{~m}$ high giving a floor area of $25.92 \mathrm{~m}^{2}$ and a volume of $93.3 \mathrm{~m}^{3}$. The space contained a bathroom area, but this was not modelled, and thus it was implicitly assumed that the ventilation of this space was balanced and had little impact on the air-flow in the ward as a whole. The room was assumed to be entirely surrounded by other similar spaces on five sides (zero-net heat flux through walls, floor and ceiling) with the sixth side facing due south and having a single window measuring $1.4 \mathrm{~m}$ by $1.6 \mathrm{~m}$ giving an area of $2.24 \mathrm{~m}^{2}$ or $9 \%$ of the floor area. In all the ANV simulations conducted here the window was assumed to be closed, though, as noted above it could be operable without compromising the basic ventilation strategy.

The floor and ceiling of the room were of $200 \mathrm{~mm}$ dense cast concrete with a screed and plastic tile covering and the side and rear walls were of plastered medium weight block. On the exposed wall the block was externally insulated to give a U-value of $0.3 \mathrm{~W} / \mathrm{m}^{2} \mathrm{~K}$ and the window was of double low-emissivity glass giving a $\mathrm{U}$-value of $1.98 \mathrm{~W} / \mathrm{m}^{2} \mathrm{~K}$; both values being chosen to meet the prevailing UK building regulations [8]. The shafts and stacks were well insulted (300 $\mathrm{mm}$ of insulation was arbitrarily chosen) to prevent solar gain warming the supply air and heat loss in winter cooling the exhaust air - both of which could impair the performance of the ANV design.

The window was located between the perimeter stacks and shafts. These effectively shade the window from direct solar gain when the sun was in the east and west, i.e. total solar exclusion before 8 a.m. and after 5 p.m. (GMT), but expose the south-facing window to $60 \%$ or more of the direct radiation between 11 a.m. and 2 p.m. and to the full sun between 12 noon and 1 p.m. For the ANV design therefore a shading device, which extended $1 \mathrm{~m}$ out

\footnotetext{
${ }^{13}$ As in some discussions with the present authors it had been suggested that very low relative humidity could lead to a build-up of static charge which would attract and retain particles that might transport pathogens, which would otherwise be ventilated out of the space.
} 
from the window and spanned between the ventilation shafts and stacks was always modelled (see Fig. 6). Simulations with the London DSY showed that the $1 \mathrm{~m}$ overhang reduced the number of hours for which the predicted internal dry-resultant temperature in the ward exceeded $26^{\circ} \mathrm{C}$ by about $20 \%$. Whilst this was not critical when considering the HTM03-01 overheating criterion (see below) it could be so under future climatic conditions and in spaces with high internal gains.

The rooms modelled were assumed to be on the third floor of a building, which would actually be the top floor of the hospital design proposal (Fig. 2). A higher level room was chosen as it poses a greater design challenge, the room has less stack height to drive an airflow than rooms lower in the building and a greater length of stack up which fresh air has have to travel to reach the room. (The supply shaft is shown connected to a supply air labyrinth in Fig. 6, but in all the simulations reported here no labyrinth was in fact modelled.) The shaft delivers air into the room at low level and the stack exhaust air at high level: the vertical distance from the ground to the inlet being $9.7 \mathrm{~m}$ and from the outlet to the stack termination $3.1 \mathrm{~m}$. In the simulations concerned with peak temperature analysis (Phases 1-4), no control was exercised over the inlets and outlets, i.e. The operation of louvers was not modelled, however, in Phase 5, where energy demands and $\mathrm{CO}_{2}$ emission were studied; a louver control strategy was implemented. Provision was made to include a fan in the exhaust stack to assist air-flow if necessary. In all the ANV simulations undertaken it was assumed that winds neither assisted nor hindered ventilation.

In the basic ANV design, the maximum free opening area from the supply shaft into the room, and from the room outlet into the exhaust stack, was equivalent to $1 \%$ of the floor area (i.e. $0.26 \mathrm{~m}^{2}$ ). The openings at all other points along the flow path were the same (the shafts and stacks being $0.26 \mathrm{~m}^{2}$ in cross-sectional area) so as not to significantly restrict the air-flow. In simulations with different ventilation openings (Phases 2-4), the inlets, outlet, shafts and stacks always had matched free areas.

There is little information available on the likely internal heat gains in hospital wards, so for the base-case simulations pragmatic values were chosen. It was assumed that a patient generating $80 \mathrm{~W}$ was present $24 \mathrm{~h} /$ day, that during the day, from 7 a.m. to 9 p.m., lighting and small power items produced $15 \mathrm{~W} / \mathrm{m}^{2}$, staff visits generated $100 \mathrm{~W}$ for $5 \mathrm{~min}$ each hour and visitors $200 \mathrm{~W}$ between 1 p.m. and 2 p.m. and between 6 p.m. and 9 p.m. These give average internal gains of $21 \mathrm{~W} / \mathrm{m}^{2}$ during the day and $4 \mathrm{~W} / \mathrm{m}^{2}$ at night (9 p.m. to 7 a.m.). The resilience of ANV designs to increased internal heat gains was an important aspect of Phases 3 and 4 of this work.

The ward was assumed to be heated from 7 a.m. to 10 p.m. to the CIBSE and HTM0301 defined value of $22^{\circ} \mathrm{C}$ with a night-time set-back chosen as $20^{\circ} \mathrm{C}$, as suggested by the work of [45]. The use of a night set-back seems, to the present authors at least, to be wise given that temperatures just $2 \mathrm{~K}$ above the heating set point (i.e. $24^{\circ} \mathrm{C}$ ) may impair sleep (see above). The impact of alternative night-time heating set points on the incidence of overheating was however investigated.

\section{Phase 1: predicted environmental conditions in the ward}

Simulations to explore the hourly performance of the ANV design during the summer period were conducted using the London DSY produced by the CIBSE in 2005 (LonDSY05). Aspects investigated included the inclusion and control of a fan in the exhaust stack and alternative night-time temperature set-backs. 
Initial simulations showed that the basic ANV proposition worked well, however when the internal temperature was close to, or below, the external temperature, the ventilation flow reversed, that is the air descended the shaft and entered via the stack. This occurred on most days during the summer and as a result, at times when the flow was about to reverse, the ventilation rates were low and the internal $\mathrm{CO}_{2}$ levels high (but values over $1000 \mathrm{ppm}$ were extremely rare). Flow reversal may seem, from a ventilation cooling perspective, not be too serious, but from an infection control perspective it is undesirable. Pathogens from a room that is ventilating correctly could be carried up its exhaust stack into the common stack termination and then, from there, flow back down the stack of the room that is experiencing reverse flow. Alternatively, if a number of shafts connect to a common 'space', such as a labyrinth, the air from the ward room experiencing reverse flow could be transported down to this space and then up into the other rooms that are ventilating normally.

To prevent reverse flow a stack fan was modelled which switched on to produce a flow of $30 \mathrm{l} / \mathrm{s}$ whenever the ward room's $\mathrm{CO}_{2}$ levels reached $950 \mathrm{ppm}$ or its internal airtemperature was less than $3 \mathrm{~K}$ above ambient. A value of $30 \mathrm{l} / \mathrm{s}$ was chosen so that the supply rate would be adequate for the patient and two 'visitors', other values could easily be adopted but higher values incur an energy penalty. The temperature offset was chosen by trial and error and a smaller value would be possible for rooms on lower floors. In the simulations undertaken, the $3 \mathrm{~K}$ temperature criterion, rather than the $\mathrm{CO}_{2}$ criterion, always triggered the operation of the fan. Because fan operation is initiated when internal buoyancy-driven flows are sluggish, but the ambient temperature is still below the ward temperature (up to $3 \mathrm{~K}$ lower), the fan also helped to reduce the peak internal temperatures predicted in the ward. In all the ANV simulations conducted in this work a fan with the control proposed here was modelled.

Preliminary simulations, using LonDSY05, were also undertaken to study the effect of the night-time heating set point temperature on the incidence of elevated temperatures. Values of $18^{\circ} \mathrm{C}$, the lower value quoted in $\mathrm{HTM} 03-01,20^{\circ} \mathrm{C}$ the preferred temperature suggested by the study of He et al. [45], and $22^{\circ} \mathrm{C}$ the same as the daytime set point, were used as well as having no heating at all (equivalent to a very low night-time set point). It was found that, with any of the chosen set points, there was no impact on the occurrence of temperatures over $28^{\circ} \mathrm{C}$, however there were about $20 \%$ fewer hours over $25^{\circ} \mathrm{C}$ with a set point of $18^{\circ} \mathrm{C}$ than $22^{\circ} \mathrm{C}$ : with no heating at all the hours over $25^{\circ} \mathrm{C}$ did not decrease any further. Thus, it would seem that any passive night cooling effects that the ANV strategy offers is not unduly compromised by night-time heating, at least for the external and internal conditions studied here. In all simulations reported here the set point was kept at $20^{\circ} \mathrm{C}$ during the night.

One concern with an edge-in edge-out strategy that has the inlet and outlet on the same wall is that air will just 'short circuit' from the inlet to the outlet leaving the deeper parts of the room poorly ventilated. A brief CFD study was therefore conducted to examine the distribution of fresh air and temperatures in the room. This clearly showed that the fresh air penetrated right into the space whilst the high level outlet exhausted the stratified air at ceiling level: the desired displacement ventilation regimen was thus established.

The hourly values of predicted internal dry-resultant temperatures, relative humidity and $\mathrm{CO}_{2}$ levels, as well as the passive and active (fan induced) ventilation rates, for the hottest period in the London DSY05, are shown in Fig. 7. It can be seen that the natural buoyancy-driven ventilation rates during this period are up to $150 \mathrm{l} / \mathrm{s}$ (equivalent to about 6.8 $\mathrm{ach}^{-1}$ ) with the highest flow occurring during the night when the temperature differential between inside and outside is greatest. In the middle of the day, the air-flow is dependent on the performance of the fan, which, as noted above, was set to exhaust at a rate of $30 \mathrm{l} / \mathrm{s}$ 
(approximately $1.2 \mathrm{ach}^{-1}$ ). These air- flow rates keep the $\mathrm{CO}_{2}$ levels well below $1000 \mathrm{ppm}$ at all times.

The impact of the night-time ventilation in combination with the exposed thermal mass and external shading, can clearly be seen (Fig. 7), with the internal dry-resultant temperatures frequently being below the ambient temperature, and up to $5 \mathrm{~K}$ lower on July 22nd, the hottest day $\left(33.5^{\circ} \mathrm{C}\right)$. Although ambient daytime temperatures fall in subsequent days, the interior dry-resultant temperature continues to climb a little, due largely to the heat absorbed into the thermal mass. Thus on July 23rd, 24th and 25th, the interior dry-resultant temperature exceeds $28^{\circ} \mathrm{C}$, reaching a maximum of $29.8^{\circ} \mathrm{C}$ on July 24 th. Considering the whole year, there are only $15 \mathrm{~h}$ when the internal dry-resultant temperature exceeds $28^{\circ} \mathrm{C}$, all of which are visible in Fig. 7; this is well inside the $50 \mathrm{~h}$ HTM03-01 criterion.

At night ( 9 p.m. to 7 a.m.) during this hot period the dry-resultant temperatures exceed $26^{\circ} \mathrm{C}$ virtually every hour for four successive nights, i.e. from the night of the $22 \mathrm{nd}$ through to the night of the 25 th with peak values of just over $28^{\circ} \mathrm{C}$ occurring at 9 p.m. on all these days (Fig. 7). Considering the whole year however, there are though only $21 \mathrm{~h}$ when the internal dry-resultant temperature exceeds $26^{\circ} \mathrm{C}$ during the night, all of which are visible in Fig. 7; this is less than the CIBSE criterion of $1 \%$ of occupied hours $(36.5 \mathrm{~h})$.

During the hot nights (Fig. 7) the ambient temperature actually dipped well below the internal dry-resultant temperature, being about $9 \mathrm{~K}$ cooler at 6 a.m. on the morning of the 25 th. This suggests that additional ventilation (i.e. above the $6-7 \mathrm{ach}^{-1}$ produced by the ANV strategy) could render the space more comfortable. This might be readily effected by opening the window at night; a further reason why operable windows should be retained. The impact of such window operation was not studied in this work.

The simulation results clearly suggest that maintenance of comfortable night-time temperatures in naturally ventilate hospital wards in the London region should be given careful consideration at the design stage; they were therefore considered in the work reported here that used the current UK climate data.

The succession of elevated night-time temperatures in the LonDSY05 weather file raises the question of how representative this is of the frequency and juxtaposition of hot nights that actually do occur in the London (Heathrow) region in typical and 'hot' years. Because the DSY is an actual year (1989) selected on the basis of the average temperature between April and September, there is no reason to suppose that the night-time conditions are particularly well represented. ${ }^{14}$ A more appropriate approach would be to select years using the parameter that a particular design criterion actually uses (e.g. daytime hours over $28^{\circ} \mathrm{C}$, or night-time hours over $26^{\circ} \mathrm{C}$ ), which in turn implies the possibility of having different weather data for the different criteria. (But this is merely an extension of the current principle of using TRYs for average (e.g. energy use) predictions and DSYs for overheating analysis.) On conclusion of this work therefore is that more careful consideration needs to be given to the method by which the weather years to be used in simulation, and in association with specific performance criteria, are chosen.

\footnotetext{
${ }^{14}$ In fact, the appropriateness of DSYs for assessing (daytime) overheating risk, selected, as they are, on the basis of a longterm average (six-month) ambient temperature, is also questionable.
} 


\section{Phase 2: comparison of temperatures in wards with advanced natural ventilation with those in wards with simple natural ventilation}

The results for the basic ANV design suggest that it has the potential to keep the ward thermally comfortable in the SE of England ${ }^{15}$ as judged by the HTM03-01 criterion. However, to gauge the significance of the predicted internal temperatures, it is helpful to compare them with those predicted for conventional ward designs that use simple singlesided natural ventilation. Many possible 'conventional' designs could be used as comparators. Here a ward that might be designed for a new hospital was used. It had the same internal dimensions and construction as the ANV room but the ceiling was of suspended acoustic tiles. The window was either $2.6 \mathrm{~m}$ long by $2 \mathrm{~m}$ high, area $5.2 \mathrm{~m}^{2}$ (i.e. about $20 \%$ of floor area) or $1.3 \mathrm{~m}$ long by $2 \mathrm{~m}$ high, area $2.6 \mathrm{~m}^{2}$, which is similar to the window in the ward with ANV. Windows were shaded by an internal blind ${ }^{16}$ which was lowered when the incident solar radiation exceeded $300 \mathrm{~W} / \mathrm{m}^{2}$. The window faced either south or north and was made of either clear low-emissivity glazing (like the window in the ANV room) or solar heat control glazing with a high (visible) light transmission. ${ }^{17}$ Ventilation was via the operable windows which produced openings equal to either $12 \%$ of the window area or twice this, i.e. $24 \%$. For sash windows these are approximately equal to slot openings at the top and bottom of either 120 $\mathrm{mm}$ or $240 \mathrm{~mm}^{18}$ (opening areas in hospitals being limited on safety grounds). Since the incidence of summertime overheating was being assessed the window was assumed to be open at all times. It was assumed that the SNV space was 'semi-exposed', meaning that other buildings are of a lower height, which is consistent with modelling a third floor room.

The performance of the ANV strategy is influenced by the free area of the openings into and out of the space and by whether or not thermal mass is exposed, especially at ceiling level. Opening areas are of interest because their size, and thus the cross-sectional area of the stacks and shafts, has a significant impact on the building's appearance and cost (see discussion above). Here, the effect of reducing the openings to $0.5 \%$ and $0.25 \%$ of the floor area were studied as well as the benefits of providing larger openings, equal to $1.6 \%$ of the floor area. (Larger areas might for example, provide added resilience to future temperatures and higher internal heat gains.) The exposure of thermal mass is often a matter of debate at design stage because the established norm in many buildings is to fit lightweight suspended ceiling tiles. This is the case in hospitals, as opportunities to introduce acoustically absorbent materials elsewhere are limited, and ambient noise, which disrupts sleep, is a matter of concern in hospitals. The false ceilings also make the routing of services relatively simple and these can change frequently during the lifetime of a hospital.

The simulation results (Table 2) for a ward with simple SNV and (un-shaded) clear low-emissivity glass show that it is not possible to satisfy HTM03-01 overheating criterion irrespective of the size of the window and its orientation: and only in north-facing rooms with windows that produced large ventilation openings ( $4.8 \%$ of floor area) was it possible to meet the CIBSE night-time temperature criterion. The solar heat control glazing was clearly effective in ameliorating the solar gains, significantly reducing the incidence of overheating in the south-facing rooms (the number of hours over $28^{\circ} \mathrm{C}$ was similar in the north- and south-facing rooms with the same window area and in rooms with different window sizes provided the ventilation area was the same). However, except with windows that provided a large ventilation aperture ( $4.8 \%$ of floor area), the incidence of overheating still exceeded the

\footnotetext{
${ }^{15}$ Where urban micro-climate effects such as urban heat islands are not present.

${ }^{16}$ Shading coefficient 0.575 , short wave fraction 0.5 .

${ }^{17}$ Light transmission 0.69 , short wave shading coefficient 0.39 , U-value $1.1 \mathrm{~W} / \mathrm{m}^{2} \mathrm{~K}$

${ }^{18}$ With centre-pivot windows, the $120 \mathrm{~mm}$ slot is equal to $86 \mathrm{~mm}$ or $67 \mathrm{~mm}$ (long and short window respectively) and the $240 \mathrm{~mm}$ slot equal to $172 \mathrm{~mm}$ or $134 \mathrm{~mm}$ (long and short window respectively).
} 
HTM03-01 criterion and the CIBSE night-time temperature criterion. These results clearly have important implications for ward design particularly and for the design of naturally ventilated buildings in the SE of the UK in general.

In contrast, the basic ANV space was predicted to have only $15 \mathrm{~h}$ over $28^{\circ} \mathrm{C}$ and 21 night-time hours over $26^{\circ} \mathrm{C}$, even with a false ceiling, which doubles the number of hours over $28^{\circ} \mathrm{C}$ to 31 , the ANV design satisfied the HTM03-01 criterion. Opening areas of less than $1 \%$, increased the risk of overheating and a small opening, $0.25 \%$ of floor area, significantly increased the incidence of high temperatures both in the day and at night. With the larger opening, $1.6 \%$ of the floor area, the occurrence of high temperatures was significantly reduced; there were just $4 \mathrm{~h}$ over $28^{\circ} \mathrm{C}$ and 12 night-time hours over $26^{\circ} \mathrm{C}$.

Clearly, with today's climate in the SE of England, the ANV strategy, in conjunction with solar shading and exposed internal thermal mass, reduces the risk of summertime overheating compared to simple SNV strategies rendering the internal temperatures acceptable as judges by the HTM03-01 and CIBSE (night-time) overheating criteria.

\section{Phase 3: sensitivity to location and internal heat gains}

It is evident from the previous results that ANV has the potential to yield acceptable temperatures in hospital wards even in the SE of England, whereas only SNV spaces that have a large area of opening window and solar heat control glazing can yield acceptable conditions. To understand the wider applicability of the two ventilation strategies the risk of overheating in other UK locations and with additional internal heat gains was studied.

Three other UK locations were examined using the 2005 DSY weather data: Birmingham, Manchester and Edinburgh (BirDSY05, ManDSY05 and EdnDSY05). These span the range of temperatures found in the UK (see Fig. 3).

The internal heat gains in different areas of hospitals are very uncertain. This is partly because the gains depend on the electrical technology that is used in the care programme of each patient, and the technology used will differ markedly from one patient to another and for the same patient over time, but also because the heat output of the different items of equipment used in hospitals is unknown. Further, patients themselves tend to use TVs and other electrical items, and with the move to single bed wards the number of electrical appliances in use may increase. Building environmental control strategies must therefore be robust to the current, and the potential future, internal heat gains. In this study, the internal heat gain was arbitrarily increased by a fixed and constant amount over the basic gains: values of $+10 \mathrm{~W} / \mathrm{m}^{2}$ or $+20 \mathrm{~W} / \mathrm{m}^{2}$ were used (which yield time-averaged values of $31 \mathrm{~W} / \mathrm{m}^{2}$ day and $14 \mathrm{~W} / \mathrm{m}^{2}$ night, and $41 \mathrm{~W} / \mathrm{m}^{2}$ day and $24 \mathrm{~W} / \mathrm{m}^{2}$ night, respectively).

The study of the SNV designs (see Table 2) showed that the area of ventilation opening was the most important factor determining the internal temperatures. Therefore the SNV designs with the largest opening that might be deemed compatible with safety considerations were studied further (equivalent to a sash window with openings of $240 \mathrm{~mm}$ at the top and bottom). Of the rooms of this type studied, the one with a large north-facing window performed best and the one with the smaller south-facing window performed worst. Both were therefore modelled, each with either low-emissivity or solar heat controlling double glazing.

Considering the ANV design first, it can be seen that the risk of overheating is acceptably low with the standard heat gains profile, and, in fact, there are zero hours over $28^{\circ} \mathrm{C}$ in Birmingham, Manchester and Edinburgh (Table 3). Also, at all locations, the 
overheating risk is small even with an additional internal heat gain of $10 \mathrm{~W} / \mathrm{m}^{2}$, although in London only if the free area of opening is increased to $1.6 \%$ of floor area. Further, in all areas except London, the ANV design is robust to additional gains up to $20 \mathrm{~W} / \mathrm{m}^{2}$, i.e. $41 \mathrm{~W} / \mathrm{m}^{2}$ day and $24 \mathrm{~W} / \mathrm{m}^{2}$ night, although the opening area needs to be greater than $1 \%$ of floor area in Birmingham.

Only north-facing rooms with SNV display the same resilience to elevated internal heat gains as ANV spaces. In contrast, the SNV rooms with (unshaded) south-facing glazing, display much lower resilience to additional internal heat gains - even those with solarcontrol glazing. The occurrence of hours over $28^{\circ} \mathrm{C}$ rises rapidly with internal heat gains in all the locations studied: even in Edinburgh such spaces begin to exhibit an unacceptable overheating risk at gains of $41 \mathrm{~W} / \mathrm{m}^{2}$ in the daytime. As noted above, in London, such spaces have an unacceptable overheating risk even with relatively low internal heat gains.

Clearly, unshaded spaces on south-facing facades conditioned using SNV are likely to be a risky proposition in any location in England if internal heat gains could reach around 30 $\mathrm{W} / \mathrm{m}^{2}$ in the daytime, but in the SE of England at heat gain levels much lower than this. In contrast ANV displays resilience in the face of rising internal heat gains. This is likely to be because the higher gains, which do lead to elevated air temperatures, are countered by the additional ventilation that is induced in the stack ventilated displacement ventilation regimen. On north-facing facades, SNV presents a low risk of overheating in all locations except London, for daytime heat gains up to $31 \mathrm{~W} / \mathrm{m}^{2}$ and, with only marginal overheating in Birmingham, up to gains of $41 \mathrm{~W} / \mathrm{m}^{2}$ in more northerly locations. Thus, in these locations, ANV might be considered unnecessary on north-facing elevations.

\section{Phase 4: resilience to future elevated temperatures}

To assess the risk of overheating in the future, two important steps are required; firstly the establishment of an appropriate criterion by which to decide if a space is comfortable, and secondly the development of credible hourly future weather data.

As discussed above, the BSEN15251 adaptive standard provides the basis for assessing future comfort but it is necessary to establish an overheating risk criterion based on either the number of hours over the daily temperature limit and/or for the cumulative number of degreehours over this limit. Since the standard only relates to daytime thermal comfort it was not possible to assess future night-time comfort using the method.

To establish a suitable criterion, thermal simulations were undertaken for the ANV space with standard and additional heat gains $\left(+10 \mathrm{~W} / \mathrm{m}^{2},+20 \mathrm{~W} / \mathrm{m}^{2}\right.$ or $\left.+30 \mathrm{~W} / \mathrm{m}^{2}\right)$ and for a range of spaces with SNV. All four weather sites (London, Manchester, Birmingham and Edinburgh) were used and for each one both the TRY05 and DSY05 weather data. In total 54 sets of results were obtained.

For each set of results the number of hours in the building for which the internal dryresultant temperature exceeded $28^{\circ} \mathrm{C}$ was compared with the total number of hours over the appropriate upper temperature limits, and the cumulative number of degree-hours over this limit. ${ }^{19}$ The results, with the data for the 8 cases that produced extreme overheating (100 or more hours over $28^{\circ} \mathrm{C}$ DRT) excluded for the purposes of clarity only, are shown in Figs. 8 and 9. A second order regression lined is placed through all the data points (including those

19 As noted above the temperature limits vary daily and are different for each of the eight sets of weather data used. 
not shown in the figures), which was, in fact almost linear. It can be seen that $50 \mathrm{~h}$ over $28^{\circ} \mathrm{C}$ corresponds to about $130 \mathrm{~h}$ over the BSEN15251 temperature limit, and, rather coincidentally also to around $130^{\circ} \mathrm{C} . \mathrm{h}$.

The figures (and the raw data not given here) show that there is only one case when the HTM03-01 criterion $\left(50 \mathrm{~h}\right.$ over $\left.28^{\circ} \mathrm{C}\right)$ is clearly passed but one or other of the proposed criteria are clearly failed and two cases where the HTM03-01 criterion is failed but the $130 \mathrm{~h}$ and the $130^{\circ} \mathrm{C} \mathrm{h}$ criteria are passed.

For the purposes of this paper therefore one proposed criterion against which the ward's future performance can be assessed is that:

there must be no more than $130 \mathrm{~h}$ for which the internal dry-resultant temperature exceeds the BSEN15251 upper temperature limit for a Cat I space.

An alternative is that:

there must be no more than $130^{\circ} \mathrm{C}$.h for which the internal dry- resultant temperature exceeds the BS EN 15251 upper temperature limit for a Cat I space.

The resilience of different ward designs to future temperatures is assessed against both criteria below.

Here no distinction is made between the criterion to be used with a TRY and with a DSY. This is because, with the simulation results available, it was not possible to resolve different criteria or, put another way, on the basis of the data available the derived (130 $\mathrm{h} / 130^{\circ} \mathrm{C} \mathrm{h}$ ) criteria seem to be equally applicable for predictions made with TRYs as for predictions made with DSYs. More work is required to explore this further and this is discussed below.

To generate future climate data a morphing algorithm, as described in TM36 [21] and Belcher et al. [50], was used. This is based on firstly taking the projections of the likely average monthly UK temperatures over the next century provided by the UKCIP02 (2002) Climate Change Scenarios [22] and combining them with the TRYs and DSYs produced by the CIBSE in 2002 [44] to produce weather files for 2020, 2050 and 2080.

Clearly, the future climate of the UK depends on the assumptions that are made about future $\mathrm{CO}_{2}$ levels which in turn depend on global economic growth, population levels, use of renewable energy sources, etc. Here, in keeping with previous work, most notably in TM36 [36], the mean monthly temperatures generated for the UKCIP02 medium-high emissions scenario, which corresponds to the IPCC-SRES A2 storey line, and has the UKCIP socioeconomic title-National Enterprise, was used. This scenario yields ambient conditions towards the upper end of all the temperature rises projected by the various scenarios, but not the highest.

The CIBSE [44] weather data covers three UK sites, London, Manchester and Edinburgh, and for each both a TRY and DSY is provided. The narrative here focuses, however, on the results for the London and Manchester TRYs. Firstly because the realism of extreme years, rather than typical years, developed by the morphing method is uncertain, and secondly because the over- heating risk criterion is equally applicable to predictions made using TRYs as it to predictions made using DSYs. It is in London and Manchester that there is a risk of future overheating.

By applying the morphing algorithm for the A2 scenario to the TRY data, hourly weather files were generated for 2020, 2050 and 2080 (e.g. code LonA2TRY20, etc.). The morphing algorithm shifts and stretches the weather data to produce future weather data that 
have the mean monthly temperatures projected by the UKCIP02 model and the hourly variations of the native data files (the Manchester or London TRY). It can be seen (Figs. 10 and 11) that the peak temperatures are up to $6 \mathrm{~K}$ higher in 2080 than 2002 at both locations, with the peak temperature in London reaching $36^{\circ} \mathrm{C}$. By 2020 the London TRY has $58 \mathrm{~h}$ with temperatures over $28^{\circ} \mathrm{C}$, which is similar to the current extreme year (LonDSY05) and by 2080 there are around $285 \mathrm{~h}$ over $28^{\circ} \mathrm{C}$ (Figs. 12 and 13). By 2050 the Manchester TRY has about same number of hours over $28^{\circ} \mathrm{C}$ as London does today.

Simulations were undertaken for the ANV building with various opening areas $(0.5 \%$, $1 \%$, and $1.6 \%$ of floor area) with the standard heat gains, and for additional gains of either $10 \mathrm{~W} / \mathrm{m}^{2}, 20 \mathrm{~W} / \mathrm{m}^{2}$ or $30 \mathrm{~W} / \mathrm{m}^{2}$, giving daytime $/$ night-time gains of $31 / 14 \mathrm{~W} / \mathrm{m}^{2}, 41 / 24 \mathrm{~W} / \mathrm{m}^{2}$ and $51 / 34 \mathrm{~W} / \mathrm{m}^{2}$ respectively. The results for the best and worst performing SNV buildings with the larger opening area (as above) were also generated for comparison purposes. The results are given in Table 4 and by linear interpolation from these data, the date at which the time over $28^{\circ} \mathrm{C}$ would exceed $130 \mathrm{~h}^{20}$ was estimated (Fig. 14).

It has been shown, Table 3, that in London, south-facing SNV spaces have an unacceptable overheating risk even in today's climate. The results here show that even in a typical year the risk of overheating may be unacceptable by as early as 2010 (low-e glazing) or 2028 (solar-control glazing) (Fig. 14). The north-facing SNV space with low-e glazing was shown to have a high overheating risk in today's London climate. With solar-control glazing the risk was acceptably low (Table 3 ) and in a typical year the risk may remain low up until around 2055 (Fig. 14). The combined results (Tables 3 and 4) clearly indicate that it is unwise to adopt SNV as the environmental control strategy in new hospital developments on facades exposed to solar radiation. Even on north-facing facades, and with solar-control glazing, there will be an unacceptable risk of overheating in hot years well before 2050. Existing hospitals that utilise SNV are already likely to be at risk of overheating in hot years and will be at risk even in a typical year within the next 10-20 years.

The risk of overheating in ANV buildings with exposed thermal mass in the ceiling (HW) and standard heat gains is acceptably low in today's London climate (Table 3). In a typical year the risk remains low up to 2075 and even with a daytime heat gains of $31 \mathrm{~W} / \mathrm{m}^{2}$ the risk is acceptable up to about 2026 (though in extreme years such gains precipitate overheating even in today's climate, Table 3 ). With a thermally light weight ceiling the overheating risk is increased and the time period before over- heating exceeds $130 \mathrm{~h} /$ year is about 15 years less than for the space with an exposed concrete ceiling (Fig. 14). Thermal mass appears to increase resilience to climate change. The impact of heat gains on the period of time for which even thermally heavyweight spaces remain comfortable is however quite marked; a gain of just $10 \mathrm{~W} / \mathrm{m}^{2}$ reduces the period of acceptable overheating risk by around 50 years (Fig. 14). With a larger opening area (1.6\% of floor area) the ANV space has much greater resilience to future temperatures, and with daytime gains of $31 \mathrm{~W} / \mathrm{m}^{2}$ the space retains a low risk of overheating in a typical year until 2051; 25 years longer than the space with only $1 \%$ of free opening area.

From these results we can observe that new hospitals built using the ANV approach will be much more resilient to climate change than hospitals built using the SNV approach and that investing in larger stacks and shafts (larger free area of opening) can extend the

\footnotetext{
${ }^{20}$ Although not reproduced here, there were only three cases where the classification of a result differed depending on whether the $130 \mathrm{~h}$ or the $130^{\circ} \mathrm{C}$.h criterion was used to assess the ANV cases. In all three cases the $130 \mathrm{~h}$ criterion was failed and the $130^{\circ} \mathrm{C} \mathrm{h}$ criterion passed. The results presented here would thus be broadly the same irrespective of the criterion used.
} 
period before overheating risks are unacceptable by around 25 years. Put another way, the date at which major renovation is required, for example to fit supporting mechanical cooling, can be delayed by 25 years. However, control of internal heat gains is needed as this has a marked impact on the period of time for which ANV buildings will remain acceptably comfortable in the London area.

In the Manchester area all the spaces with SNV and the standard heat gains $\left(21 \mathrm{~W} / \mathrm{m}^{2}\right.$ in the day) retain a low risk of overheating in a typical year right through to 2080 or so, and so too do the ANV spaces (Fig. 14). The ANV design with the larger area of opening (1.6\% floor area) have a low overheating risk until 2080 and beyond even with internal gains up to $31 \mathrm{~W} / \mathrm{m}^{2}$ in the daytime and with $41 \mathrm{~W} / \mathrm{m}^{2}$ in the daytime the risks remain acceptable in a typical year until about 2073 (Fig. 14). The period of time for which the overheating risk remained acceptable decreased by about 40 years for each $10 \mathrm{~W} / \mathrm{m}^{2}$ of additional heat gain; i.e. less than in the London region. The corollary to these observations is that the period of acceptable performance (with regard to elevated internal temperatures) can be extended by reducing the heat input to high heat gain spaces.

Extending this form of analysis it would be possible to set out recommendations for the design of naturally ventilated hospital wards that is sensitive to location and to current and anticipated internal heat gains. However, as far as the authors can tell, the heat gains associated with the equipment used in the care of patients is unknown, and this would seem to be an area in need of attention. The implications for patient well-being, the direct emission of $\mathrm{CO}_{2}$, and costs (e.g. of earlier refurbishment using mechanical cooling), of not being aware of, and failing to control, equipment gains seem rather profound. However, the ANV strategy does enable mechanical systems to be integrated relatively easily, to create a hybrid ventilation strategy, which can extend the useful life of the building further still.

\section{Phase 5: comparison of energy demands and $\mathrm{CO}_{2}$ emissions for the $\mathrm{ANV}$ and alternative ventilation strategies}

The ANV strategy is more resilient to climate change and to increases in internal heat gain, than other simpler natural ventilation strategies. It is important, however, to ascertain whether the strategy will contribute to mitigating climate change and to helping the NHS meet its energy demand targets for new build and refurbishment: $35-55 \mathrm{GJ} / 100 \mathrm{~m}^{3}$ and $55-65$ $\mathrm{GJ} / 100 \mathrm{~m}^{3}$ respectively. Therefore, predictions were made of the likely energy demands for heating and ventilation and for lights and appliances (at $15 \mathrm{~W} / \mathrm{m}^{2}$ during the day) and from these the delivered energy and hence the $\mathrm{CO}_{2}$ emissions ${ }^{21}$ were calculated. Predictions were made for typical current London weather (LonTRY05) conditions and in one case for typical 2080 London data (LonA2TRY80).

The basic ANV ward room (i.e. $2.24 \mathrm{~m}^{2}$ of shaded low-emissivity south-facing glazing, openings equivalent to $1 \%$ floor area, intermittent stack fan operation) with the standard internal heat gains profile was used in the simulations. A suitable operating algorithm for the louvers that control the flow of air into and out of the space had to be devised because energy use, rather than summertime peak temperatures, was the focus. True feedback from sensors cannot be modelled in most simulation systems (e.g. from $\mathrm{CO}_{2}$ and temperature sensors) and there are limited control options available. After some experimentation, louver operating regimes based on external ambient temperature were used in which the inlet and outlet louvers were open by a fixed amount for ambient (outside) dry bulb temperatures below $15^{\circ} \mathrm{C}$

${ }^{21}$ Conversion coefficients from HTM07-02 [15] were used to determine the $\mathrm{CO}_{2}$ emissions (see Table 5). 
and by $100 \%$ for ambient dry bulb temperatures above $22^{\circ} \mathrm{C}$; a linear ramp function was used between $15^{\circ} \mathrm{C}$ and $22^{\circ} \mathrm{C} .{ }^{22}$ Two cases were modelled:

- Case $1 \mathrm{a}$ - the louvers were open $25 \%$ below $15^{\circ} \mathrm{C}$ to produce a winter air-flow rate of $40-501 / \mathrm{s}$ (i.e. $\left.1.5-2.3 \mathrm{ach}^{-1}\right)$; and

- Case $1 \mathrm{~b}$-louvers were open only $8 \%$ below $15^{\circ} \mathrm{C}$ to produce a winter air-flow rate of $10-201 / s$ (i.e. the minimum fresh air rate for one to 2 persons, equivalent to $0.38-0.75 \mathrm{ach}^{-1}$ ).

The boiler was assumed to have an overall efficiency of $60 \%$ and the stack fan was assumed to be efficient ( $2 \mathrm{~W} / \mathrm{l} / \mathrm{s}$, as recommended in HTM03-01).

A 'conventional' mechanically ventilated (MV) ward room with no mechanical cooling was used as a comparator because simple naturally ventilation is unable to deliver acceptable internal temperatures in the current London weather conditions. An air- conditioned alternative was not used because, as noted in HTM03-01, "owing to capital and running cost, full air-conditioning is only used in essential areas". The same geometry, heat gains and heating set point as used in the Phases 3 and 4 were used $\left(2.6 \mathrm{~m}^{2}\right.$ of south- facing, solarcontrol glass, with the same standard heat gains profile and heating set point as in the ANV room). The MV system was assumed to deliver $6 \mathrm{ach}^{-1}$ (HTM03-01, appendix table) via a fullfresh air system that incorporated an air-handling unit with a heat exchanger of either:

- Case $2 \mathrm{a}-50 \%$ efficiency; or

- Case $2 b-70 \%$ efficiency.

These cover the range of efficiencies found in well-maintained premises with $70 \%$ representing very good in-use performance; but much lower in-use efficiencies are not uncommon [51]. The heat exchanger had a by-pass for summer conditions.

Looking at the energy demand predictions (Table 5, col. 1) it is evident that the ANV cases require much the same, or less, heating energy input than the MV cases, despite these spaces having efficient heat recovery. In the well-controlled ANV space which delivers the minimum required fresh air in winter (Case $1 \mathrm{~b}$ ), the space heating energy demand is very low (less than half that assumed for lights and appliances). The higher heating energy demand for the less well-controlled space indicates the importance of ventilation control in ANV buildings (because they have no heat recovery device). In the MV spaces a very efficient heat recovery device is crucial to achieving low heating energy demands (Table 5, col. 1). The very small energy demand of the small, intermittently operated, fans in the ANV stacks is notable.

Turning to the calculated delivered energy figures (Table 5, col.4) it is evident that the electricity needed to power the fans, even though efficient fans were assumed, is substantial for both MV cases ( $2 \mathrm{a}$ and $2 \mathrm{~b}$ ). As a consequence, the delivered energy to the MV spaces was above the lower bound DoH target of $35 \mathrm{GJ} / 100 \mathrm{~m}^{3}$ for new build and with a lower efficiency heat exchanger almost exceeds the upper bound of $55 \mathrm{GJ} / 100 \mathrm{~m}^{3}$. In contrast both ANV spaces were comfortably below this target. All the modelled cases met the upper bound target for refurbishment of $65 \mathrm{GJ} / 100 \mathrm{~m}^{3}$. It would seem that the new-build targets are difficult to meet with 'conventional' MV systems even if good system design and plant maintenance is achieved whereas the ANV approach easily met the target and is also resilient to sub-optimal control.

\footnotetext{
${ }^{22}$ Without such control, winter-time ventilation rates exceeded $9 \mathrm{ach}^{-1}$, resulting in very high heating energy demands.
} 
Because the carbon intensity of grid electricity is roughly three times that of gas, and because fan energy is a substantial portion of all the energy used in the MV spaces, the $\mathrm{CO}_{2}$ emissions from the MV spaces are much higher than from the ANV spaces. The MV space with a heat exchanger of $50 \%$ efficiency, which is typical (case 2a), generated over twice the emissions of the well-controlled ANV space (case 1a). The electricity consumed by the fans is the source of much of the $\mathrm{CO}_{2}$ emitted by the MV buildings and so by careful modulation of the fresh air supply these emissions can, in theory, be reduced. This would also reduce the heating-related emission substantially. A rough calculation suggests that such modulation, if achieved in practice, would produce emissions comparable to ANV case 1a; the heatingrelated emissions reduce by $1 / 5$ th and the ventilation-related emissions are more than halved. Further fan-energy reductions are difficult to achieve because the fans must operate yearround and deliver at least $6 \mathrm{ach}^{-1}$ in summer to control peak temperatures. In the ANV space, the emissions associated with the lights and appliances represent $50-80 \%$ of the whole; clearly the provision of daylight with artificial lighting controls and local task lighting for patients, and the specification of low-energy appliances is very important to controlling $\mathrm{CO}_{2}$ emissions.

As the climate warms the need for heating will decline. Simulations for the less wellcontrolled ANV space (case 1a) for 2080 indicate a heating demand reduction of about $35 \%$, which translates to a reduction in the overall $\mathrm{CO}_{2}$ emissions of about $17 \%$, from about $81.4 \mathrm{kgCO}_{2} / \mathrm{m}^{2}$ to $67.5 \mathrm{kgCO}_{2} / \mathrm{m}^{2}$ (Table 5). The proportion of all the emissions due to lights and appliances increases from about $50 \%$ to $60 \%$.

Because the DoH sets targets based on delivered energy, there is no policy target against which to compare $\mathrm{CO}_{2}$ emissions. But it is perhaps worth noting that the figures for the MV space exceed those for typical air-conditioned offices, but hospitals are occupied day and night, 365 days/year. This does prompt the obvious point that if climate change is the primary reason that the DoH wishes to set targets, the targets ought to be set in terms of $\mathrm{CO}_{2}$ emissions not delivered energy. This would have the effect of correctly representing the impact of electricity usage and point up the true implications of increased use of technology in care programmes. And it would also properly reflect the climate change mitigation contribution of electricity saving technologies, such as combined heat and power, medium sized wind turbines, etc.

Finally, we might question the use of a blanket target for all the spaces in a hospital complex because the space composition of hospitals might differ markedly, and even buildings on the same site might fulfil very different functions. It might be quite reasonable to set low $\mathrm{CO}_{2}$ emission targets for buildings that fulfil largely administrative functions, but in areas where life threatening medical procedures are undertaken, $\mathrm{CO}_{2}$ targets might have a low priority, and quite rightly so. (The equipment used in such areas might be very energy intensive both of itself and because it needs to be in a conditioned space but such energy usage is largely out of the hands of the managers of health care; facilities.) A more disaggregated approach to setting $\mathrm{CO}_{2}$ targets in health care facilities would however require more discriminatory energy metering, but the need for this is beginning to be recognised.

\section{Discussion}

In reflecting on the work undertaken, it is most useful to focus on aspects that have generic value, i.e. beyond the confines of healthcare buildings, and which are especially pertinent when investigating the resilience of existing and new buildings to climate change. In the UK, most existing buildings are naturally ventilated, and there are merits in retaining 
these as they invariably produce lower $\mathrm{CO}_{2}$ emissions than mechanically conditioned spaces; as the research reported here demonstrates. Climate warming could easily provoke an upsurge in the use of air-conditioning and to counter this, robust, credible and easily applicable methods of assessing the resilience of new and refurbished buildings to climate change are needed. Central to such methods are a procedure for determining the future risk of overheating and the setting of criteria for determining when temperatures are unacceptably high.

The new BSEN15251 standard has been shown to provide a basis for calculating the risk of overheating, which, unlike other methods, may account of human adaptation to climatic warming and the adaptive capabilities of different 'categories' of people. A criterion for determining if the overheating risk as calculated by the adaptive method is, or is not, acceptable has been proposed. This was developed by correlating the overheating risk predicted by the adaptive method with the risk predicted by the prevailing non-adaptive methods in the current climate. Whilst this approach has some merit it does raise some questions. Is the criterion devised widely applicable or only applicable to the particular group of naturally ventilated buildings studied here? How should a criterion be developed for other types of space - the current method would have the peculiar effect of producing an apparently more stringent criterion for category II spaces (normal occupancy) then category I spaces (sensitive and fragile occupants)? ${ }^{23}$ To what extent is the criterion affected by the choice of weather data (the BS EN 152521 standard does not define the weather data to be used) and how can the method be used with the emerging UKCIP08 probabilistic approach to describing the future climate? This adaptive standard, and the current ASHRAE Standard 55 'alternative' method [47], are constrained to spaces that are (or in BSEN15251 also 'can be') regulated by occupants by opening and closing windows. ANV spaces are free-floating and naturally ventilated but occupant control may not be needed, and in some variants may even be undesirable, one wonders if this restriction is appropriate, especially given the imperative to combat climate change?

The BSEN15251 method does not offer a way of assessing the risk of nighttime overheating, and a way of doing this could be important in the future as the frequency and intensity of heat waves increases. Current evidence suggests that our tolerance of elevated temperatures is reduced at night (the CIBSE use a $26^{\circ} \mathrm{C}$ threshold at night rather than the $28^{\circ} \mathrm{C}$ threshold used in the day) and, of course, individuals' adaptive opportunity is diminished: the operation of windows will disrupt sleep, there is no solar gain at night for blinds and shading to ameliorate, and clothing is already minimal. As noted in the preceding text, it might be that the juxtaposition of successive nights of elevated temperatures is important (rather than the accumulated instances of isolated nights each with a small number of warm hours). Such matters require further research before the appropriateness of otherwise of an adaptive (BSEN51215-type) approach can be judged.

The simulation analyses undertaken using the current UK climatic data showed clearly that the internal temperatures in the SNV spaces were very sensitive to the area of ventilation opening provided and also sensitive, but less so, to the glazing type and orientation. However, even with a relatively large opening aperture, equivalent to $4.8 \%$ of the floor area of the space, and low heat gains $\left(21 \mathrm{~W} / \mathrm{m}^{2}\right.$ day and $4 \mathrm{~W} / \mathrm{m}^{2}$ night $)$, the SNV strategy with unshaded low-emissivity glazing was unable to maintain an acceptably low overheating risk in the London area. The north-facing, low-e glazed space only marginally exceeded the threshold defining unacceptable overheating and the north and south-facing spaces with solar control

\footnotetext{
${ }^{23}$ Because for any space there will be more hours over the lower category I temperature limit than the higher category II limit (see Fig. 5).
} 
glazing did not exceed the threshold: so designers might be tempted to use such SNV designs, especially, on north-facing elevations. However, this would not be wise as the all these SNV spaces studied were sensitive to additional heat gains, with an additional gain of just $10 \mathrm{~W} / \mathrm{m}^{2}$ (i.e. $31 \mathrm{~W} / \mathrm{m}^{2}$ in the day) increasing the number of hours over $28^{\circ} \mathrm{C}$ by over $30 \mathrm{~h}$ (cf. maximum permissible by HTM03-01 of 50h) even on the north-facing elevations. Clearly, any reduction in the free area available for ventilation, especially at night, will also adversely affect performance. These results would suggest that SNV is not a viable strategy for any type of space in the London region and, in fact, it suggests that many such buildings are currently likely to be experiencing unacceptably high summertime temperatures.

Moving further north, to cooler parts of the UK, the predicted risk of overheating in SNV buildings in today's climate gradually diminishes as does the sensitivity of temperatures to additional internal heat gains. Thus north-facing SNV spaces have a low overheating risk up to gains of $31 \mathrm{~W} / \mathrm{m}^{2}$ in Birmingham and up to $41 \mathrm{~W} / \mathrm{m}^{2}$ at more northerly latitudes. Southfacing spaces with a restricted area of opening (2.4\% of the floor area) are only acceptable for gains up to $21 \mathrm{~W} / \mathrm{m}^{2}$ in Birmingham and Manchester. One must conclude therefore, that even at these more northerly latitudes, care over the design of SNV spaces is needed and analysis is required to test whether or not a design proposition will or will not be deemed comfortable. These analyses must correctly model nighttime window operation-it may simply not be possible to leave windows open at night in many locations.

Turning to the ANV design, the risk of overheating was always less than for an SNV space with the same heat gains and location. Although the risk of overheating is very sensitive to the free area of the ventilation openings, they can be much smaller than those necessary in SNV spaces (for the spaces studied, which had quite low heat gains, just $1.6 \%$ of the floor area of the space or less). Also, the sensitivity to additional internal heat gains was much less, for example, in London the additional overheating risk is just $42 \mathrm{~h}$ for an additional gain of $10 \mathrm{~W} / \mathrm{m}^{2}$ compared to an increased risk of over $235 \mathrm{~h}$ for the (similarly south-facing) SNV space studied. The greater resilience occurs for two reasons, firstly, because the ventilation rate in buoyancy-driven systems 'automatically' adjusts in line with the prevailing inside-to-outside temperature difference and secondly because the ventilation apertures are automatically controlled. The first of these has three useful influences: (i) when the ambient temperature approaches, or is higher than, the temperature inside the building, the ventilation rate diminishes, thus preventing the space being heated by the ambient $\operatorname{air}^{24}$; (ii) as the internal heat gains increase, threatening to warm the interior, the ventilation rate will increase, thereby reducing their impact; and (iii) when the ambient temperatures are less than those inside the space such as at night, large ventilation rates are generated through the exhaust stack. The automatic control of the apertures ensures that nighttime ventilation will always occur when needed. In contrast, the ventilation rates in an SNV space are only loosely coupled with the inside-to-outside temperature difference, being much more heavily influenced by wind speed and direction. Thus they are particularly vulnerable to overheating, firstly because of undesirable ventilation when it is hotter outside than in, and secondly because on still days, even those when it is cooler outside than in, ventilation can be poor.

In the ANV buildings, just as in the SNV buildings, both the risk of overheating in the current climate, and the additional risk brought by additional internal gains decreased as the weather became cooler. Thus the ANV strategy offered an acceptably low overheating risk, even on south-facing facades, up to $31 \mathrm{~W} / \mathrm{m}^{2}$ in London and up to $41 \mathrm{~W} / \mathrm{m}^{2}$ in cooler areas. However, as the climate warms, the risk of overheating increases. The period of time before the overheating risk becomes unacceptable, i.e. the life-expectancy of the building, decreases

${ }^{24}$ But in the design reported here is maintained by the fan at the minimum required for fresh air provision only. 
with heat gains and the current warmth of the locality. Thus, although an ANV space with gains of $31 \mathrm{~W} / \mathrm{m}^{2}$ is comfortable now in London, the life-expectancy is short - just 15 or so years for a design with just $1 \%$ free opening area; this can be extended to 40 years by enlarging the opening. In Manchester the life-expectancy with the same gains is over 75 years, even with the smaller opening area.

It should be clear from this discussion that, in designing naturally ventilated spaces, it is crucial to consider the impact of likely climatic warming, and to progress without doing so, particularly for buildings in the warmer parts of the UK, would be unwise. To promote such an approach, design guidelines and analysis methods need to be developed and fortunately some of the building blocks are being put in place: the Technical Memorandum TM36, which raises awareness of the issue; BSEN15251 and similar adaptive approaches to thermal comfort, such as ANSI/ ASHRAE Standard 55; the recent release by CIBSE of future weather years ${ }^{25}$ [43]; and the development of more rigorous approaches to designing for future uncertainly, such as methods based on the forthcoming UKCIP08 probabilistic weather data.

However, no matter what simulation strategy is used, because of the global warming we have experienced, that we know is bound to occur, and that might occur in the future, natural ventilation designs will need to be much more carefully tailored to location, orientation, window opening opportunity (both in the day and at night), occupants - especially their adaptive capacity, internal heat gains, and the design life-expectancy of the building. Such a carefully considered approach to design simulation is important for all building types but for some, such as health care buildings, it is critically important and the present 'state of the art' needs much improvement. Failure to grapple effectively with this challenge could exacerbate global warming (through the use of air- conditioning) and/or lead to socially unacceptable consequences in the more intense and frequent heat waves of the future.

\section{Conclusions}

\subsection{Assessing overheating risk}

1. Naturally ventilated buildings have a key role to play in mitigating climate change because they tend to precipitate lower $\mathrm{CO}_{2}$ emissions than mechanically ventilated alternatives; as has been demonstrated in this paper. However, climate change has the potential to tip naturally ventilated buildings that currently have a low risk of overheating into a position where the risk will be deemed unacceptable at some point within the coming century. Therefore, the resilience of naturally ventilated buildings to climate change should be assessed as an integral part of any new-build or refurbishment design process.

2. Alternative existing methods that might enable overheating risk in naturally ventilated spaces subject to future warmer climatic conditions to be quantified have been evaluated. The new BSEN15251 adaptive method enables the possible adaptation of individuals to the warming climate to be accounted for. However, no overheating risk assessment criterion and associated current or future weather data has hitherto been proposed for use in association with the method.

3. A simple regression method has been used to develop an overheating risk assessment criterion for use with the BSEN15251 method. For health-care spaces (i.e. Category I) an adaptive overheating criterion that "there should be no more than $130 \mathrm{~h}$ or $130^{\circ} \mathrm{C} . \mathrm{h}$ for which the dry-resultant temperature exceeds the BSEN15251 upper temperature limit" is tentatively

${ }^{25}$ So designers do not need to construct their own, as the authors of this paper did. 
proposed. For the spaces studied, this criterion provides daytime overheating risk assessments for the current climate that is compatible with the assessment provided by the HTM03-01 method.

4. Current guidance specific to the design of naturally ventilated spaces in health care buildings is inadequate. The guidance in Heath Technical Memorandum HTM03-01 is unconvincing and does not properly define the method by which overheating risk should be determined; herein the number of hours for which the dry-resultant temperature exceeds $28^{\circ} \mathrm{C}$ is used. HTM03-01 offers no method for assessing the risks of elevated nighttime temperatures. A more thorough treatment of these topics, which covers both adaptation to -, and mitigation of, climate change is needed to support design teams pursuing natural ventilation strategies.

5. The risk of elevated nighttime temperatures is an important component of any analysis process that seeks to assess the impact of heat waves on health and well-being. This is especially so when analysing the performance of residential spaces such as hospital wards. The CIBSE method, of counting the number of nighttime hours for which the dry-resultant temperature exceeds $26^{\circ} \mathrm{C}$ in a design summer year (DSY), was used herein to quantify the risk of nighttime overheating. The appropriate- ness of this approach is discussed, in particular the use of the DSY. It is suggested that more work is needed to understand the impact of elevated nighttime temperatures on sleep and the extent to which different individuals might adapt to such temperatures. This would enable a more credible method of assessing nighttime overheating risk to be developed.

\subsection{Simple natural ventilation and overheating risk in the current climate}

6. Simulations using the current DSY weather data for the London region indicated that in spaces with clear glazing and no external shading, simple single-sided natural ventilation was unable to control the risk of daytime or nighttime overheating to acceptable levels. With solar-control glazing, and low internal heat gains $\left(21 \mathrm{~W} / \mathrm{m}^{2}\right.$ day and $4 \mathrm{~W} / \mathrm{m}^{2}$ night $\left.^{26}\right)$ the risk of overheating in north-facing spaces, both during the day and at night, was reduced to acceptable levels. However, even a modest increase in internal heat gains (to $31 \mathrm{~W} / \mathrm{m}^{2}$ in the daytime) resulted in unacceptable overheating risk even in these spaces. It is concluded therefore that even in today's climate, and without consideration of urban heat island effects, SNV is unlikely to offer a robust temperature control strategy for buildings located in the London environs.

7. Heat gains of just $31 \mathrm{~W} / \mathrm{m}^{2}$ in the day resulted in an unacceptable overheating risk in south-facing SNV spaces without external shading in Birmingham, Manchester (and London), even those with solar-controlled glazing and modest window areas ( $10 \%$ of the floor area of the space). In Edinburgh such south-facing spaces retained a low overheating risk up to daytime heat gains of $41 \mathrm{~W} / \mathrm{m}^{2}$. In north-facing rooms with daytime gains of 41 $\mathrm{W} / \mathrm{m}^{2}$, the risk of overheating remained low for all the locations studied except London. Thus in many areas of England (i.e. those warmer than Manchester), south-facing spaces which are conditioned using SNV, even those with relatively modest internal heat gains, may already be experiencing levels of overheating that would be deemed unacceptable in a new building. Retrofitting with solar- control glass, but no external shading, is unlikely to provide a robust long-term remedial measure.

\footnotetext{
${ }^{26}$ From here on in the conclusions section, only the daytime heat gains will be quoted, the nighttime gains were always exactly $17 \mathrm{~W} / \mathrm{m} 2$ less.
} 


\subsection{ANV design and overheating risk in the current climate}

8. An evolved edge-in, edge-out advanced natural ventilation strategy has been examined. The strategy can be implemented in new buildings or as a facade refurbishment strategy. The strategy can be effected without invading the building's floor plate or substantially altering to the internal geometry of the parent building by locating stacks around the building's perimeter. By also incorporating air-supply shafts, the strategy offers a ready up-grade path by which mechanical cooling can be introduced to some, or all, perimeter spaces; for example to combat increased internal heat gains or rising outdoor temperatures. The perimeter spaces can have operable or sealed windows, but operability could reduce the risk of nighttime overheating. The strategy could be used as a climate adaptation measure in many types of building but they must be under a certain height. The relationship of this height to the plan depth of the perimeter spaces has been elucidated.

9. In buildings where reverse air-flow must be avoided, or where even brief periods with low ventilation rates are unwelcomed, it is prudent to include a fan in the exhaust stack from each space. When controlled purely to prevent such effects, and not for the purpose of general ventilation, the fans can also help to reduce peak summertime temperatures but will use minimal electrical energy and have extremely small associated $\mathrm{CO}_{2}$ emissions.

10. The nighttime ventilation cooling of spaces is often thought to be incompatible with the comfortable occupation of spaces during the evening and night. It has been shown however, that provided that the nighttime ventilation rates are adequate, maintaining nighttime temperatures up to about $20^{\circ} \mathrm{C}$ has little impact on the risk of daytime overheating (i.e. the occurrence of temperatures over $28^{\circ} \mathrm{C}$ on the following day).

11. The risk of overheating in the ANV spaces was sensitive to the free-area provided for the ventilation air. A free area of $1-1.6 \%$ of the floor area of the space was however adequate to control the risk of overheating in today's climate for all the UK locations studied provided the daytime heat gains were $31 \mathrm{~W} / \mathrm{m}^{2}$ or less. This is a much smaller area, by a factor of $3-5$, than the free area of window opening needed in SNV spaces and yet provides superior temperature control.

12. In the ANV space with low-heat gains, the overheating risk in the London region increased notably if a light weight (false) ceiling, rather than a thermally massive (concrete) ceiling, was used; but the overheating risk would still be acceptably low in today's climate.

13. The ANV spaces were much more resilient to increases in internal heat gain than the SNV spaces. For example, an increase in gains from 31 to $41 \mathrm{~W} / \mathrm{m}^{2}$ in the day increased the risk of overheating in south-facing ANV spaces by less than $50 \mathrm{~h}$ at all four of the locations studied. In the SNV spaces the corresponding increase was around $200 \mathrm{~h}$ in Birmingham and Manchester and over 500h in London. Consequently, the risk of overheating in ANV buildings remained acceptably $l_{0}{ }^{27}$ in all locations except London even with daytime heat gains of $41 \mathrm{~W} / \mathrm{m}^{2}$.

14. Simulations using current and future typical weather data and the adaptive overheating risk criterion indicate that a building's life-expectancy, i.e. the time before the overheating risk becomes unacceptably high, depends on the location, internal heat gains and the ventilation area. The predicted life- expectancy in the London area was around 45 years (i.e. until 2050) for a gain of $31 \mathrm{~W} / \mathrm{m}^{2}$ and $1.6 \%$ free area, and exceeded 75 years for gains of just $21 \mathrm{~W} / \mathrm{m}^{2}$. In contrast the south-facing SNV spaces were at risk of overheating even in

${ }^{27}$ In Birmingham provided the ventilation area exceeds $1 \%$ of the floor area. 
today's climate. Reducing the ventilation area from 1.6 to $1 \%$ of the floor area reduced the life-expectancy by 25 years.

15. The simulations suggest that refurbishment of an overheating building using ANV rather than SNV will result in much greater resilience to future climate change (and to increases in internal heat gains). The strategy also offers a route to up-grading to a hybrid strategy via the introduction of cooled air through the perimeter shafts; the SNV strategy cannot offer this.

\subsection{Impact of internal heat gains}

16. Controlling internal heat gains is an important component of climate change adaptation strategies. It has been shown that, even in well-designed and well-controlled passively ventilated and cooled spaces, additional gains of just $10 \mathrm{~W} / \mathrm{m}^{2}$ (day and night) can reduce the time-frame for which spaces in central and south east England will retain an acceptably low overheating risk by 40 to 50 years depending on location. In the SE of England, spaces that might otherwise remain comfortable until around 2070 could suffer unacceptable overheating within just 15 years. Thus, in a warming world, internal gains can have a substantial impact on a building's life-expectancy.

17. In well-designed naturally conditioned spaces, the $\mathrm{CO}_{2}$ emissions associated with even a modest internal electrical load $\left(15 \mathrm{~W} / \mathrm{m}^{2}\right)$ can represent as much as $60 \%$ of all the emissions and this fraction increases as the climate warms and heating energy use declines. Controlling internal electrical loads thus has an important, and increasing, role to play in mitigating climate change.

18. There seems to be very little information available about the internal heat gains generated in hospital spaces of different type. These could vary substantially depending on patients' care programmes. Work to gather such information is necessary to enable the design of robust and optimal low-energy design solutions.

\subsection{Mitigating climate change}

19. The predicted energy use of conventional mechanically ventilated spaces exceeded the NHS targets for new-build due, in part, to the electrical energy consumed by the fans. In contrast, the ANV spaces met the targets comfortably. This suggests that natural ventilation should play a crucial role in new-build projects if the NHS is to meet its energy use targets. Both the MV and ANV strategies could meet the target for refurbishment projects.

20. The estimated $\mathrm{CO}_{2}$ emissions of the typical MV space were twice those of the wellcontrolled ANV space, by modulating of the fans in the MV space the $\mathrm{CO}_{2}$ emissions might be more comparable to those in the ANV space.

21. It is suggested that if climate change mitigation is the principal driver for establishing NHS policy targets these ought to be couched in terms of $\mathrm{CO}_{2}$ emissions rather than delivered energy. This would highlight the need to rigorously control electrical energy use to control the use of electrical equipment and thus limit internal heat gains.

22. For design purposes, rather than post-occupancy energy management, targets might usefully be set on a space-by- space, rather than whole hospital, basis: the period of occupancy, the precision required over internal conditions, the level of internal heat gains, and the control that can be exercised over energy using equipment, all differ markedly with 
the function performed by hospital spaces. The targets might be lower and more rigorously enforced for some (less life-critical) spaces than for others.

\section{Acknowledgements}

The authors are grateful to the Department of Health who funded this work, to Short and Associates who led the project and from whom much stimulus was gained, and to Prof V I Hanby, of the Institute of Energy and Sustainability at De Montfort University, for generating the morphed weather files. The paper was written whilst a Visiting Fellow at Clare Hall Cambridge kindly supported by a Research Fellowship from the Leverhulme Trust. 


\section{Appendix A. Some geometrical consideration related to the evolved edge-in edge-out ANV strategy}

As noted in the forgoing text and as shown in Fig. 2, the cluster of stacks and shafts on a facade can occupy a relatively large area. This area is limited by the total external wall area available and the need also to provide windows. The proportion of a room's external wall width covered depends on the number of shafts and stacks and also on their size.

As is evident from Fig. 2, there is one shaft and one stack per floor of the building (N) running past each room, i.e. a direct linear relationship. Thus as the building height increases so does the number of stacks and shafts and the width of facade occupied.

The free area of stack and shaft inlets and outlets is often expressed as a percentage, or fraction (F) of the floor area served, where F will, typically, be around 0.005-0.015 (i.e. 0.5$1.5 \%$ of floor area, see [33]). If the shafts and stacks are not to constrict air-flow unduly they must have a cross-sectional area equal to, or greater than, that of the inlets and outlets, F. Although the F-values look small, the size of the stacks/shafts nevertheless becomes a major design determinant and they begin to dominate the facade when rooms are narrow and deep and as building height increases (see Fig. 2 for example, in which the rooms are twice as deep as they are wide and there are 3 floors to the building).

In a space of width $W$, and depth $n . W$, where $\mathrm{n}$ is the aspect ratio (depth/W), the crosssectional area of one stack/shaft, $A_{s}$, is given by:

$$
A_{s}=F \cdot n \cdot W^{2} \quad\left(m^{2}\right)
$$

If the stacks/shafts are square in section, then the minimum side length, $l$ (i.e. excluding for now any insulation and cladding, which can bulk up the stacks/shafts quite considerably) is given by:

$$
l=\sqrt{F \cdot n \cdot W^{2}} \quad \text { (m) }
$$

For a building of $N$ storeys the total width is thus:

$$
L=N \cdot \sqrt{F \cdot n \cdot W^{2}}
$$

And the percentage of the room width occupied by shafts and stacks $(P)$ is given by:

$$
P=N \cdot \sqrt{F \cdot n} \times 100 \%
$$

As an example, the ward in Fig. 2 is $7.2 \mathrm{~m}$ deep and $3.6 \mathrm{~m}$ wide, i.e. $\mathrm{n}$ is 2 . If the stacks/shafts are sized to provide free areas of $1 \%$ floor area $(F=0.01)$ then the width of each square stack/shaft $(l)$ is about $0.5 \mathrm{~m}$ (Eq. (1)). The building had three floors $(N)$ and so the total width is $1.5 \mathrm{~m}$, which expressed as a percentage $(P)$ of the facade width (Eq. (2)) is about $42 \%$. If the shafts and stacks were sized to give a free cross-sectional area of $1.6 \%$ of the floor area this value would increase a little to $54 \%$. The impression of the facade created in Fig. 2 is thus realistic.

The general relationship between the percentage of the facade width occupied by stacks and shafts $(P)$ and the aspect ratio of the rooms $(n)$, for shafts and stacks of $0.5 \%, 0.75 \%$, $1.0 \%, 1.5 \%$ or $2.0 \%$ of the floor area of perimeters rooms and buildings with up to 7 storeys $(N)$ is shown in Fig. A1. For buildings which have a different number of storeys from those plotted, linear interpolation, between and beyond the graphs drawn (i.e. vertically in the figure) provides a precise result for $P$. The figure clearly shows that for rooms that are twice as deep as they are wide, e.g. those shown in Fig. 2, shafts and stacks with a free area equal to 
$1 \%$ of the room floor area would cover virtually the entire facade of a seven storey building (top right hand corner of the graph).

The purpose of the graph is to enable architects and others to quickly generating an impression of the impact that the evolved edge-in edge-out strategy will have on the appearance of a building's facade. Most importantly, the figure can be used to gauge whether or not there is sufficient space on a building's facade to locate adequately sized windows.

It is worth reiterating that the equations above assume the stacks and shafts to be square and no allowance has been made for insulation. The use of rectangular section stacks and shafts, where the narrower dimension is adjacent to the wall of the room (and facing the exterior) would result in them occupying less of the facade (but the transition from each shaft to the room inlet and from the room outlet into each stack would need to be considered carefully to avoid restricting the free areas).

Finally, it is worth noting that these equations apply equally well to the other generic forms of the ANV strategy which have perimeter stacks, i.e. the centre-in, edge-out and edgein, edge-out strategies as depicted in Fig. 1. The accumulated width of the exhaust stacks will limit the height of the building over which these strategies can be applied, even if there are no perimeter supply shafts. However the lack of such shafts can free up facade space on lower floors which might then be given larger windows (for example, to combat any reduced daylight availability). 


\section{Appendix B. The BSEN15251 Standard calculation method and an example application using the London DSY05 weather data}

For free-running buildings the BSEN15251 Standard [40] provides a method of assessing thermal comfort in which the allowable maximum and minimum operative temperatures $\left(\mathrm{T}_{\mathrm{imax}}\right.$ and $\left.\mathrm{T}_{\mathrm{imin}}\right)$ depend on the running mean of the outdoor temperature according to the equation:

$$
\begin{array}{llrl}
\mathrm{T}_{\text {imax }}=0.33 \mathrm{~T}_{\mathrm{rm}}+18.8+\mathrm{X} & { }^{\circ} \mathrm{C} & \text { for } 10^{\circ} \mathrm{C}<\mathrm{T}_{\mathrm{rm}}<30^{\circ} \mathrm{C} \\
\mathrm{T}_{\text {imin }}=0.33 \mathrm{~T}_{\mathrm{rm}}+18.8-\mathrm{X} & { }^{\circ} \mathrm{C} & \text { for } 15^{\circ} \mathrm{C}<\mathrm{T}_{\mathrm{rm}}<30^{\circ} \mathrm{C}
\end{array}
$$

where $T_{i}$ is the limit value of the operative temperature, $T_{r m}$ is the running mean daily outdoor temperature, and X varies with the space category, being $2 \mathrm{~K}, 3 \mathrm{~K}$ or $4 \mathrm{~K}$ for Cat I, Cat II or Cat III respectively. The slope of the relationship is 0.33 , which means that the temperature limits rise by $1 / 3 \mathrm{rd}$ of the increase in the running mean temperature.

The running mean temperature is given by:

$$
\mathrm{T}_{\mathrm{rm}}(1-\propto)\left(T_{e d-1}+\alpha T_{e d-2}+\alpha^{2} T_{e d-3} \ldots \ldots\right)
$$

which simplifies to:

$$
\mathrm{T}_{\mathrm{rm}}=(1-\alpha) T_{e d-1}+\alpha T_{r m-1}
$$

where $\mathrm{a}$ is 0.8 and $\mathrm{T}_{\text {ed-1 }}$ is the daily mean external temperature for the previous day, $\mathrm{T}_{\text {ed-2 }}$ is the daily mean external temperature for the day before yesterday, etc., and $\mathrm{T}_{\mathrm{rm}}$ is the running mean temperature for today.

Note that the running mean temperature for today does not include today's actual mean temperature and that the running mean weights the previous days temperature highly, the temperature of the day before less highly and so on - thermal experience depends on the previous day's temperatures, to a lesser extent on the temperature the day before that and so on. This means that changes in the temperature limits lag behind changes in ambient temperature.

Because the limit values for the internal operative temperature vary with the time of year, as well as the geographical location, it is more difficult to grasp the implications for building design than when using fixed (CIBSE or HTM03) criteria. This said, the limits can easily be calculated for a given weather year and this only has to be done once. By way of illustration the running mean temperature for the London DSY (LonDSY05) and the maximum limit of the operative temperature for a Category I space are shown in Fig. $\mathrm{B} 1^{28}$.

It can be seen, of course, that the running mean temperature is less variable than the daily mean temperature and that the peaks lag by a day or two. The highest running mean temperature is $22.1^{\circ} \mathrm{C}$ on July $23 \mathrm{rd}$, one day behind the hottest day, which had an average temperature of $26.5^{\circ} \mathrm{C}$ (and a peak temperature over $33.5^{\circ} \mathrm{C}$ ). The maximum limit value of the indoor operative temperature is $28.1^{\circ} \mathrm{C}$; which is very similar to the threshold values used in the CIBSE and HTM03-01 overheating criteria (i.e. $28^{\circ} \mathrm{C}$ dry-resultant and dry-bulb temperature, respectively). For a Cat II space such as a nurse's station, office, consulting room, etc., the maximum limit value will be $1 \mathrm{~K}$ higher at $29.1^{\circ} \mathrm{C}$. We might conclude

\footnotetext{
${ }^{28}$ The standard suggests that beyond the range of running mean temperatures for which the adaptive standard applies, i.e. below $10^{\circ} \mathrm{C}$ and above $30^{\circ} \mathrm{C}$ (see Fig. 5) the allowable temperatures should be those specified for conditioned buildings. In the CIBSE guide the range of winter operative temperatures for hospital wards is given as $22-24^{\circ} \mathrm{C}$. The graph (Fig. B1) uses the $24^{\circ} \mathrm{C}$ value as this avoids a discontinuity in the plot. Such a discontinuity would arise for Cat II and Cat III spaces. Such issues will become clarified with the wider practical application of the standard.
} 
therefore, that our assessment of the overheating risk in ward rooms using the London DSY05 will change little whether we use the BSEN15251 Standard or the HTM03-01 or CIBSE criteria. This observation is helpful in the context of this paper. However, the wider implications of using the BSEN15251 Standard for designing different types of NV buildings, in different locations in the UK, does need more thorough consideration. 


\section{References}

[1] DTi, Our energy future - creating a low carbon economy, Energy White Paper, Department of Trade and Industry, The Stationary Office, 24 March 2003, 142 pp.

[2] DEFRA, Draft Climate Change Bill, Department for Food and Rural Affairs Source. http://www.defra.gov.uk/Environment/climatechange/uk/legislation/index.htm, 2008 (accessed 22 November 2008).

[3] DEFRA, Climate Change the UK Programme, Department for Food and Rural Affairs, March 2006, 202 pp.

[4] Environmental Audit Committee, Beyond Stern: From the Climate Change Programme Review to the Draft Climate Change Bill, Environmental Audit Committee, Seventh Report of Session 2006-07, The Stationary Office, 10th July 2007, 216 pp.

[5] The European Commission, An energy policy for Europe, SEC 12 (2007) 2007.

[6] CLG, Building a Greener Future: Policy Statement, Communities and Local Government, Communities and Local Government, 23 July 2007.

[7] UKGBC, Report on carbon reductions in new non-domestic buildings, Report from UK Green Building Council, Department of Communities and Local Government, Queen's Printer, December 2007, 2008, 131 pp.

[8] ODPM, The Building Regulations 2000, Approved Document L2A: Conservation of Fuel and Power (New Buildings Other than Dwellings), 2006 ed., 2006, ISBN: 978185946 2195.

[9] Hansard Commons, On the NHS Carbon Reduction Strategy, The Parliamentary UnderSecretary of State for Health (Mr. Ivan Lewis), Houses of Parliament, Hansard of the House of Commons, 3 June 2008, Column 53WS, 2008.

[10] B. Boardman, Examining the carbon agenda via the $40 \%$ House scenario, Building Research and Information 35 (4) (2007) 363-378.

[11] D. Johnston, R. Lowe, M. Bell, An exploration of the technical feasibility of achieving $\mathrm{CO} 2$ emission reductions in excess of $60 \%$ within the UK housing stock by the year 2050 , Energy Policy 33 (13) (2005) 1643-1659.

[12] R. Lowe, Technical options and strategies for decarbonising UK housing, Building Research and Information 35 (4) (2008) 412-425, ISSN: 0961-3218.

[13] K.J. Lomas, Carbon reduction in existing buildings: a trans-disciplinary approach, Building Research and Information, Special Issue CaRB Project, Vol 38, Iss 1, pp 1-11, (2010) ISSN 0961-3218

[14] DETR, Action in the UK-UK Climate Change Programme 2000, Department for Environment Transport and the Regions, The Stationary Office, 2000, 12 pp. (Summary).

[15] DoH, Health Technical Memorandum 07-02: EnCO2de-, Making Energy Work in Healthcare, Environment and Sustainability, Department of Health Estates and Facilities Division, The Stationary Office, 2006, ISBN: 0-11-322731-0.

[16] DoH, Statistic on Energy Performance and Carbon and CO2 Emissions NHS England $1999 / 00$ to 2004/05 (with predictions to 2009/10), The Stationary Office, London, 2006, 37 pp., ISBN: 9780113227495. 
[17] NHS Confederation, Taking the Temperature: Towards an NHS Response to Global Warming, NHS Confederation Publications, London, 2007.

[18] NHS Sustainable Development Unit, Saving Carbon, Improving Health, A Draft Carbon Reduction Strategy for the NHS in England-A Consultation Document, July 2008, 36 pp.

[19] DoH, Estates Returns Information Collection (ERIC), Department of Health, 25 January 2008.

[20] Hansard Lords, Written Ministerial Statement, Parliamentary Under-Secretary of State, Department of Health (Ivan Lewis), Hansard of the House of Lords, 3 June 2008 (Column WS18).

[21] CIBSE, Climate Change and the Indoor Environment: Impacts and Adaptation, Technical Memorandum 36, The Chartered Institution of Building Services Engineers, London, 2005, ISBN: 1903287502.

[22] M. Hulme, G.J. Jenkins, X. Lu, J.R. Turnpenny, T.D. Mitchell, R.G. Jones, J. Lowe, J.M. Murphy, D. Hassell, P. Boorman, R. Mcdonald, S. Hill, Climate Change Scenarios for the United Kingdom The UKCIP02 Scientific Report, Norwich, University of East Anglia, 2002.

[23] S. Hajat, R.S. Kovats, R.W. Atkinson, A. Haines, Impact of hot temperatures on death in London: a time series approach, Journal of Epidemiology and Community Health 56 (2002) $367-372$.

[24] H. Johnson, G. McGregor, H. Walton, The impact of the 2003 heat wave on mortality and hospital admissions in England, Health Statistics Quarterly 25 (6.2) (2005) 114-128.

[25] B. Bordass, R. Cohen, M. Standeven, A. Leaman, Assessing building performance in use 3: energy performance of the PROBE buildings, Building Research and Information 29 (2) (2001) 114-125.

[26] NHS, Heat Wave Plan for England, Protecting Health and Reducing Harm from Extreme Heat and Heatwaves, May 2008, 32 pp.

[27] Telegraph, Babies Swelter in 90F at New hospital, Celia Hall, Medical Editor, Telegraph 21 July 2006. http://www.telegraph.co.uk/news/1524435/Babies- swelter-in-90F-at-new-hospital.html (accessed 23 November 2008).

[28] H.R. Rubin, A.J. Owens, G. Golden, Status Report (1998): An Investigation to Determine Whether the Built Environment Affects Patient Medical Outcomes. The Centre for Health Design, Inc., 1998, ISBN: 0-9638938-5-8.

[29] DoH, Health Technical Memorandum 03-01: Specialised Ventilation for Health- care Premises, Department of Health, The Stationary Office, 2007, 120 pp.

[30] K.J. Lomas, M.J. Cook, Sustainable Buildings for a Warmer World. Proceedings of the World Renewable Energy Congress, Elsevier, Aberdeen, May 22-27, (2005), p.26, ISBN: 0080-44671-X.

[31] B. Krausse, M. Cook, K. Lomas, Environmental performance of a naturally ventilated city centre library, Energy and Buildings 39 (7) (2007) 792-801, ISSN: 0378-7788.

[32] CIBSE, Guide B (Heating, Ventilation, Air Conditioning and Refrigeration), Chartered Institution of Building Services Engineers, May 2005.

[33] K.J. Lomas, Architectural design of an advanced naturally ventilated building form, Energy and Buildings 39 (2007) 166-181, ISBN: 03787788. 
[34] C.A. Short, K.J. Lomas, A. Woods, Design strategy for low-energy ventilation and cooling within an urban heat island, Building Research and Information 32 (3) (2004) 187206, ISSN: 0961-3218.

[35] C.A. Short, Q.M. Pop, M.J. Cook, K.J. Lomas, An Innovative Low Energy Integrated Health and Social Care Building for a Deprived Community PLEA 2003-The 20th Conference on Passive and Low Energy Architecture, Santiago, Chile, 9-12 November, 2003, $5 \mathrm{pp}$.

[36] C.A. Short, K.J. Lomas, Exploiting a hybrid environmental design strategy in a US continental climate, Building Research and Information 35 (2) (2007) 119-143, ISSN: 09613218 .

[37] K.J. Lomas, M.J. Cook, and D. Fiala, Low energy architecture for a severe US climate: design and evaluation of a hybrid ventilation strategy, Energy and Buildings 39 (1) (2006) 32-44, ISBN: 03787788.

[38] Y. Ji, K.J. Lomas, M.J. Cook, Hybrid ventilation for low energy building design in south China, in: Proceedings of the First International Conference on Building

Energy and Environment (COBEE), 13-16 July, Dalian, China, (2008), pp. 1222-1229, ISBN: 978-0-9816881.

[39] CIBSE, Guide A Environmental Design, 7th ed., Chartered Institution of Building Services Engineers, 2006 ISBN: 978190387668.

[40] British Standard EN1251, Indoor Environmental Input Parameters for Design and Assessment of Energy Performance of Buildings Addressing Indoor Air Quality, Thermal Environment Lighting and Acoustics, British Standards Institute (2008), Brussels, 2007, 56 pp., ISBN: 9780580553912.

[41] BS EN 13779 (2004) Ventilation for non-residential buildings. Performance Requirements for Ventilation and Room-conditioning Systems, July 2005, 52 pp., ISBN: 0 580461181 .

[42] BSI, Ventilation for Buildings. Performance Requirements for Ventilation and Airconditioning Systems. British Standards Institution, London, 2005.

[43] CIBSE, Current CIBSE TRY/DSY Hourly Weather Data Set-14 Sites, Chartered Institution of Building Services Engineers, 2008. See http://www.cibse.org/ index.cfm?go=publications.view\&item=332 (accessed 4 December 2008).

[44] CIBSE, Guide J; Weather, Solar and Illuminance Data, Chartered Institution of Building Services Engineers, 2002.

[45] J. He, A.N. Young, A. Pathan, T Oreszczyn, Air-conditioning Energy Use in Houses in Southern England, Conference on Dynamic Analysis, Simulation and Testing Applied to the Energy and Environmental Performance of Buildings, Athens, 12 October, 2005, 21 pp.

[46] J.F. Nicol, M.A. Humphreys, Thermal comfort as part of a self-regulating system, Building Research and Practice (J. CIB) 6 (3) (1973) 191-197.

[47] ANSI/ASHRAE, Thermal Conditions for Human Occupancy, American National Standards Institute (ANSI), American Society of Heating, Refrigeration and Air- conditioning Engineers (AHSRAE), Standard 55, 2004, 170 pp.

[48] F. Nicol, J. Hacker, B. Spires, H. Davies, Suggestion for new approach to overheating diagnostics, in: Proceedings of Conference: Air Conditioning and the Low Carbon Cooling 
Challenge, Cumberland Lodge, Windsor, UK, 27-29 July 2008, Network for Comfort and Energy Use in Buildings, London, 2008.

[49] IES, Integrated Environmental Solutions, IES VE Software Version 5.8, 2008. http://www.iesve.com (accessed 02.12.08).

[50] S.E. Belcher, J.N. Hacker, D.S. Powell, Constructing design weather data for future climates, Building Services Engineering Research and Technology 26 (1) (2005), 49-61.

[51] C.-A. Roulet, F.D. Heidt, F. Foradini, M.-C. Pibiri, Energy and Buildings 33 (May (5)) (2001), 495-502(8). 
Table 1: Characteristics of different simple and advanced ventilation strategies (adapted from [32])

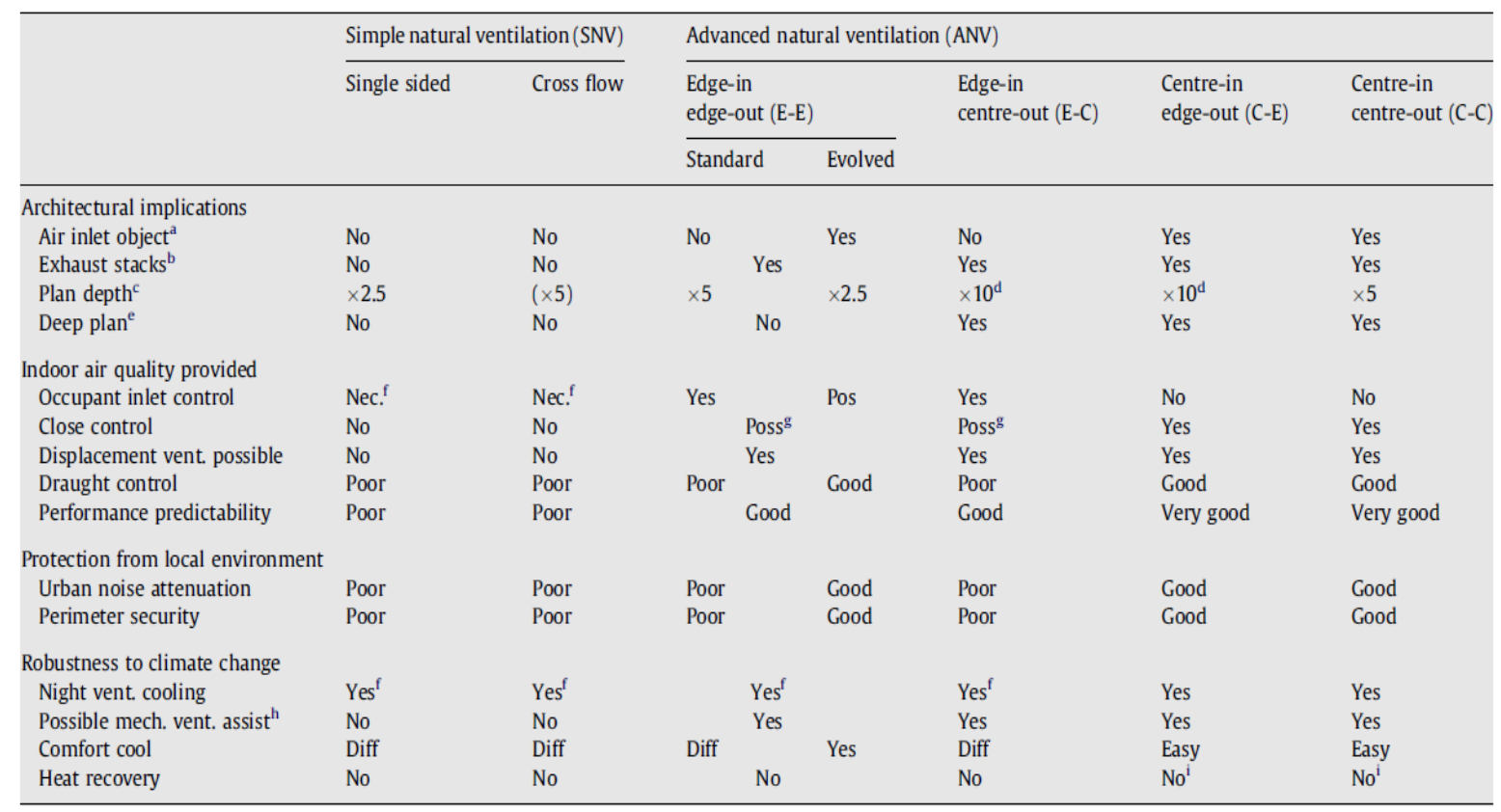

a Such as plenum or lightwell for centre-in strategies or shaft for evolved edge-in strategy.

b Might utilise other feature, such as an exhaust air light well.

c Rules of thumb (e.g. [20]) based on multiples of the floor-to-ceiling height. For single-sided ventilation this is the room depth, but for cross-flow ventilation it is the floor plate width perimeter-to-perimeter.

d With a row of centrally located stacks, exhausting both sides of the building (E-C), or a central air inlet shaft supplying both sides of the building $(\mathrm{C}-\mathrm{C})$, the perimeter-to-perimeter depth may be $\mathrm{x} 10$.

e Exceeding, about $20 \mathrm{~m}$ perimeter-to-perimeter.

f Occupant control necessary.

$\mathrm{g}$ If mechanically controlled perimeter air inlets are used.

$\mathrm{h}$ For example, fan in a stack or a fan pressurised supply.

i However, since the air is exhausted through discrete vertical stacks, heat recovery is possible when a mixed mode variant of the building is operated in mechanical mode. 
Table 2: Comparison of temperatures in ward with advanced natural ventilation with those in wards with simple natural ventilation: London DSY05 weather data

\begin{tabular}{|c|c|c|c|c|c|c|c|c|c|}
\hline \multirow{2}{*}{$\begin{array}{l}\text { Vent. } \\
\text { Strat. }\end{array}$} & \multirow{2}{*}{$\begin{array}{c}\text { Ceiling } \\
\text { type }\end{array}$} & \multicolumn{2}{|c|}{$\begin{array}{c}\text { Window } \\
\text { area }\end{array}$} & \multicolumn{2}{|c|}{$\begin{array}{c}\text { Ventilation } \\
\text { area }\end{array}$} & \multirow{2}{*}{$\begin{array}{l}\text { Window } \\
\text { Orient. }\end{array}$} & \multirow{2}{*}{$\begin{array}{l}\text { Glass } \\
\text { type }\end{array}$} & \multirow{2}{*}{$\begin{array}{c}\text { Total } \\
\text { Hours } \\
\text { over } \\
28^{\circ} \mathrm{C}^{\mathrm{a}}\end{array}$} & \multirow{2}{*}{$\begin{array}{c}\text { Night } \\
\text { Hours } \\
\text { Over } \\
26^{\circ} \mathrm{C}^{\mathrm{b}}\end{array}$} \\
\hline & & $\mathrm{m}^{2}$ & $\%$ FA & $\mathrm{m}^{2}$ & $\%$ FA & & & & \\
\hline \multirow{15}{*}{ SNV } & \multirow{15}{*}{ LW } & \multirow{4}{*}{5.2} & \multirow{4}{*}{20} & \multirow{4}{*}{$0.62^{c}$} & \multirow{4}{*}{2.4} & \multirow{2}{*}{ South } & Low-e & 143 & 83 \\
\hline & & & & & & & Solar Control & 78 & 56 \\
\hline & & & & & & \multirow{2}{*}{ North } & Low-e & 97 & 72 \\
\hline & & & & & & & Solar Control & 70 & 51 \\
\hline & & \multirow{4}{*}{2.6} & \multirow{4}{*}{10} & \multirow{4}{*}{$0.31^{c}$} & \multirow{4}{*}{1.2} & \multirow{2}{*}{ South } & Low-e & 405 & 335 \\
\hline & & & & & & & Solar Control & 276 & 249 \\
\hline & & & & & & \multirow{2}{*}{ North } & Low-e & 332 & 281 \\
\hline & & & & & & & Solar Control & 231 & 224 \\
\hline & & \multirow{4}{*}{5.2} & \multirow{4}{*}{20} & \multirow{4}{*}{$1.24^{d}$} & \multirow{4}{*}{4.8} & \multirow{2}{*}{ South } & Low-e & 63 & 31 \\
\hline & & & & & & & Solar Control & 47 & 24 \\
\hline & & & & & & \multirow{2}{*}{ North } & Low-e & 51 & 30 \\
\hline & & & & & & & Solar Control & 42 & 22 \\
\hline & & \multirow{3}{*}{2.6} & \multirow{3}{*}{10} & \multirow{3}{*}{$0.62^{d}$} & \multirow{3}{*}{2.4} & \multirow{2}{*}{ South } & Low-e & 98 & 77 \\
\hline & & & & & & & Solar Control & 79 & 58 \\
\hline & & & & & & North & Solar Control & 74 & 58 \\
\hline & & & & 0.06 & 0.25 & & & 253 & 289 \\
\hline & HW & & & 0.13 & 0.5 & & & 73 & 62 \\
\hline ANV & & 2.24 & 9 & ก? & 1 & South & Low-e & 15 & 21 \\
\hline & LW & & & 0.26 & 1 & & & $31^{e}$ & $24^{e}$ \\
\hline & $\mathrm{HW}$ & & & 0.42 & 1.6 & & & 4 & 12 \\
\hline
\end{tabular}

Shading shows when either the total hours of the night-time hours exceed the criterion limiting value.

a HTMO3-01 criterion limiting value is 50h, values in excess of this are in bold.

b For These spaces, the CIBSE criterion limiting value is $35 \mathrm{~h}$, values in excess of this are in bold.

c Equivalent to $12 \%$ of the window's area.

d Equivalent to $25 \%$ of the window's area.

e Results for the basic design as described in the Phase 1 work. 
Table 3: Comparison of temperatures in ward with advanced natural ventilation with those in wards with simple natural ventilation: additional internal heat gains and different locations - London, Birmingham, Manchester and Edinburgh DSY05.

\begin{tabular}{|c|c|c|c|c|c|c|c|c|c|c|c|}
\hline \multirow{3}{*}{ Locn. } & \multirow{3}{*}{$\begin{array}{l}\text { Vent } \\
\text { Type }\end{array}$} & \multirow{3}{*}{$\begin{array}{c}\text { Win } \\
\text { Area } \\
\mathrm{m}^{2}\end{array}$} & \multirow{3}{*}{$\begin{array}{l}\text { Vent. } \\
\text { Area } \\
\% \text { FA }\end{array}$} & \multirow{3}{*}{$\begin{array}{l}\text { Win. } \\
\text { Orn. }\end{array}$} & \multirow{3}{*}{$\begin{array}{l}\text { Glass } \\
\text { type }\end{array}$} & \multicolumn{6}{|c|}{$\begin{array}{l}\text { Hours over the HTM03-01 and CIBSE thresholds for } \\
\text { various internal heat gains }\end{array}$} \\
\hline & & & & & & \multicolumn{2}{|c|}{$21 / 4 \mathrm{~W} / \mathrm{m}^{2 \mathrm{a}}$} & \multicolumn{2}{|c|}{$31 / 14 \mathrm{~W} / \mathrm{m}^{2 \mathrm{~b}}$} & \multicolumn{2}{|c|}{$41 / 24 \mathrm{~W} / \mathrm{m}^{2} \mathrm{~b}$} \\
\hline & & & & & & $\mathrm{HTMO}^{\circ}$ & CIBSE $^{d}$ & $\mathrm{HTMO3}^{\mathrm{a}}$ & CIBSE $^{d}$ & $\mathrm{HTMO}^{\mathrm{a}}$ & CIBSE $^{d}$ \\
\hline \multirow{6}{*}{ Lon. } & \multirow{4}{*}{ SVN } & 5.2 & 4.8 & $\mathrm{~N}$ & Low-e & 51 & 30 & 97 & 57 & 204 & 101 \\
\hline & & & & & S.C. & 42 & 22 & 75 & 52 & 161 & 88 \\
\hline & & 2.6 & 2.4 & S & Low-e & 98 & 77 & 400 & 276 & 936 & 576 \\
\hline & & & & & S.C. & 79 & 58 & 314 & 230 & 821 & 534 \\
\hline & \multirow{2}{*}{ ANV } & 2.24 & 1.0 & $S$ & Low-e & 15 & 21 & 78 & 71 & 271 & 167 \\
\hline & & & 1.6 & & Low-e & 4 & 12 & 46 & 35 & 91 & 71 \\
\hline \multirow{5}{*}{ Birm. } & \multirow{4}{*}{ SVN } & 5.2 & 4.8 & $\mathrm{~N}$ & Low-e & 10 & 4 & 38 & 15 & 65 & 29 \\
\hline & & & & & S.C. & 5 & 1 & 26 & 12 & 55 & 22 \\
\hline & & 2.6 & 2.4 & S & Low-e & 38 & 23 & 130 & 79 & 353 & 218 \\
\hline & & & & & S.C. & 23 & 18 & 98 & 71 & 301 & 191 \\
\hline & ANV & 2.24 & 1.0 & $\mathrm{~S}$ & Low-e & 0 & 0 & 21 & 17 & 67 & 47 \\
\hline \multirow{5}{*}{ Man. } & \multirow{4}{*}{ SVN } & 5.2 & 4.8 & $\mathrm{~N}$ & Low-e & 5 & 0 & 18 & 6 & 37 & 24 \\
\hline & & & & & S.C. & 3 & 0 & 12 & 5 & 28 & 17 \\
\hline & & \multirow{2}{*}{2.6} & 2.4 & $S$ & Low-e & 14 & 16 & 126 & 91 & 311 & 205 \\
\hline & & & & & S.C. & 7 & 6 & 85 & 78 & 277 & 186 \\
\hline & ANV & 2.24 & 1.0 & $\mathrm{~S}$ & Low-e & 0 & 0 & 6 & 8 & 40 & 45 \\
\hline \multirow{5}{*}{ Edin. } & \multirow{4}{*}{ SVN } & \multirow{2}{*}{5.2} & \multirow{2}{*}{4.8} & \multirow{2}{*}{$\mathrm{N}$} & Low-e & 0 & 0 & 0 & 0 & 0 & 0 \\
\hline & & & & & S.C. & 0 & 0 & 0 & 0 & 0 & 0 \\
\hline & & \multirow{2}{*}{2.6} & \multirow{2}{*}{2.4} & \multirow{2}{*}{ S } & Low-e & 0 & 0 & 0 & 3 & 59 & 67 \\
\hline & & & & & S.C. & 0 & 0 & 0 & 1 & 40 & 53 \\
\hline & ANV & 2.24 & 1.0 & $S$ & Low-e & 0 & 0 & 0 & 0 & 0 & 0 \\
\hline
\end{tabular}

Italic shoes when hours do not exceed criterion limiting value. Bold font shows when hours do exceed criterion limiting value. Shading shows when either the total hours or the night-time hours exceed the criterion limiting value.

a Heat gains average $21 \mathrm{~W} / \mathrm{m}^{2}$ in the day and $4 \mathrm{~W} / \mathrm{m}^{2}$ at night.

b Extra $10 \mathrm{~W} / \mathrm{m}^{2}$ or $20 \mathrm{~W} / \mathrm{m}^{2}$ day and night.

c Total hours over the HTM03-01 threshold of $28^{\circ} \mathrm{C}$.

d Night-time hours over CIBSE threshold of $26^{\circ} \mathrm{C}$. 
Table 4: Number of hours over the BSEN15251 limits, for 2020, 2050 and 2080: London A2TRY (top) and Manchester A2TRY (bottom)

\begin{tabular}{|c|c|c|c|c|c|c|c|c|c|c|c|c|}
\hline \multicolumn{6}{|c|}{ Built Form } & \multirow{3}{*}{$\begin{array}{c}\text { Heat } \\
\text { Gains } \\
\text { W/m } \\
\text { day/night }\end{array}$} & \multicolumn{2}{|c|}{ Weather Data } & \multirow{2}{*}{\multicolumn{4}{|c|}{$\begin{array}{c}\text { Hours over derived adaptive } \\
\text { criterion in year }\end{array}$}} \\
\hline \multirow{2}{*}{$\begin{array}{l}\text { Venting } \\
\text { strategy }\end{array}$} & \multirow{2}{*}{$\begin{array}{l}\text { Ceiling } \\
\text { type }\end{array}$} & \multirow{2}{*}{$\begin{array}{c}\text { Win. } \\
\text { area } \\
\mathrm{m}^{2}\end{array}$} & \multirow{2}{*}{\begin{tabular}{|c|} 
Vent \\
area \\
$\%$ \\
FA \\
\end{tabular}} & \multirow{2}{*}{ Orn. } & \multirow{2}{*}{$\begin{array}{l}\text { Glass } \\
\text { type }\end{array}$} & & \multirow{2}{*}{ Location } & \multirow{2}{*}{ Type } & & & & \\
\hline & & & & & & & & & 2005 & 2020 & 2050 & 2080 \\
\hline \multirow{4}{*}{ SNV } & \multirow{4}{*}{ LW } & \multirow{2}{*}{5.2} & \multirow{2}{*}{4.8} & \multirow{2}{*}{$\mathrm{N}$} & Low-e & \multirow{4}{*}{$21 / 4$} & \multirow{4}{*}{ London } & \multirow{4}{*}{ TRY } & 31 & 75 & 168 & 385 \\
\hline & & & & & S.C. & & & & 24 & 47 & 105 & 295 \\
\hline & & \multirow{2}{*}{2.6} & \multirow{2}{*}{2.4} & \multirow{2}{*}{ S } & Low-e & & & & 47 & 169 & 374 & 774 \\
\hline & & & & & SC & & & & 28 & 81 & 257 & 639 \\
\hline \multirow{10}{*}{ ANV } & $\mathrm{HW}$ & \multirow{10}{*}{2.24} & 1.0 & \multirow{10}{*}{ S } & \multirow{10}{*}{ Low-e } & $21 / 4$ & \multirow{10}{*}{ London } & \multirow{10}{*}{ TRY } & 0 & 0 & 17 & 181 \\
\hline & LW & & 1.0 & & & $21 / 4$ & & & 3 & 15 & 60 & 260 \\
\hline & \multirow{8}{*}{$\mathrm{HW}$} & & 1.6 & & & $21 / 4$ & & & 0 & 0 & 7 & 94 \\
\hline & & & 0.5 & & & $21 / 4$ & & & 5 & 35 & 192 & 633 \\
\hline & & & \multirow{3}{*}{1.0} & & & $31 / 14$ & & & 23 & 94 & 260 & 638 \\
\hline & & & & & & $41 / 24$ & & & 182 & 383 & 655 & 1169 \\
\hline & & & & & & $51 / 34$ & & & 425 & 733 & 1105 & 1772 \\
\hline & & & \multirow{3}{*}{1.6} & & & $31 / 14$ & & & 10 & 41 & 118 & 359 \\
\hline & & & & & & $41 / 24$ & & & 67 & 167 & 323 & 661 \\
\hline & & & & & & $51 / 34$ & & & 182 & 344 & 556 & 982 \\
\hline
\end{tabular}

\begin{tabular}{|c|c|c|c|c|c|c|c|c|c|c|c|c|}
\hline \multicolumn{6}{|c|}{ Built Form } & \multirow{3}{*}{$\begin{array}{c}\text { Heat } \\
\text { Gains } \\
\text { W/m² } \\
\text { day/night }\end{array}$} & \multicolumn{2}{|c|}{ Weather Data } & \multirow{2}{*}{\multicolumn{4}{|c|}{$\begin{array}{c}\text { Hours over derived } \\
\text { adaptive criterion in year }\end{array}$}} \\
\hline \multirow{2}{*}{$\begin{array}{l}\text { Venting } \\
\text { strategy }\end{array}$} & \multirow{2}{*}{$\begin{array}{c}\text { Ceiling } \\
\text { type }\end{array}$} & \multirow{2}{*}{$\begin{array}{c}\text { Win. } \\
\text { area } \\
\mathrm{m}^{2}\end{array}$} & \multirow{2}{*}{\begin{tabular}{c|} 
Vent \\
area \\
$\%$ \\
FA
\end{tabular}} & \multirow{2}{*}{ Orn. } & \multirow{2}{*}{$\begin{array}{l}\text { Glass } \\
\text { type }\end{array}$} & & \multirow{2}{*}{ Location } & \multirow{2}{*}{ Type } & & & & \\
\hline & & & & & & & & & 2005 & 2020 & 2050 & 2080 \\
\hline \multirow{4}{*}{ SNV } & \multirow{4}{*}{ LW } & \multirow{2}{*}{5.2} & \multirow{2}{*}{4.8} & \multirow{2}{*}{$\mathrm{N}$} & Low-e & \multirow{4}{*}{$21 / 4$} & \multirow{4}{*}{ Manchester } & \multirow{4}{*}{ TRY } & 23 & 21 & 40 & 72 \\
\hline & & & & & S.C. & & & & 13 & 5 & 26 & 50 \\
\hline & & \multirow{2}{*}{2.6} & \multirow{2}{*}{2.4} & \multirow{2}{*}{ S } & Low-e & & & & 40 & 29 & 62 & 143 \\
\hline & & & & & $\mathrm{SC}$ & & & & 19 & 9 & 26 & 76 \\
\hline \multirow{10}{*}{ ANV } & $\mathrm{HW}$ & \multirow{10}{*}{2.24} & 1.0 & \multirow{10}{*}{ S } & \multirow{10}{*}{ Low-e } & $21 / 4$ & \multirow{10}{*}{ Manchester } & \multirow{10}{*}{ TRY } & 0 & 0 & 0 & 4 \\
\hline & LW & & 1.0 & & & $21 / 4$ & & & 0 & 0 & 6 & 27 \\
\hline & \multirow{8}{*}{$\mathrm{HW}$} & & 1.6 & & & $21 / 4$ & & & 0 & 0 & 0 & 0 \\
\hline & & & 0.5 & & & $21 / 4$ & & & 0 & 0 & 2 & 31 \\
\hline & & & \multirow{3}{*}{1.0} & & & $31 / 14$ & & & 20 & 18 & 32 & 96 \\
\hline & & & & & & $41 / 24$ & & & 91 & 83 & 161 & 333 \\
\hline & & & & & & $51 / 34$ & & & 205 & 238 & 363 & 728 \\
\hline & & & \multirow{3}{*}{1.6} & & & $31 / 14$ & & & 9 & 5 & 20 & 48 \\
\hline & & & & & & $41 / 24$ & & & 52 & 42 & 71 & 149 \\
\hline & & & & & & $51 / 34$ & & & 99 & 103 & 177 & 318 \\
\hline
\end{tabular}

Italic shows when hours do not exceed 130h. Bold and shading shows when hours do exceed 130h. 
Table 5: Predicted energy demands, estimated energy delivered (used) and carbon emissions: typical climate data for London (LonTRY05).

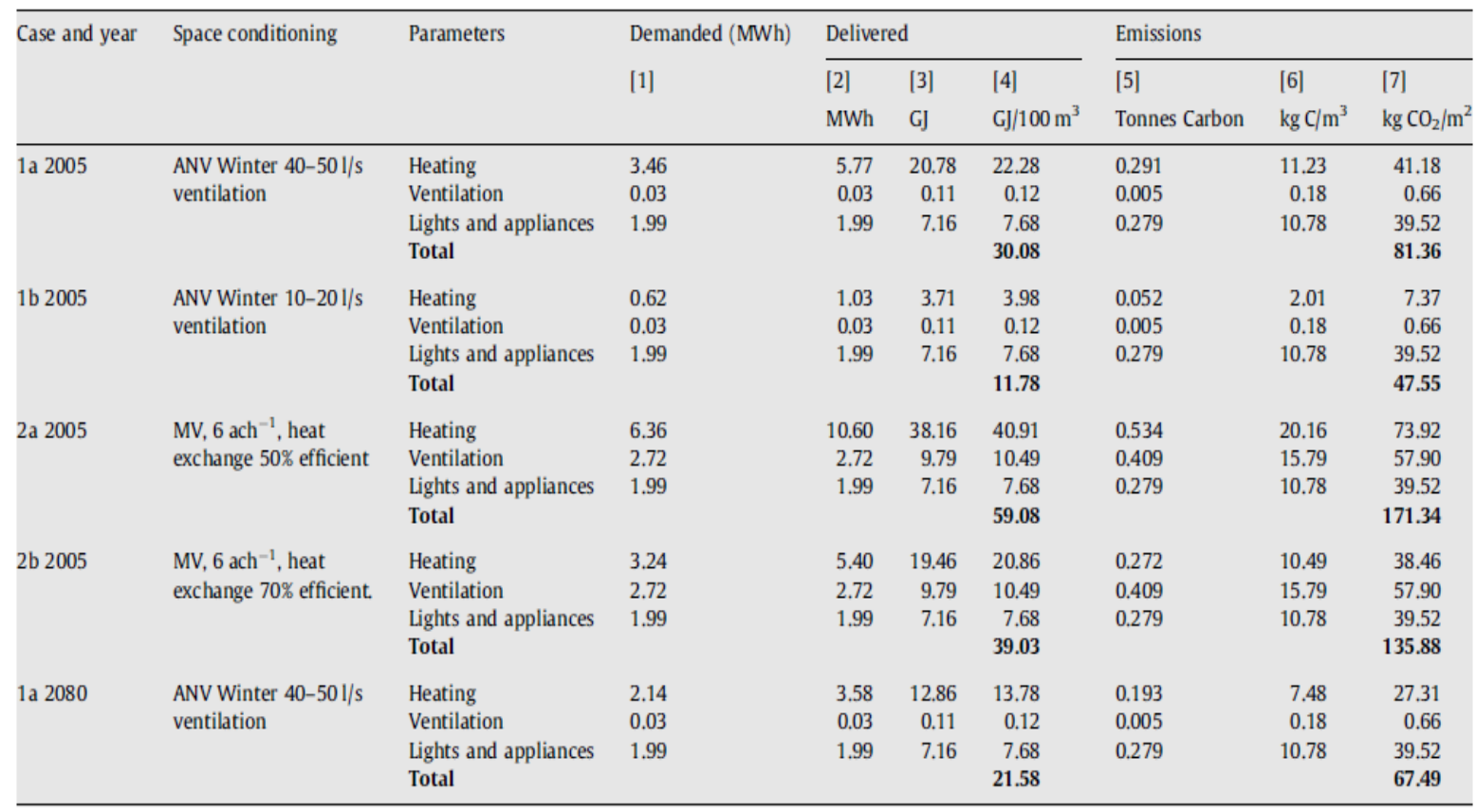

Column number notes: [1] heating demand as predicted. For MV cases, heat recovery efficiency assumed at $50 \%$ (case $2 \mathrm{a}$ ) or $70 \%$ (case $2 \mathrm{~b}$ ), ventilation based on a $2 \mathrm{~W} / \mathrm{l} / \mathrm{s}$ with $155.51 / \mathrm{s}$ flow $\left(6 \mathrm{ach}^{-1}\right)$. For ANV cases no cooling or heat recovery. Case $1 \mathrm{a}$ - louvers opened by $25 \%$ in winter, producing about $40-501 / \mathrm{s}$ ventilation, case $1 \mathrm{~b}$ - louvers opened $15 \%$ in winter, producing about $10-20 \mathrm{l} / \mathrm{s}$ ventilation. Ventilation by fan in stack as needed, $2 \mathrm{~W} / \mathrm{l} / \mathrm{s}$. Lighting and appliance loads as specified (average $21 \mathrm{~W} / \mathrm{m}^{2}$ day and $4 \mathrm{~W} / \mathrm{m}^{2}$ night). [2] Heat efficiency assumed to be $60 \%$ and electrical efficiency (ventilation and lights and appliances) $100 \%$. Thus derived from column [1]: heating/0.6; ventilation/1.0; lights and appliances/1.0. [3] Derived from column [2] x 3.6. [4] Using [3] /(93.3/100), $93.3 \mathrm{~m}^{3}$ is the room volume. [5] The conversion factors from GJ to tonnes of carbon are taken from Table 2 of HTM07-02, ie Elec: [3] x 0.039; Gas: [3] x 0.014. [6] Calculations for kilograms of carbon per meter square of floor area is by [5] x1000/25.92, where $25.92 \mathrm{~m}^{2}$ is the floor area of the ward space. [7] Using [6] $\mathrm{x} 44 / 12$ to give $\mathrm{kgCO}_{2} / \mathrm{m}^{2}$. 
Figure 1. Schematic diagrams of the different forms of stack ventilation (after [32]).
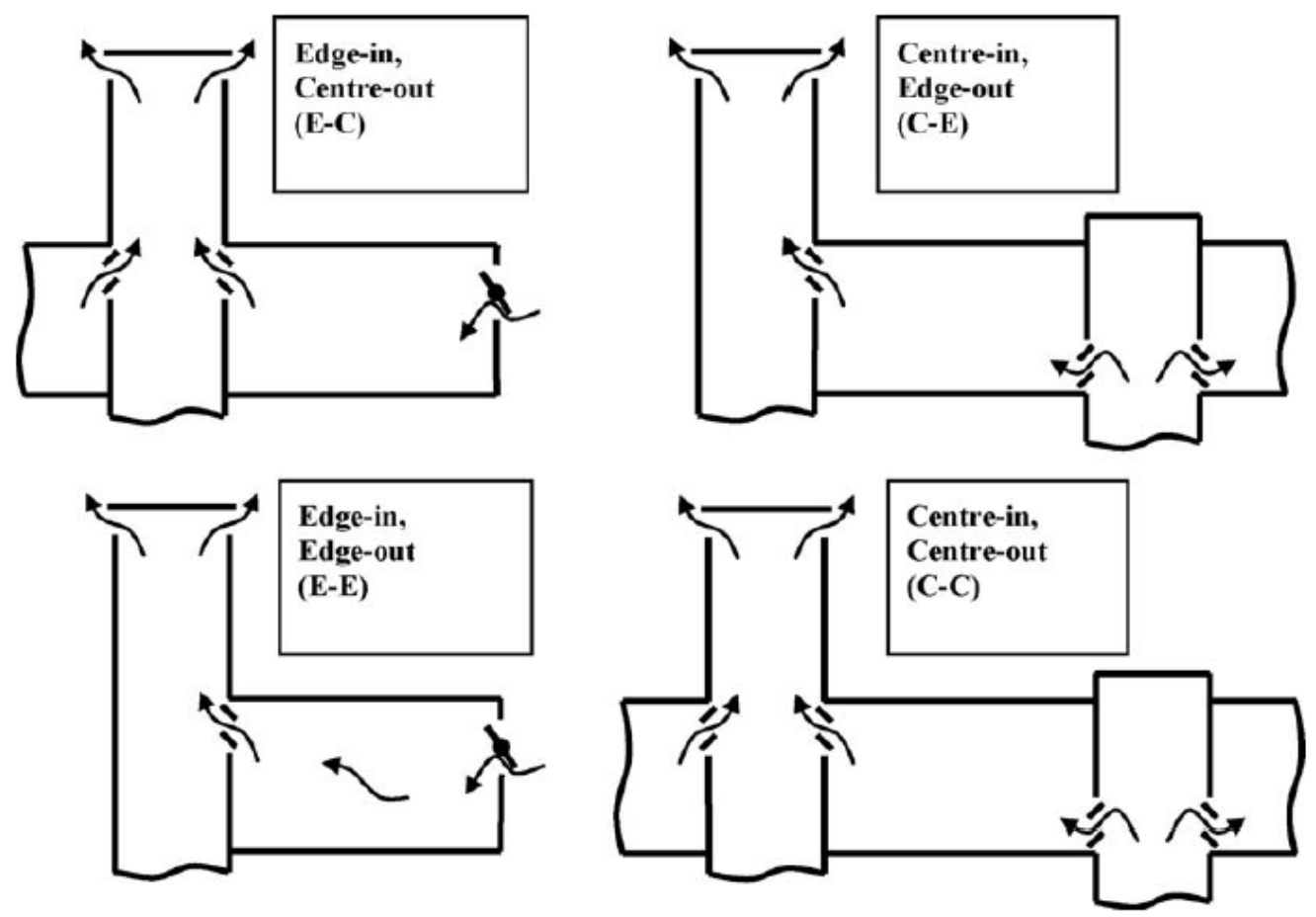

Figure 2. Proposed edge-in, edge-out advanced ventilation strategy for ventilating wards is a three storey hospital (source Short and Associates).

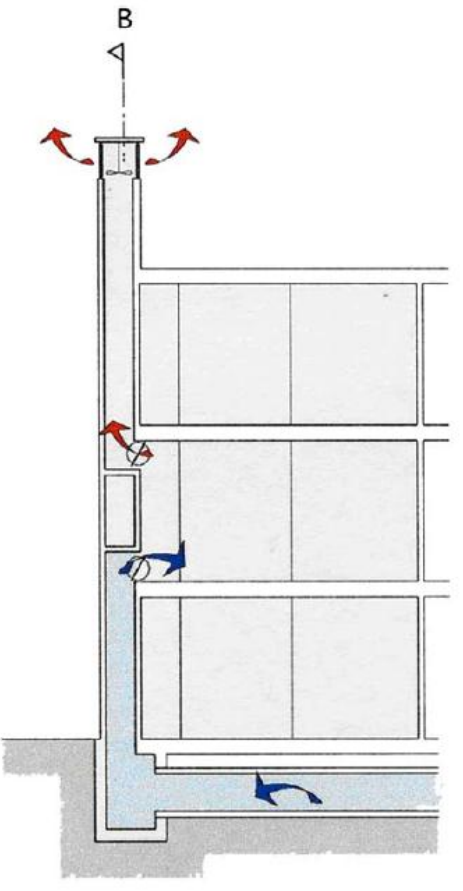

A. Section through intake shaft
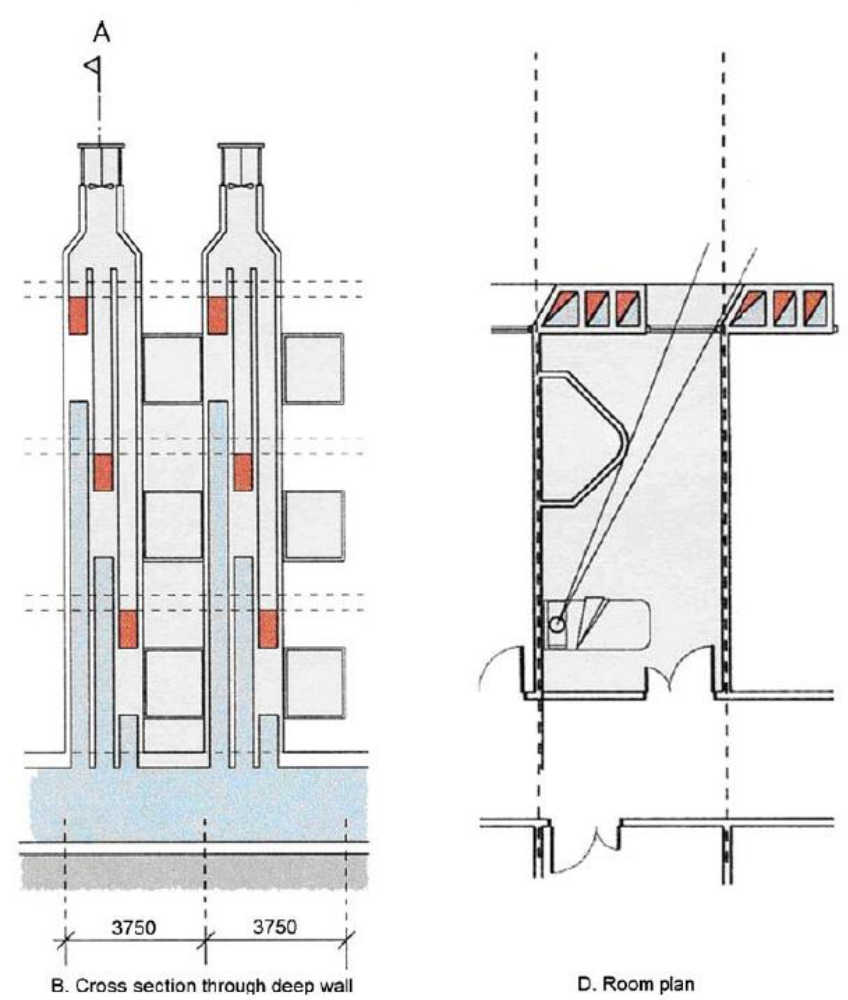

D. Room plan 
Figure 3. Annual number of hours over various ambient dry-bulb temperatures in the 14 CIBSE DSYs published in 2005.

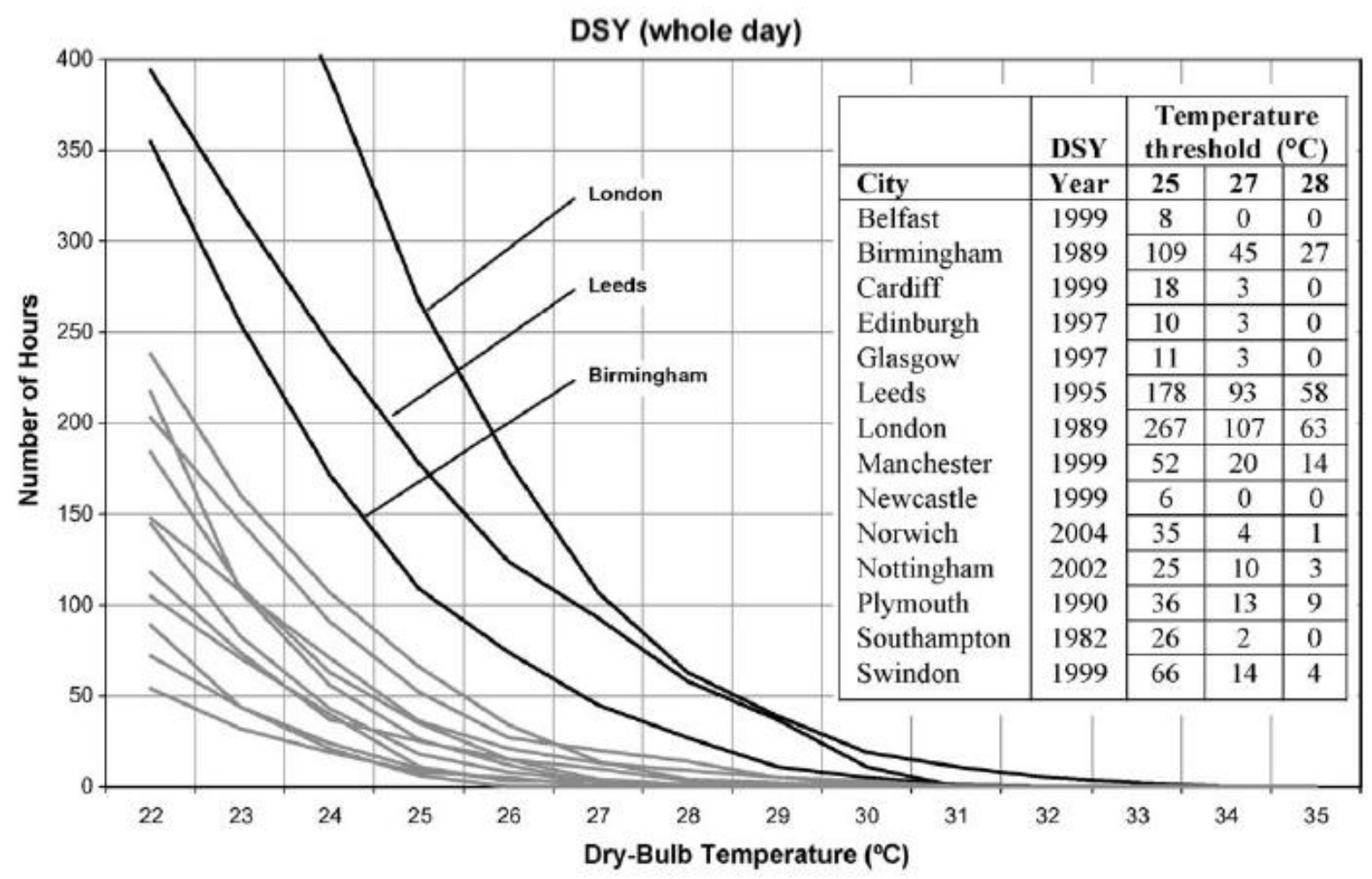

Figure 4. Annual number of hours over various ambient dry-bulb temperatures in the 14 CIBSE TRYs published in 2005.

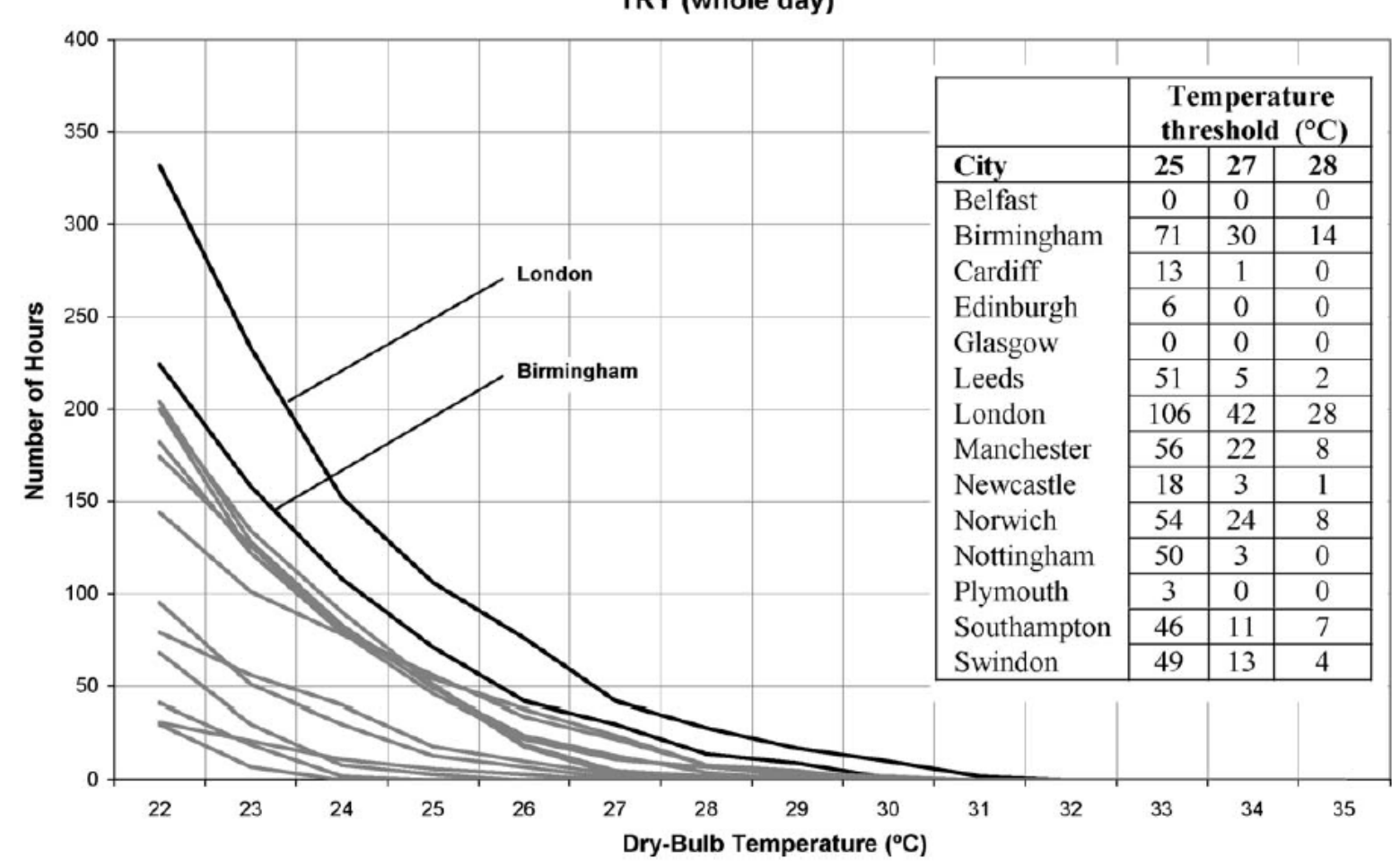


Figure 5. Relationship between the running mean outdoor temperature and the space category and the temperature thresholds for free-running buildings as presented in BSEN15251 [40]

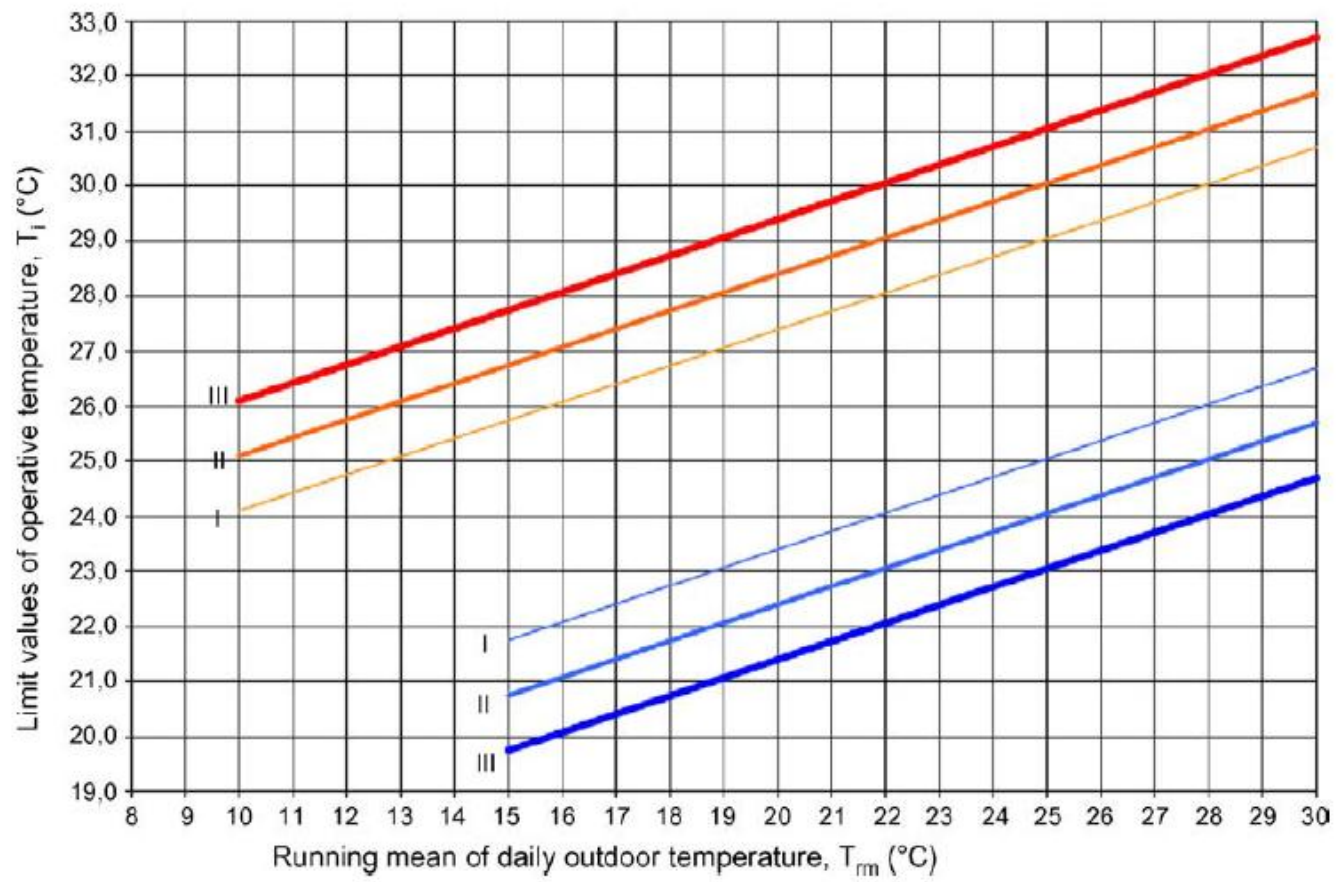

Figure 6. Schematic of the ANV geometry used in the simulations
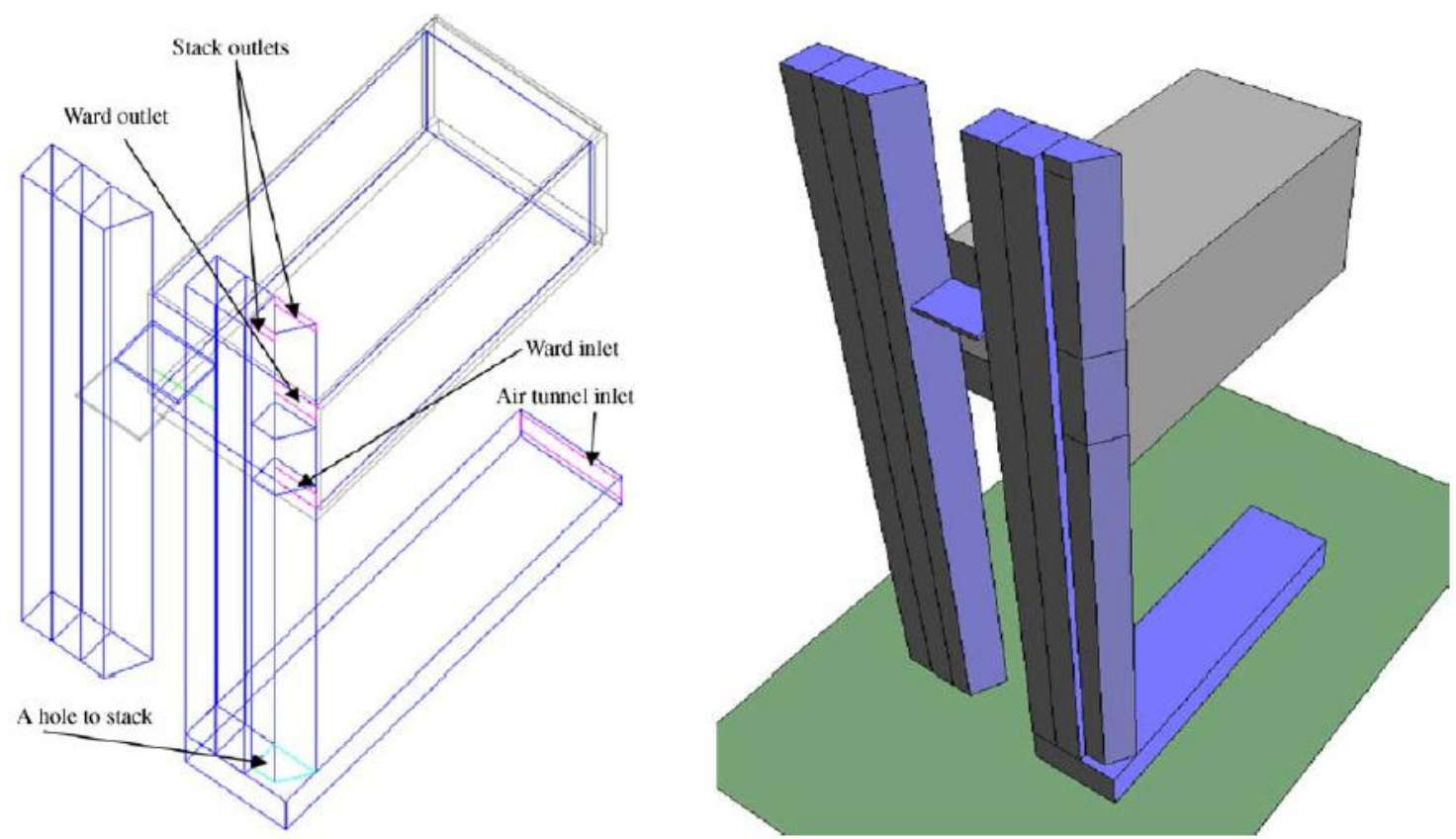
Figure 7. Predicted temperatures and ventilation rates (top) and relative humidity and CO2 levels (bottom) during the hottest period in the London Design Summer Year (2127 July)
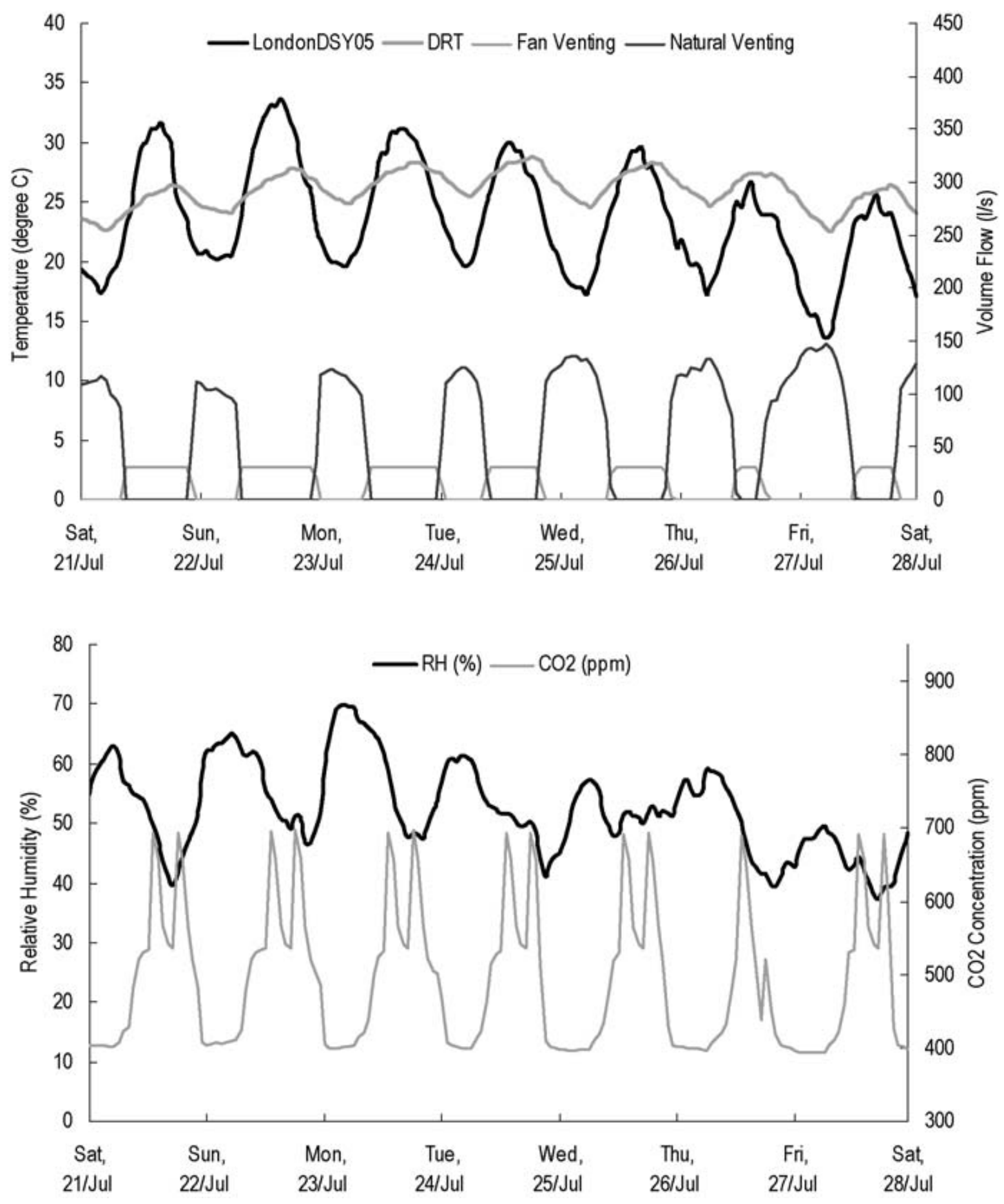
Figure 8. Comparison of predicted hours over $28^{\circ} \mathrm{C}$ and hours over the BS EN 15251 upper bound temperature (Cat I) using current (2005) weather data for Edinburgh, Manchester, Birmingham and London and various ANV and SNV designs.

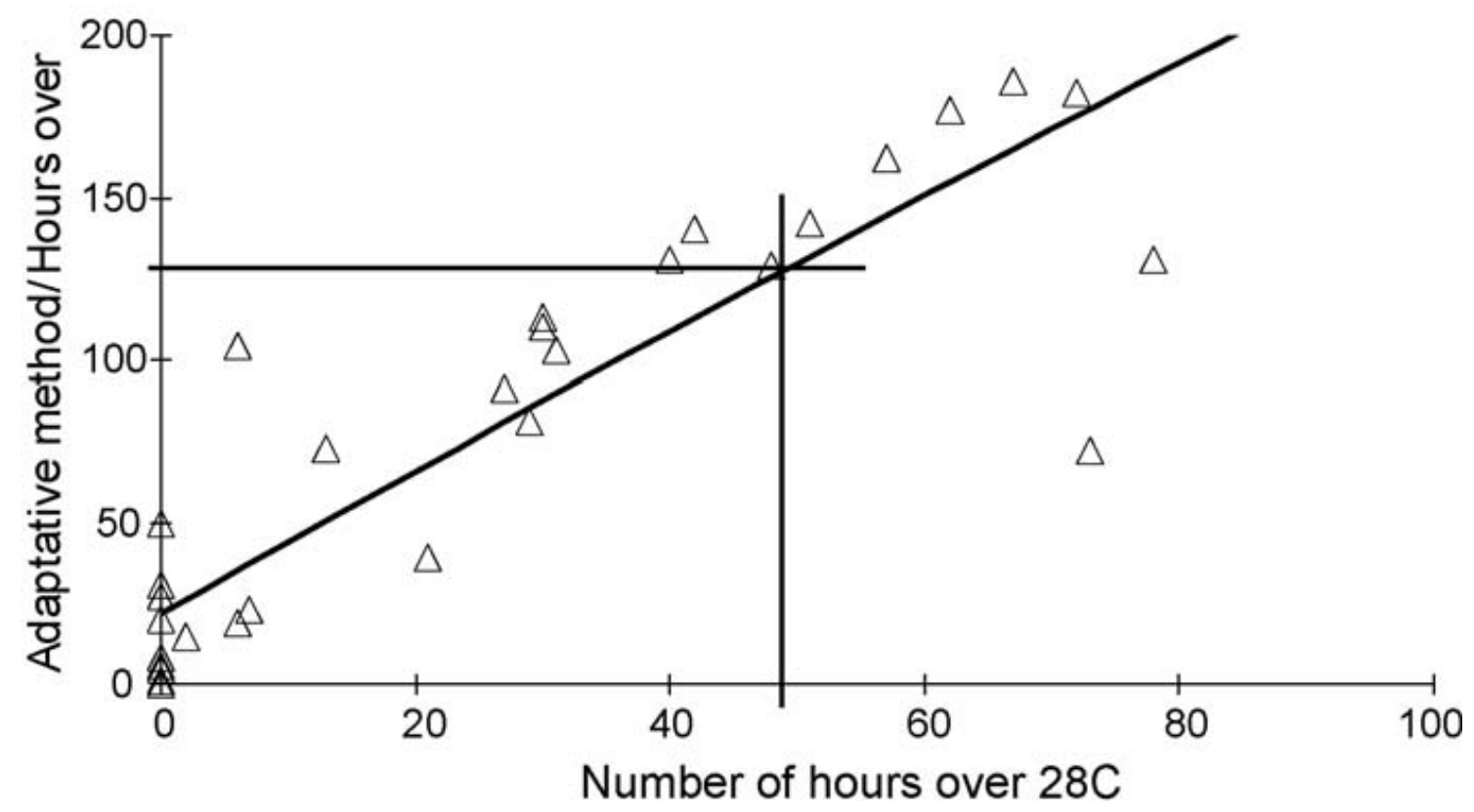

Figure 9. Comparison of predicted hours over $28^{\circ} \mathrm{C}$ and degree.hours over the BS EN15251 upper bound temperature (Cat I) using current (2005) weather data for Edinburgh, Manchester, Birmingham and London and various ANV and SNV designs

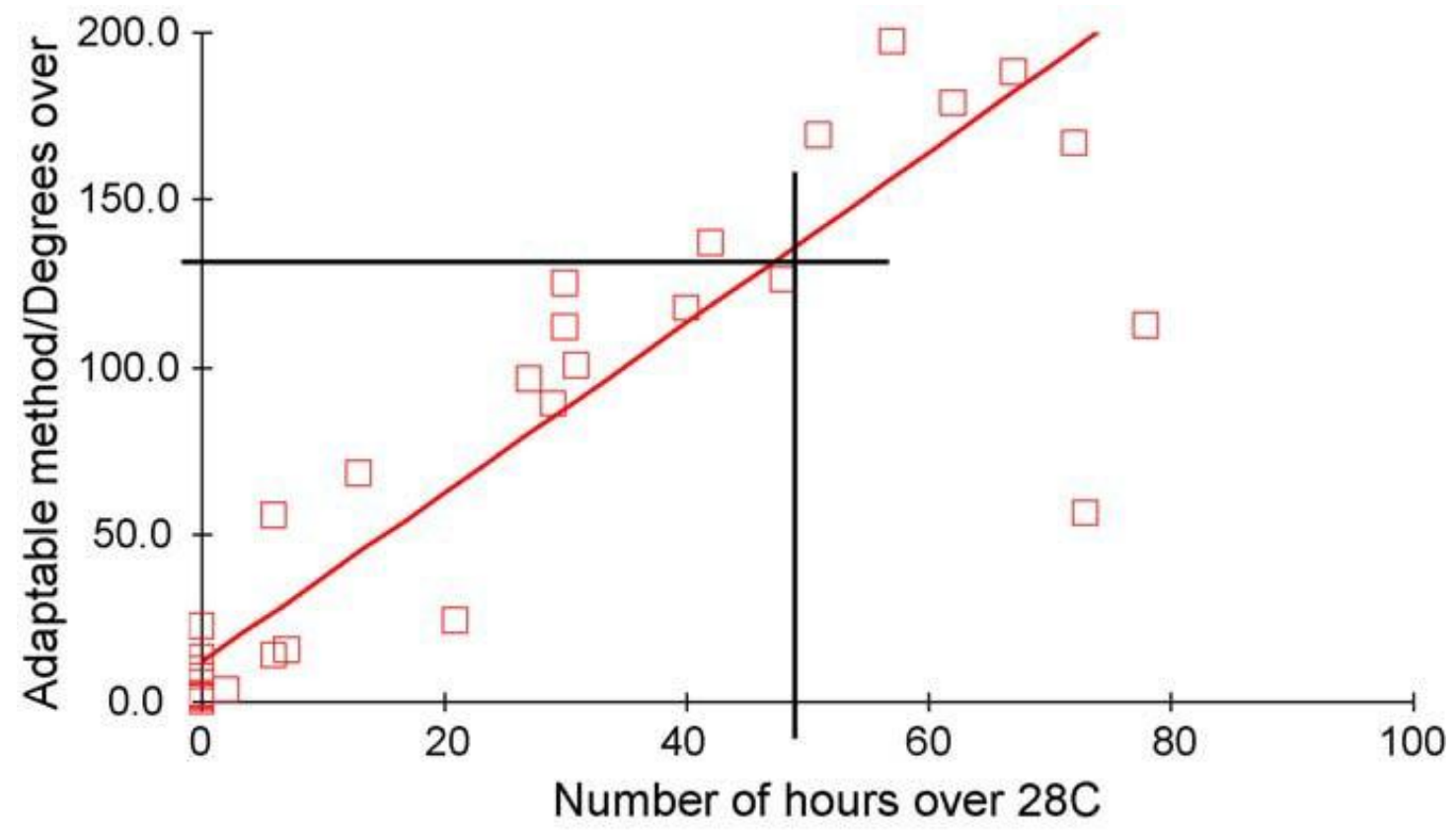


Figure 10. Temperatures within the London, Test Reference Year, between mid-June and mid-July and the projected temperatures for the year 2080 (based on an A2 socioeconomic development track

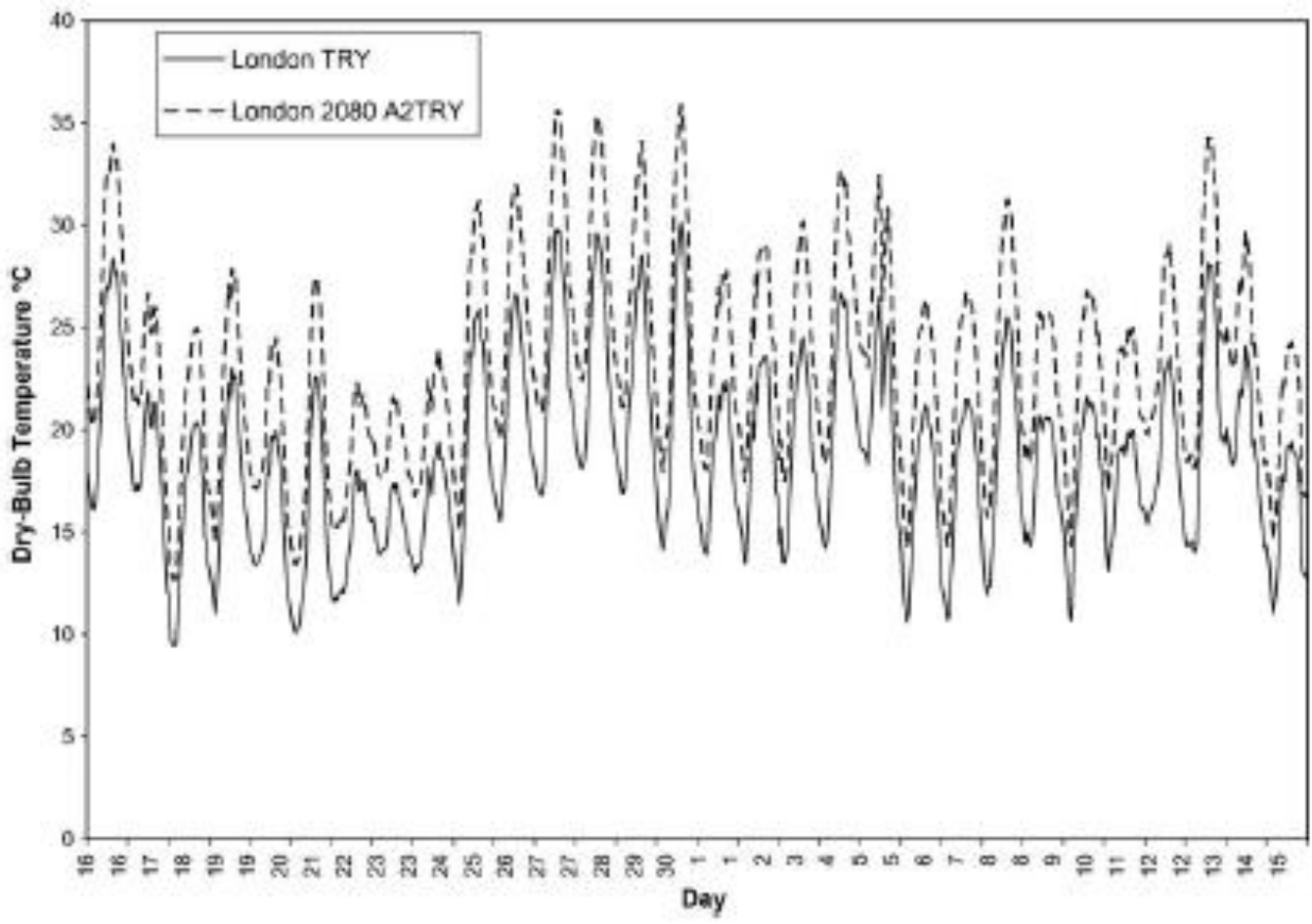

Figure 11. Temperatures within the Manchester 2002 Test Reference Year between midJune and mid-July and the projected temperatures for 2080 (based on A2 socioeconomic development track)

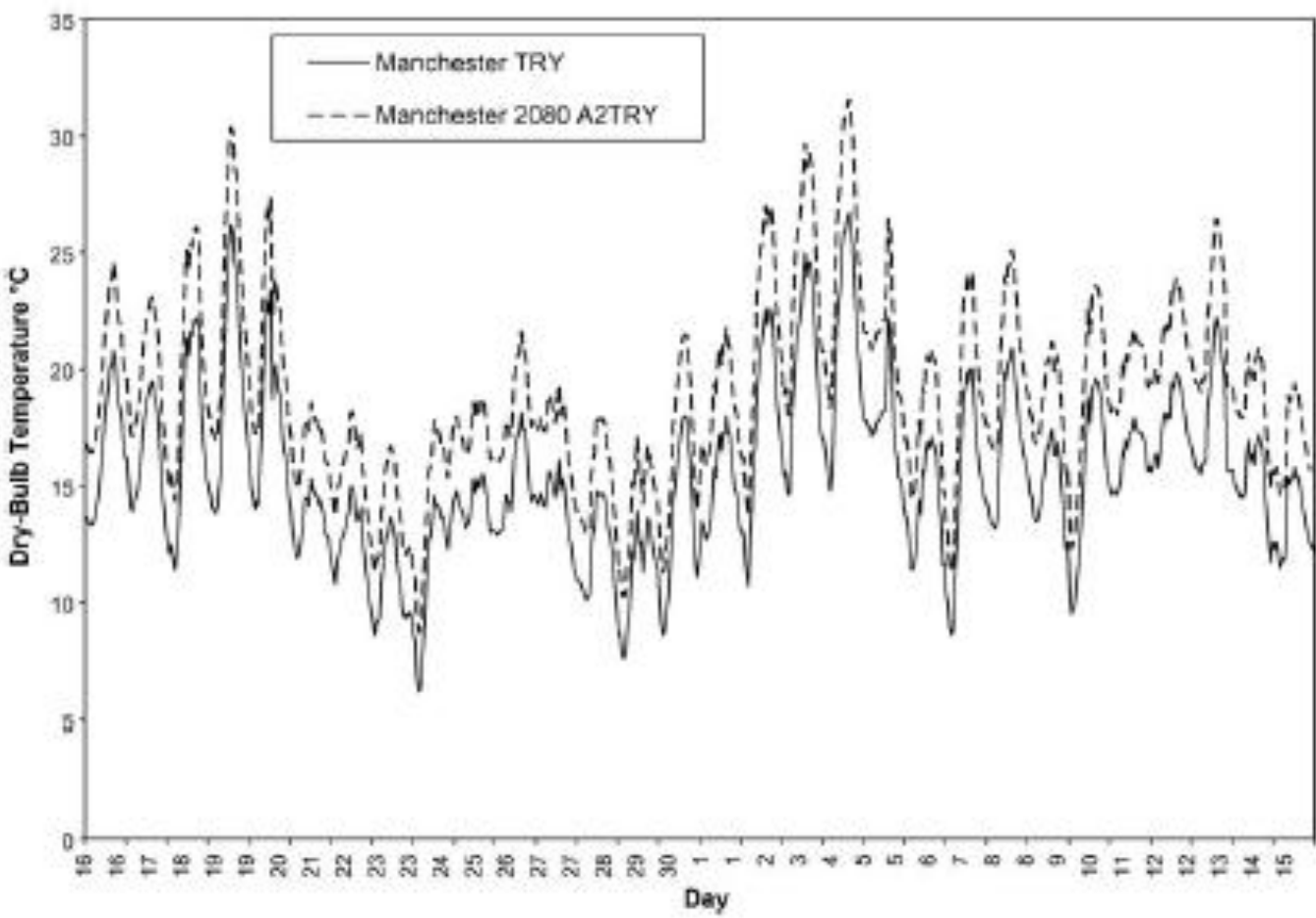


Figure 12. Total hours per year above the stated ambient dry-bulb temperature for the CIBSE 2005 TRY for London and the London 2020, 2050 and 2080 TRYs.

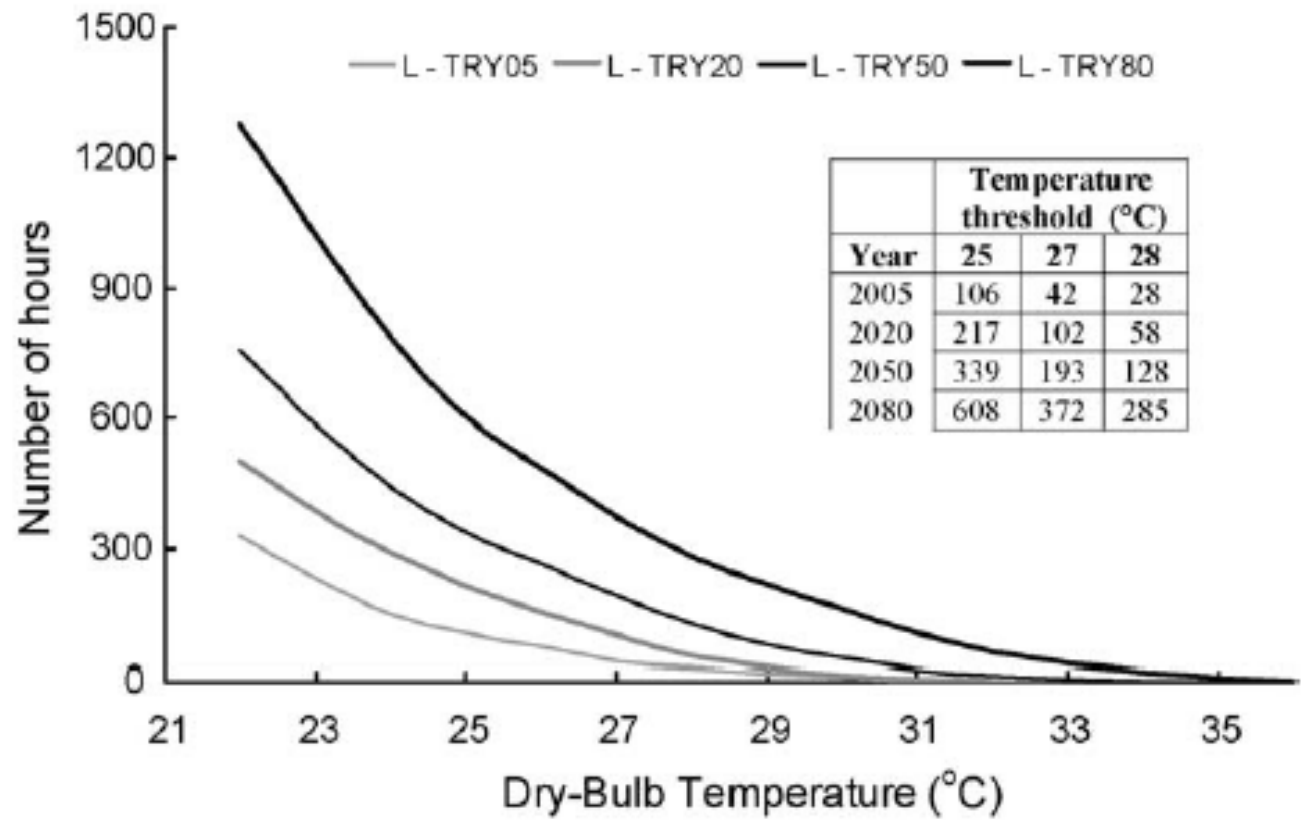

Figure 13. Total hours per year above stated ambient dry-bulb temperature for the CIBSE'05 TRY for Manchester and the Manchester 2020, 2050 and 2080 TRYs

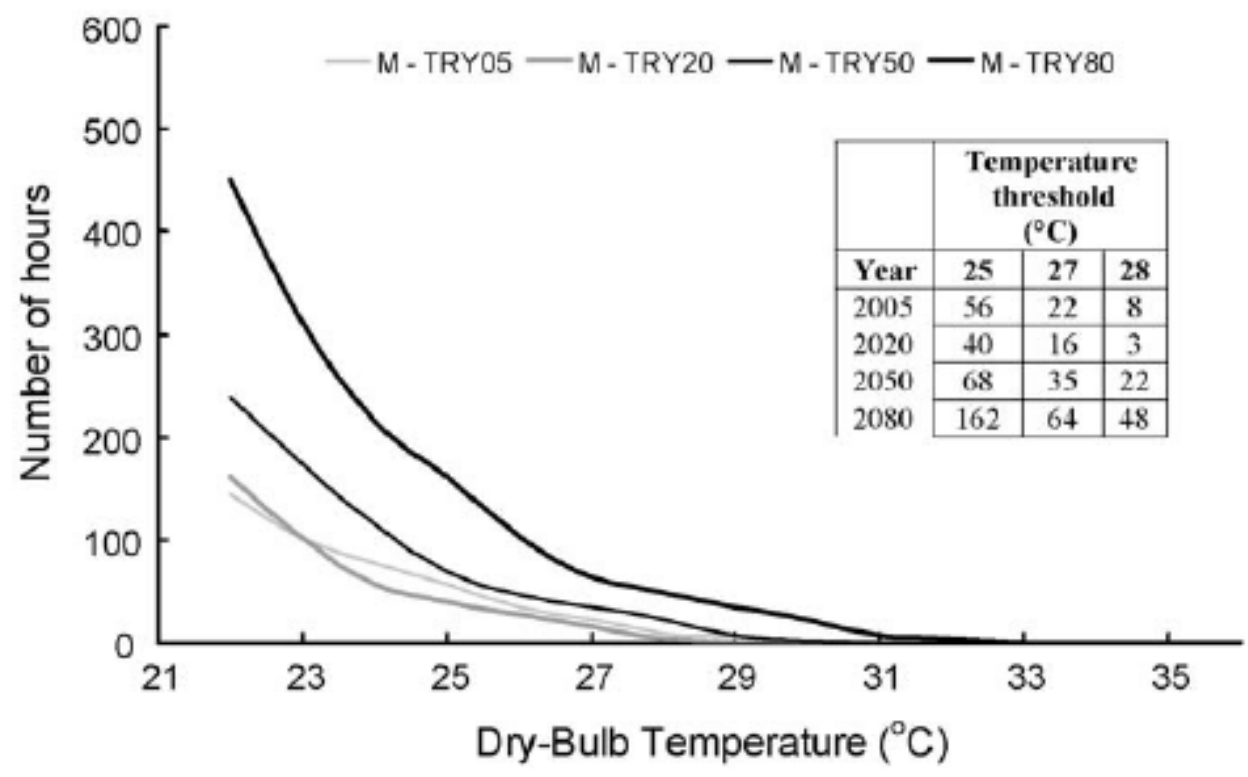


Figure 14. Period of time for which the overheating risk is acceptable in a typical year i.e. less than $130 \mathrm{~h}$ above the adaptive temperature limit for various $\mathrm{SNV}$ and $\mathrm{ANV}$ buildings: dark bars London A2TRY, grey bars A2TRY.

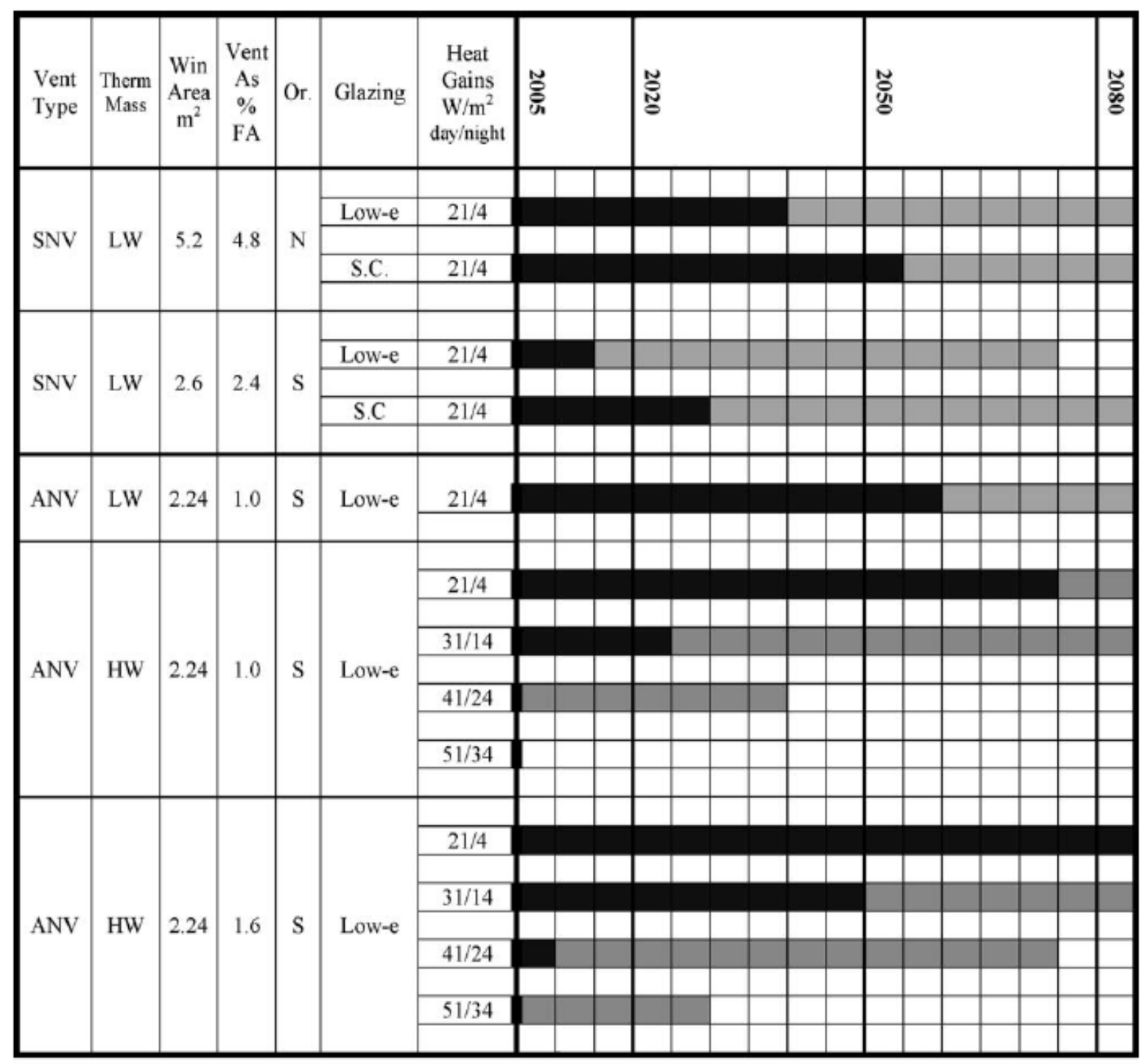

Bar extending to the right of 2080 indicates space has less than 130 hours over the adaptive temperature limit even in 2080. Data plotted to nearest 5 years. 
Figure A1. Relationship between the percentage of the facade width covered by stacks and shafts and the depth to-width ratio of perimeter spaces for different free-areas of ventilation opening (expressed as a fraction of the floor area of the space, $F$ and the number of floors in the building, $N$ ). For buildings with a different number of floor from those plotted linear interpolation between and beyond the curves is exact.

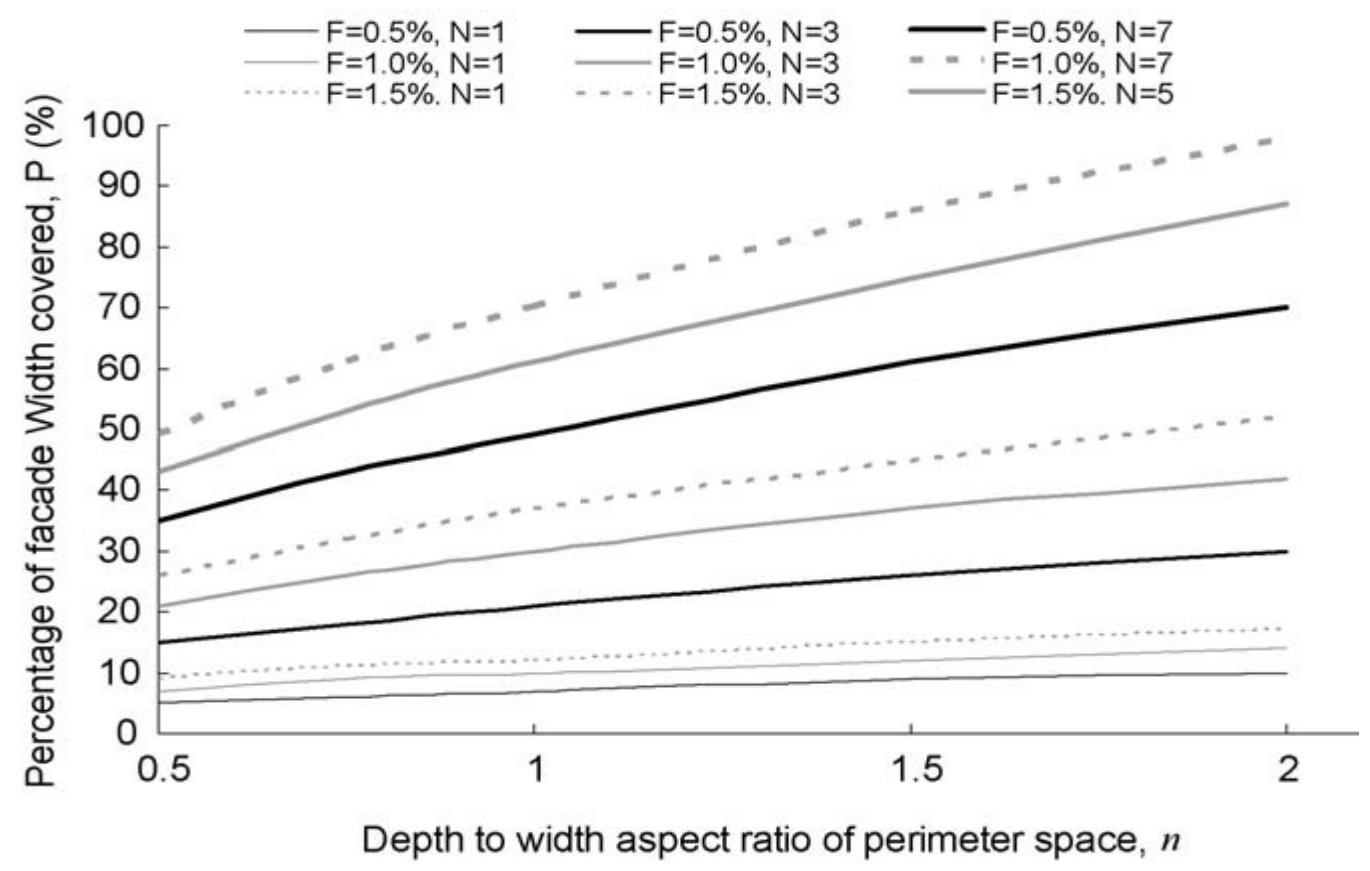

Figure B1. The hourly temperatures in the London DSY05, the running mean temperature and the upper limit value of the operative temperature in Category $I$ spaces (BS EN 15251)

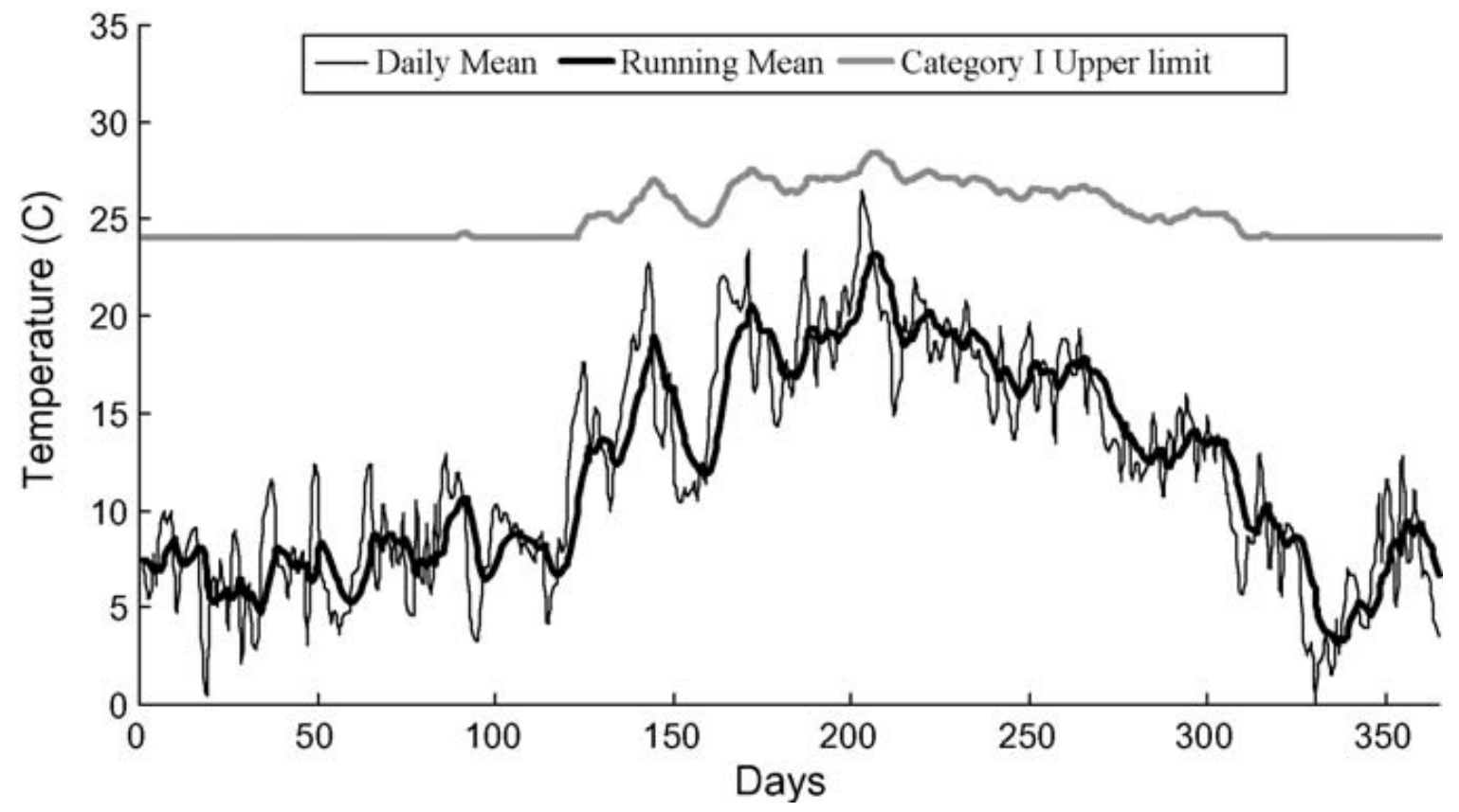

